January 2019

\title{
Precipitation Evaluation Of The North Dakota Cloud Modification Project (NDCMP) Using Rain Gauge Observations
}

Matthew Erik Tuftedal

How does access to this work benefit you? Let us know!

Follow this and additional works at: https://commons.und.edu/theses

\section{Recommended Citation}

Tuftedal, Matthew Erik, "Precipitation Evaluation Of The North Dakota Cloud Modification Project (NDCMP) Using Rain Gauge Observations" (2019). Theses and Dissertations. 2591.

https://commons.und.edu/theses/2591

This Thesis is brought to you for free and open access by the Theses, Dissertations, and Senior Projects at UND Scholarly Commons. It has been accepted for inclusion in Theses and Dissertations by an authorized administrator of UND Scholarly Commons. For more information, please contact und.commons@library.und.edu. 


\title{
PRECIPITATION EVALUATION OF THE NORTH DAKOTA CLOUD MODIFICATION PROJECT (NDCMP) USING RAIN GAUGE OBSERVATIONS
}

\author{
by \\ Matthew E. Tuftedal \\ Associate of Arts, Kalamazoo Valley Community College, 2013 \\ Bachelor of Science, Central Michigan University, 2017
}

\author{
A Thesis \\ Submitted to the Graduate Faculty \\ of the \\ University of North Dakota \\ in partial fulfillment of the requirements
}

for the degree of

Master of Science

Grand Forks, North Dakota

August

2019 
This thesis, submitted by Matthew E. Tuftedal in partial fulfillment of the requirements for the Degree of Master of Science from the University of North Dakota, has been read by the Faculty Advisory Committee under whom the work has been done and is hereby approved.

Dr. David Delene

Dr. Andrew Detwiler

Dr. Aaron Kennedy

This thesis is being submitted by the appointed advisory committee as having met all of the requirements of the School of Graduate Studies at the University of North Dakota and is hereby approved.

\author{
Chris Nelson \\ Dean of the School of Graduate Studies
}

Date 


\title{
PERMISSION
}

PRECIPITATION EVALUATION OF THE NORTH
DAKOTA CLOUD MODIFICATION PROJECT (ND-
CMP) USING RAIN GAUGE OBSERVATIONS

Department Atmospheric Sciences

Degree $\quad$ Master of Science

\begin{abstract}
In presenting this thesis in partial fulfillment of the requirements for a graduate degree from the University of North Dakota, I agree that the library of this University shall make it freely available for inspection. I further agree that permission for extensive copying for scholarly purposes may be granted by the professor who supervised my thesis work or, in her absence, by the Chairperson of the department or the dean of the School of Graduate Studies. It is understood that any copying or publication or other use of this thesis or part thereof for financial gain shall not be allowed without my written permission. It is also understood that due recognition shall be given to me and to the University of North Dakota in any scholarly use which may be made of any material in my thesis.
\end{abstract}

Matthew E. Tuftedal

July 27, 2019 
TABle of Contents

LITT OF FIGURES $\ldots \ldots \ldots \ldots \ldots \ldots \ldots \ldots \ldots \ldots$

LI\$T OF TABLES . . . . . . . . . . . . . . . . . . . vi

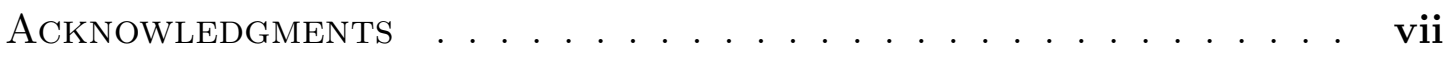

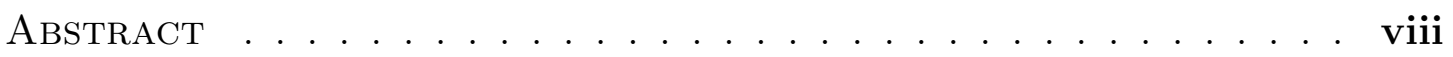

CHAPTER

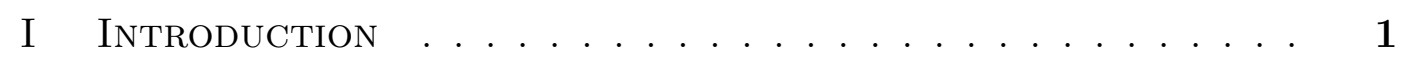

$\amalg$ DATA . . . . . . . . . . . . . . . . . . . . . . 11

NORTH DAKOTA ATMOSPHERIC RESOURCE BOARD COOPERATIVE OBSERVER NETWORK . . . . . . . . . 11 NATIONAL WEATHER SERVICE COOPERATIVE OBSERVER PROGRAM . . . . . . . . . . . . . . . . . . . . . 13

IIIMETHODOLOGY . . . . . . . . . . . . . . . . . . . . . . . . . . . . 15

TARGET/CONTROL $\ldots \ldots \ldots \ldots \ldots \ldots$ MISSING DATA $\ldots \ldots \ldots \ldots \ldots$ RAINFALL EVALUATION . . . . . . . . . . . . . . 20 COUNTY CIRCLES . . . . . . . . . . . . . . . . 22 COUNTY BASED EVALUATION . . . . . . . . . . . . . . 24 ONE TARGET, ONE CONTROL . . . . . . . . . . . . . 26 SINGLE AND DOUBLE RATIOS . . . . . . . . . . . . . . 26 SINGLE AND MULTIPLE LINEAR REGRESSION . . . . 28 BOOTSTRAPPING STATISTICAL TEST . . . . . . . . . 33

IVRESULTS . . . . . . . . . . . . . . . . . . . . . . . . . . . . . . 38

COUNTY CIRCLES: RAINFALL EVALUATION . . . . 38 COUNTY CIRCLES: SINGLE AND DOUBLE RATIOS . 41 COUNTY CIRCLES: BOOTSTRAPPING RATIOS . . . . 43 COUNTY BASED: RAINFALL EVALUATION . . . . . . 46 
COUNTY BASED: SINGLE AND DOUBLE RATIOS. . . 49 COUNTY BASED: BOOTSTRAPPING RATIOS . . . . . 51 ONE TARGET, ONE CONTROL . . . . . . . . . . . . . 55

$\mathrm{V}$ DISCUSSION $\ldots \ldots \ldots \ldots \ldots \ldots \ldots \ldots \ldots$

VI CONCLUSIONS . . . . . . . . . . . . . . . . . . . . 67

REFERENCES . . . . . . . . . . . . . . . . . . 69

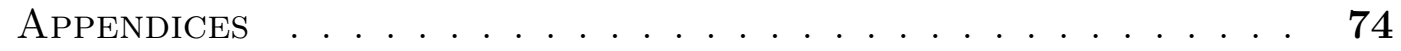

APPENDIX A: SINGLE AND MULTIPLE LINEAR REGRESSION . . . . . . . . . . . . . . . 75 APPENDIX B: RAIN GAUGES NECESSARY FOR ADEQUATE COUNTY-BASED MEASUREMENTS . . . . . . 80 CONSTANT NUMBER OF RAIN GAUGES . . . . . . . . 82 APPENDIX C: YEARS NEEDED TO DETECT SEEDING EFFECTS . . . . . . . . . . . . . . . . . . . . . . . . . 84 APPENDIX D: MANN-WHITNEY U TEST . . . . . . . . 87 


\section{LIST OF FIGURES}

1 Basic conceptual model of the cloud base seeding and direct injection method used in the North Dakota Cloud Modification Project (NDCMP). For cloud base seeding, aircrafts use a combination of wing-mounted ice nucleus generators and burn-in-place flares; while for direct injection, aircrafts use ejectable flares and dry ice. . . . . . . . . . . . . . . . . .

2 The North Dakota Cloud Modification Project (NDCMP) Operational Target Areas in western North Dakota. Operation seeding areas are broken into District I (light green) in southwest North Dakota and District II (dark green) in northwest North Dakota. Image was created using Google Earth

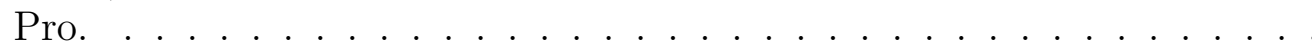

3 The Tru-Chek wedge rain gauge (A) used by the NDARBCON observers and the standard 8-inch rain gauge (B) used by National Weather Service (NWS) Cooperative Observer Network (COOP). Tru-Check rain gauge dimensions are 13 " by 2.5 " by 2.5 (Height by Width by Depth). The standard 8-inch rain gauge dimensions are 8" by 27" (Diameter by Depth). 12

$4 \quad$ NDARBCON and NWS COOP rain gauge locations within target (red) and control (blue) counties from 1950 to 2018. . . . . . . . . . . . . . . 17

$5 \quad$ All available National Weather Service (NWS) Cooperative Observer Program (COOP) and North Dakota Atmospheric Resource Board Cooperative Observer Network (NDARBCON) rain gauges for McKenzie County from 1950 to 2018 for June (blue), July (red), and August (black). . . . . 19

$6 \quad 40 \mathrm{~km}$ circular areas selected as target (red), ND control (green), and MT control (blue) for rainfall analysis. . . . . . . . . . . . . . 23 
7 County-based areas for Target (red) and Control (blue). Image created using Google Earth Pro. . . . . . . . . . . . . . . . . . . . 25

8 Probability distribution function for McKenzie County seasonal rainfall for 1977-2018. . . . . . . . . . . . . . . . . . . 35

$9 \quad$ Probability distribution function for the calculated single ratios for countybased seasonal rainfall from the target county McKenzie and control county Billings for 1977-2018. . . . . . . . . . . . . . . . . . . . 35

10 Seasonal rainfall in inches for circular method target and control regions using NWS COOP and NDARBCON rain gauges for 1950-1975 and 1977-

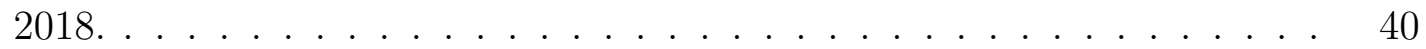

11 Distribution of mean double ratios for seasonal rainfall calculated from the circular method bootstrapped 10,000 for McKenzie/Wibaux. The mean (red) observed double ratio and 95\% confidence interval (black) are shown. 46

12 Seasonal rainfall in inches for county-based method target and control regions using NWS COOP and NDARBCON rain gauges for 1950-1975 and 1977-2018. . . . . . . . . . . . . . . . . . . . . . . . 48

13 Distribution of mean double ratios for seasonal rainfall calculated from the county-based method bootstrapped 10,000 for McKenzie/Wibaux. The mean (red) observed double ratio and 95\% confidence interval (black) are

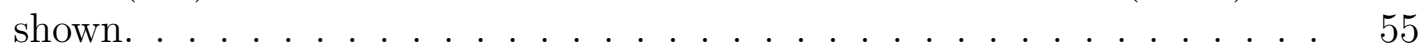

14 Image recreated from the NDCMP 2018 final report showing the 10-statue mile buffer zone for Districts I and II. The area shaded in red is the buffer zone that is no longer active as of 2018. . . . . . . . . . . . . . . . 63

A1 McKenzie county-based seasonal rainfall (blue) in inches compared to the single linear regression predicted seasonal rainfall for McKenzie using Billings (red) and Wibaux (black) as predictors. . . . . . . . . . 76

A2 McKenzie county-based seasonal rainfall (blue) in inches compared to the multiple linear regression predicted seasonal rainfall for McKenzie using Wibaux and Richland (red) and Richland and Roosevelt (black) as pre-

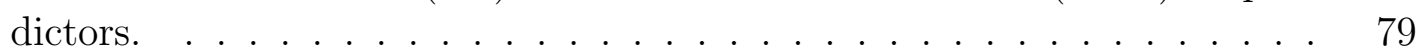


B1 Necessary number of rain gauges to adequately measure the average rainfall for McKenzie County in June 1977. The blue dots show the high end of the $95 \%$ confidence interval and the orange shows the low end. The average county-based rainfall is shown in red. . . . . . . . . . . . . . . 81

B2 Average number of rain gauges within each Target (red) and Control (blue) area for the county-based method. . . . . . . . . . . . . . . . 82 


\section{LIST OF TABLES}

Table

1 List showing the seeding district, period of participation, and total number of years counties took part in the North Dakota Cloud Modification Project (NDCMP). . . . . . . . . . . . . . . . . . . . 4

$2 \quad$ The latitude and longitude of county center point circles shown in Figure 6.22

3 25-year monthly and seasonal total observed weighted rainfall in inches calculated using NWS COOP rain gauges for 1950-1975. . . . . . . . . . 39

4 41-year monthly and seasonal total rainfall in inches for target/control circle analysis over 1977-2018. . . . . . . . . . . . . . . . . . . . . . . . . 39

5 Pre-NDCMP Single ratios calculated for target/control observed weighted rainfall over 1950-1975. . . . . . . . . . . . . . . . . . . . . . . . . 42

$6 \quad$ NDCMP Single ratios calculated for Target/Control observed weighted rainfall over 1977-2018. . . . . . . . . . . . . . . . . . . . . . . . . . . . 42

7 Double ratios for June, July, August, and Seasonal computed from target/control observed single ratios from weighted rainfall by dividing 19772018 by $1950-1975$ single ratios. . . . . . . . . . . . . . . . . . . . . . . . 43

8 Natural variation in single ratios between target/control weighted circles determined using bootstrap statistics for the pre-NDCMP years. The bootstrapped data were sampled 10,000 times. . . . . . . . . . . . . . . . 44

$9 \quad$ The natural variation in single ratios between target/control using weighted circles calculated using the bootstrap statistics over the NDCMP years. The bootstrapped data were sampled 10,000 times. . . . . . . . . . . . . 44 
10 Bootstrapped double ratio statistic between target/control weighted circles using 10,000 samples. The double ratios were calculated from the single ratios for 1977 to 2018 and 1950-1975. . . . . . . . . . . . . . . . 45

11 25-year monthly and seasonal total county-based rainfall, in inches, calculated from NWS COOP rain gauge network for 1950-1975. . . . . . . . . 49

12 41-year monthly and seasonal total county-based rainfall in inches calculated from the NWS COOP and NDARBCON rain gauge network over 1977-2018. . . . . . . . . . . . . . . . . . . . 49

13 Single ratios calculated from target/control observed county average rainfall over 1950-1975. . . . . . . . . . . . . . . . . . . . 50

14 NDCMP Single ratios calculated for target/control observed county averaged rainfall over 1977-2018. . . . . . . . . . . . . . . . . 51

15 Double ratios computed from target/control observed single ratios from county-based rainfall for 1977-2018 and 1950-1975. . . . . . . . . . . . 51

16 Natural variation in county based single ratios between target/control determined using 10,000 samples for the bootstrap statistics for the preNDCMP years. . . . . . . . . . . . . . . . . 52

18 The bootstrapped double ratio statistic between target/control countybased precipitation using the single ratios for 1950-1975 and 1977-2018. Each bootstrapping test was sampled 10,000 times. . . . . . . . . . . . . 54

17 Natural variation in county based single ratios between target/control determined using bootstrap statistics for the NDCMP years. . . . . . . . 54

19 25-year total average rainfall in inches for June, July, August, and Seasonal for 1950-1975 in the target and control region using NWS COOP rain gauge data. The average number of rain gauges over the 25 -year period are shown. . . . . . . . . . . . . . . . . . . 57

20 41-year total average rainfall in inches for June, July, August, and Seasonal for 1977-2018 in the target and control region using NDARBCON and NWS COOP rain gauge data. The average number of rain gauges over the 41 years are shown for each month and seasonal average. . . . . . . . 57 
21 Natural variation in rainfall calculated for 1950 to 1975,1977 to 2018 and the double ratio. The bootstrap statistic sampled seasonal observed rainfall by year 10,000 times. . . . . . . . . . . . . . . . 57

A1 Correlation Coefficients for 1950 to 1975 between target and control counties based off seasonal rainfall calculated from the county-based method. $\quad 75$

A2 Single Linear Regression results generated from the 1950 to 1975 rainfall regression equation. The total rainfall and average rainfall in inches were calculated over the period of 1977 to 2018. . . . . . . . . . . . . . . . . . 77

A3 Multiple Linear Regression results using two predictors for the seasonal rainfall total in inches for a selected target region. Pairings with a standard error of the estimate less than 1.50 are shown, except for Ward. The single ratio is determined from the total observed and total predicted rainfall. . $\quad 78$

C1 Standard Error, number of years, and t statistic calculated from observed and single linear regression predicted rainfall. These estimates the number of years of data needed to predict a 5 and $10 \%$ effect within a $95 \%$ confidence interval. . . . . . . . . . . . . . . . . . . . . 85

C2 Standard Error, number of years, and t statistic calculated from observed and multiple linear regression predicted rainfall. These estimates the number of years of data needed to predict a 5 and $10 \%$ effect within a $95 \%$ confidence interval. . . . . . . . . . . . . . . . . . . 85

D1 Mann-Whitney U statistic test on the 1950-1975 and 1977-2018 single ratios. The U statistic and p-value are calculated for the target/control

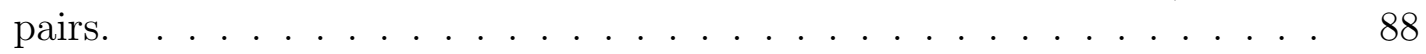




\section{ACKNOWLEDGMENTS}

I would like to thank Dr. David Delene, Dr. Andrew Detwiler, and Dr. Aaron Kennedy for their guidance and insight throughout this entire project. I would like to thank my brother, Kristofer Tuftedal, for his support and endless nights troubleshooting code with me. Chelsea Augustine, for supporting me while I follow my dreams and all her patience. My Mom, Linda Tuftedal, for always supporting my crazy ideas and dreams since I was a little kid. Without everyone's support, none of this would have been possible. 


\begin{abstract}
North Dakota farmers' interest in using weather modification to increase precipitation and reduce hail damage resulted in a managed cost-sharing program, the North Dakota Cloud Modification Project (NDCMP), being started in 1976. The goal of this research is to determine the effectiveness of NDCMP at increasing precipitation by using the rain gauge observations of National Weather Service (NWS) Cooperative Observer Program (COOP) and North Dakota Atmospheric Resource Board Cooperative Observer Network (NDARBCON). The rain gauge analysis uses target and control regions. Target regions are selected from counties in District I and II that have participated in all 41 years of the NDCMP. Control regions are counties adjacent to the target counties. Precipitation is evaluated on a monthly and seasonal (June, July, and August) basis over the 41-year program.

Multiple analysis methods are used to examine the available rain gauge data. In one method, rain gauge data is analyzed by overlaying a circle with a radius of 40 $\mathrm{km}$ over each target and control region. Rain gauges are weighted to a central point within the circle. Monthly and seasonal rainfall totals are calculated within these circles. In another method, rain gauge data from the entire county is used to calculate county-wide average monthly and seasonal rainfall totals. In a third approach, all rain gauges from the target and control counties are combined to generate one large target and one large control dataset. Single and double ratios are calculated for each target and control region in the circle-based and county-based analyses. Bootstrapping is applied to the single and double ratios to determine the natural variation over the 41 years. An exploratory analysis in which single and multiple linear regression is
\end{abstract}


created using 1950-1975 seasonal rainfall to predict what the rainfall in the target area would be without the seeding effect. These various methods provide an exploratory statistical analysis of the program, not a physical process evaluation.

The circular method shows that four out of the nine target/control double ratios have the target region receiving 2 to $8 \%$ more precipitation during the NDCMP years; however, only one out of the four increases are considered statistically significant based off the one tailed significance test. The $95 \%$ confidence intervals for these target/control pairs range from a small decrease to a small increase. The county-based method shows that six out of the nine double ratios have a range of 2 to $12 \%$ more precipitation in the target than the control region during the NDCMP years. Of those six, three cases are determined to be statistically significant by one tailed significance test. The single linear regression method shows an increase of 1 to $12 \%$ in target areas during NDCMP years in all but two of the target/control pairings when the standard error of the estimate is less than $1.50( \pm 6 \%)$. Multiple linear regression shows an increase of 3 to $7 \%$ in target areas during NDCMP years when the standard error is less than $1.50( \pm 6 \%)$ in 7 out of 12 analyzed cases.

Increases in rainfall due to cloud seeding in most instances are small and hard to detect statistically because it is difficult to predict how much rain would have fallen in the target areas during NDCMP years if seeding had not occurred. Uncertainties are caused by limited rain gauge data in the years before the NDCMP, from which natural target/control relationships can be determined. Results show that McKenzie county has an increase in rainfall when compared to control counties to its south and southwest, likely due to these cloud seeding efforts. 


\section{CHAPTER I}

\section{INTRODUCTION}

North Dakota farmers have been interested in using weather modification to increase precipitation since the 1930s; however, the idea of weather modification dates back to the 1800s (Smith et al. 2004). In the 1940s, the development of seeding techniques using dry ice and silver iodide smoke were discovered by General Electric (Schaefer 1968). Weather modification projects started in the 1950s within North Dakota, where ground-based generators were used to deliver seeding agents into clouds. By the 1960s, aircraft-based delivery of seeding agents was the preferred delivery method. A managed cost-sharing program, the North Dakota Cloud Modification Project (NDCMP), was started in 1976 (Schneider and Langerud 2011) with the primary goal of hail suppression to reduce crop loss. It quickly added a secondary goal of rainfall enhancement. NDCMP currently conducts hail suppression and rain enhancement operations over western North Dakota in two areas during the months of June, July, August, and occasionally early September.

Cloud seeding is a weather modification technique that aims to increase the amount precipitation by introducing materials into clouds (Bruintjes 1999). By dispersing materials such as silver iodide, dry ice pellets, potassium iodide, or hygroscopic particles into clouds, the microphysical and dynamical properties of clouds are changed. Ice nuclei make the precipitation formation process more efficient by converting supercooled (temperature below $0{ }^{\circ} \mathrm{C}$ ) liquid cloud drops into larger ice

particles (Delene 2016). Ice nuclei may be dispersed by a ground generator or released 
from an aircraft. Changing the dynamical properties is done by utilizing the energy stored in the latent heat of freezing and sublimation to develop localized convergence in a storm (Schaefer 1968). Since the start of NDCMP, there have been changes in the delivery of seeding agents, the number and types of aircraft employed, and the type of seeding agents used (NDARB 2018). Currently, NDCMP uses aircraft to release seeding materials at cloud base and by directly injecting materials into supercooled clouds (Fig. 1). For cloud base seeding, aircrafts use a combination of wing-mounted ice nucleus generators and burn-in-place flares; while, for direct injection, aircraft use ejectable flares and dry ice (NDARB 2014).

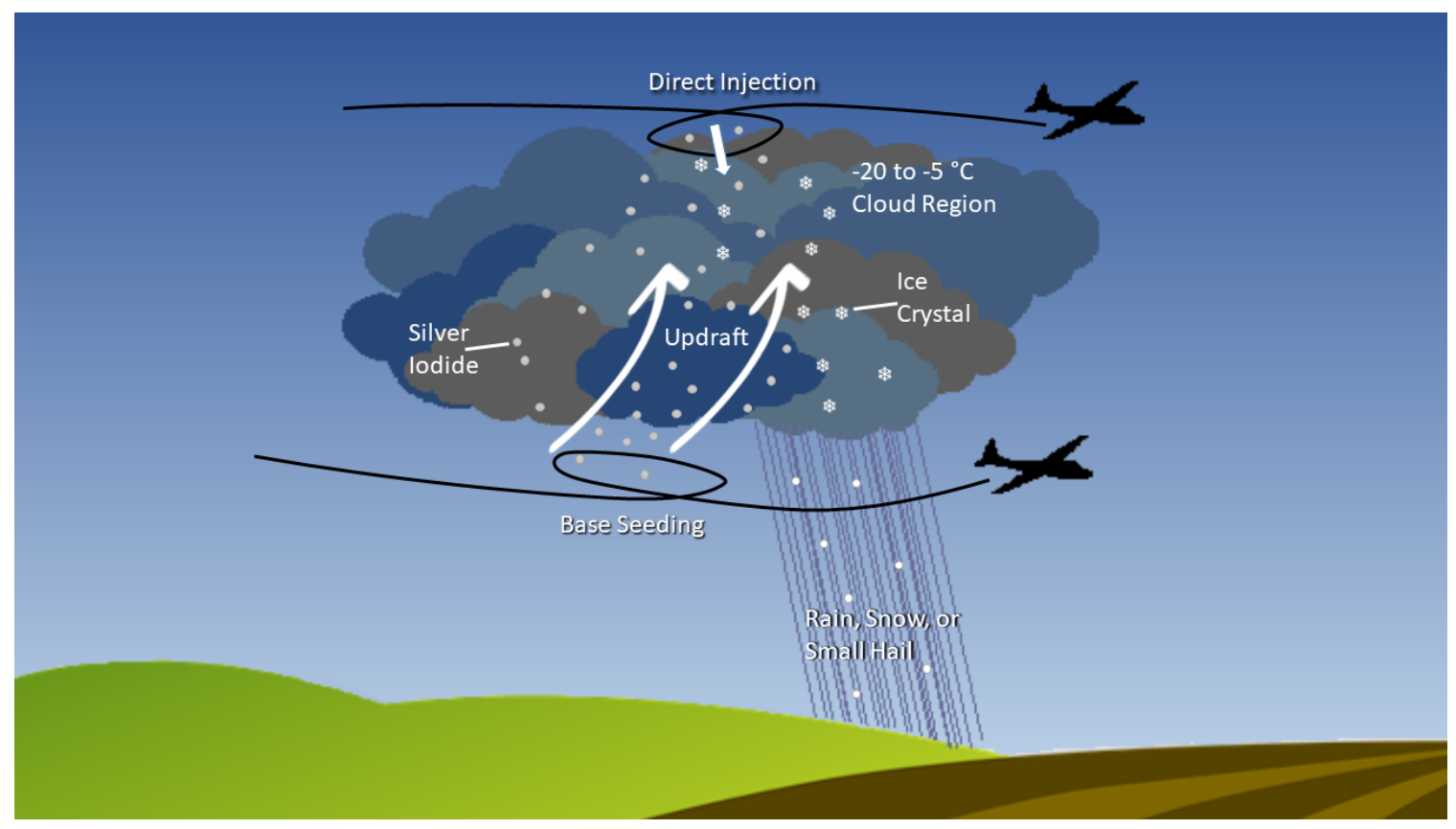

Figure 1: Basic conceptual model of the cloud base seeding and direct injection method used in the North Dakota Cloud Modification Project (NDCMP). For cloud base seeding, aircrafts use a combination of wing-mounted ice nucleus generators and burn-in-place flares; while for direct injection, aircrafts use ejectable flares and dry ice.

NDCMP is a non-randomized operational program, meaning any cloud that meets the seeding criteria will be seeded if possible. There is no process for randomly 
selecting some clouds for seeding and other equivalent clouds to be left untreated. Good seeding targets have a sustained updraft and contain supercooled liquid water (NDARB 2014). To be a rain enhancement target, a cloud shall be considered for treatment if not considered to be a hail threat but believed capable of producing additional precipitation if stimulated by the addition of ice nuclei. Characteristics of a general rain fall enhancement candidate are crisp, cauliflower-like tops and sides, firm flat, rain-free bases (NDARB 2010). Other criteria include: storms must have cloud bases lower than $8000 \mathrm{ft}$ mean sea level (MSL), obvious convective storm behavior, and inflow between 100-500 fpm, determined by flying near the base of the storm (NDARB 2018). Hail suppression targets are defined using the same parameters; however, slightly different guidelines: radar reflectivity $\leq 45 \mathrm{dBZ} 5,000 \mathrm{ft}$ above the freezing level, and pilot reported inflow between 500-800 fpm (NDARB 2018).

The NDCMP suspends cloud seeding under several criteria, which includes radar indicated or public reported tornado warnings, flash flood warnings, flood warnings, and areal flood advisories. For tornado warnings, pilots suspend all seeding operations and a determination is made if a tornado is present. If a tornado is not present, seeding operations may resume. However, if a tornado is ongoing, there is a 30-minute minimum suspension on all seeding operations. Seeding operations are only resumed 30-minutes after the last tornado report (NDARB 2018).

The target areas change from year to year based on whether county residents vote to participate in the project. The counties that are presently participating include Bowman, Slope, McKenzie, Williams, Mountrail, Ward, and Burke Counties (Fig. 2). Some counties, such as Adams, Hettinger, and McLean counties, have previously participated in the project (Table 1). The cost for NDCMP operations are shared between the state and counties that are participating. 


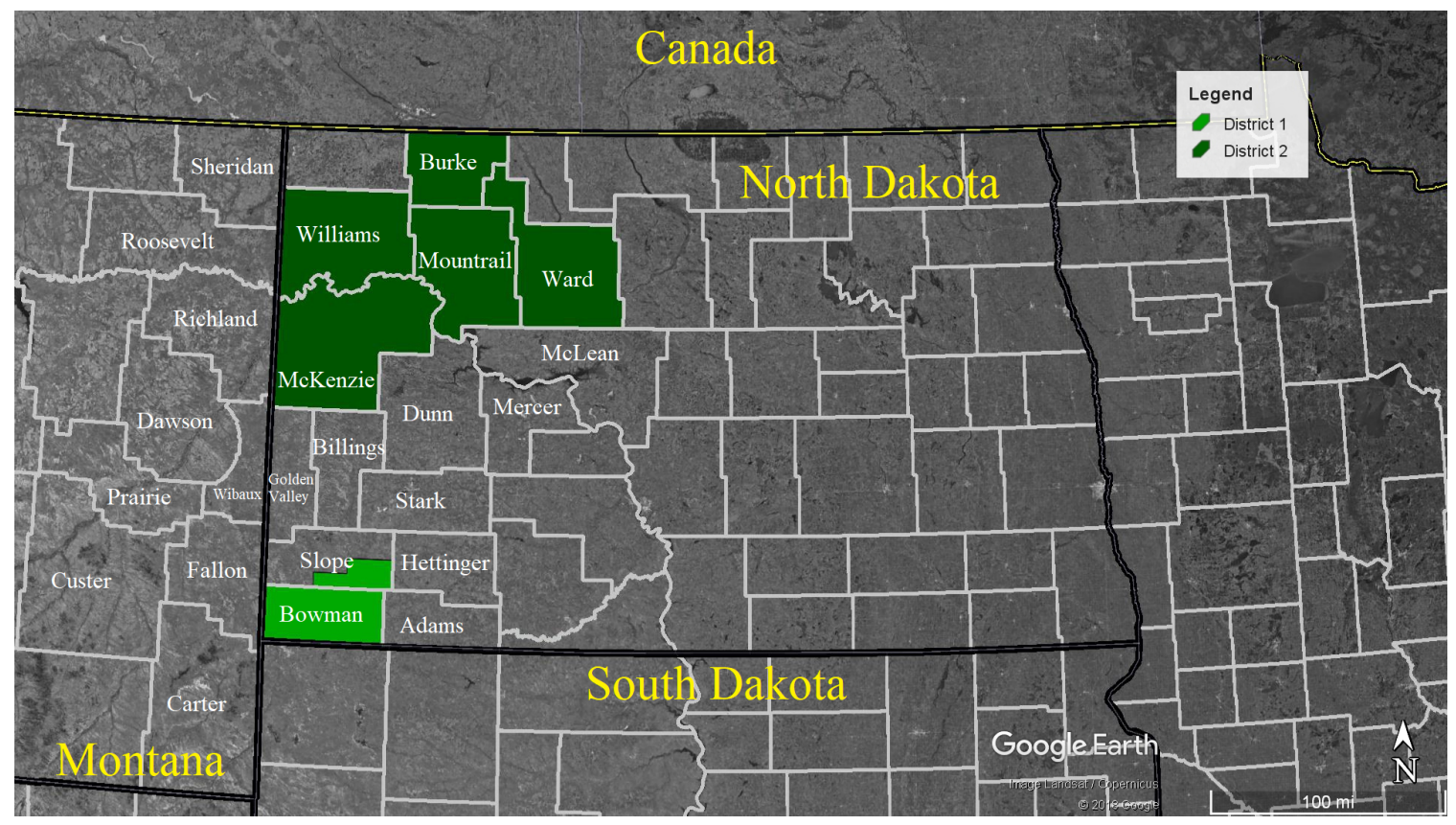

Figure 2: The North Dakota Cloud Modification Project (NDCMP) Operational Target Areas in western North Dakota. Operation seeding areas are broken into District I (light green) in southwest North Dakota and District II (dark green) in northwest North Dakota. Image was created using Google Earth Pro.

Table 1: List showing the seeding district, period of participation, and total number of years counties took part in the North Dakota Cloud Modification Project (NDCMP).

\begin{tabular}{|c|c|c|c|}
\hline Counties & District & Years Participated & Total Years \\
\hline Adams & 1 & $1977-1980$ & 3 \\
Bowman & 1 & $1977-2018$ & 41 \\
Hettinger & 1 & $1977-1988$ & 11 \\
Slope & 1 & $1977-2018$ & 41 \\
\hline Burke & 2 & $2015-2018$ & 3 \\
McKenzie & 2 & $1977-2018$ & 41 \\
McLean & 2 & $1977-1984$ & 7 \\
Mountrail & 2 & $1977-2018$ & 41 \\
Ward & 2 & $1977-2018$ & 41 \\
Williams & 2 & $1997-2018$ & 21 \\
\hline
\end{tabular}

Evaluations of a weather modification program can investigate the physical processes involved and/or conduct a statistical analysis between the program activities and whether desired results were achieved. Physical process studies can determine 
whether the atmospheric environment is suitable for the proposed weather modification method (e.g. Delene et al. 2011), or conduct measurements linking different processes involved in the cloud seeding chain of events that occurs between material release and rainfall (Bruintjes 1999). Experiments linking the physical processes can be performed in a controlled laboratory environment (i.e. cloud chamber) or in the atmosphere. Field project examples include the North Dakota Thunderstorm Project (NDTP) in 1989 (Boe et al. 1992) and the North Dakota Tracer Experiment (NDTE) in 1993 (Boe and North Dakota Atmospheric Research Board 1997). Statistical methods to evaluate cloud modification programs include: single and double ratio analysis of precipitation amounts (Gabriel 1999; Muralikrishna et al. 2009), multiple linear regression analysis (He et al. 2014; Muralikrishna et al. 2009; Gabriel 1999), and bootstrapping statistical analysis (Zhang et al. 2017).

Several studies have linked cloud seeding to notable increases in rainfall in a target region compared to a control region. However, very few have been able to directly link cloud seeding as the direct cause of the increase in rainfall (Silverman 2003). Most cases that state a dramatic increase have struggled to show statistical or physical evidence that these increases in rainfall were in fact related to cloud seeding or have reproducible results (National Research Council 2003). Statistical analysis on projects without well-defined control and target areas is difficult, as there is no way to compare the two areas' rainfall. Operational projects generally do not want a control area since they try to seed all available clouds. Physical process studies are difficult due to the large amount of detailed measurements required of the many processes involved. Advancements in both the dynamical understandings of weather modification and applied concepts have improved greatly in recent years, with more studies showing promising results (Garstang et al. 2005). Studies such as the one 
presented in this paper further try to analyze any induced effects on precipitation due to cloud seeding practices.

In Bari and Casona, Italy a randomized target/control rain enhancement experiment was executed from 1988-1994 (List et al. 1999) that used cloud seeding methods similar to NDCMP and was evaluated statistically. It was estimated before the experiment began that 303 rainy days were required to establish a $15 \%$ increase in rain at a significance level of 0.05 and $90 \%$ confidence. However, the experiment was terminated earlier than originally planned with only 260 rainy days. There was no apparent seeding effect found using root double ratio and root regression ratios calculated from data obtained.

Muralikrishna et al. (2009) examined a hygroscopic seeding operation in twelve districts of Andhra Pradesh, India from 2003 to 2008. The operational period was from June to November during both the southwest and northeast monsoon period. A linear regression equation was developed from 30 years' worth of rain fall data prior to the seeding project to estimate natural rainfall in the target area based on rainfall in control areas. The estimated rainfall in the target area based on the regression was $66 \mathrm{~mm}$ of rain while the observed rainfall was $118 \mathrm{~mm}$ of rain, which resulted in a claim of a $44 \%$ increase in rainfall in the target areas due to cloud seeding. When dividing the available data into target, control, and downwind regions for 2004 to 2008, a measured rainfall increase in target areas of 6 to $18 \%$ was seen. For the double ratio analysis, ten years of historical rain gauge data was used to normalize the rainfall during the seeding campaign. Results from the double ratio test also showed percentage changes from 22 to 127\%; however, no statistical significance was provided.

Prior to the development of the NDCMP, the North Dakota Pilot Project (NDPP) took place in McKenzie County from 1969-1972 with the addition of Moun- 
trail and Ward Counties in 1972. The principle seeding method was using silver iodide generators on aircrafts below the cloud base, similar to modern methods used by the NDCMP. Data was collected by radar, instrumented aircraft and a rain gauge network of 67 rain gauges (Dennis et al. 1975). Results for this study showed that seeding on days with dynamic seedability, determined from a simple 1-dimensional cloud model, produced increases in the frequency of rainfall events and in the magnitude of rainfall events, thus, leading to an increase in total rainfall on the target area.

While difficult, the long-term availability of rain gauge data in and around the NDCMP region does provide the opportunity to conduct an exploratory statistical analysis. NDCMP has been the subject of several studies to evaluate the project's effectiveness using different methods. Schaffner et al. (1983) conducted a three-section study on the economic benefit of added growing season rainfall to four areas of North Dakota. Section one looked at the impact of added growing season rainfall. Section two studied the resources and organization of agriculture under normal conditions and evaluated operation costs. Section three estimated the total impact of the direct returns to agriculture from cloud seeding on the state's economy. For western North Dakota, which includes all the counties examined in this current study except for Ward County, a gain of nearly $\$ 53.0$ million, or $\$ 3.63$ per planted acre was found, and for west central North Dakota, a gain of approximately $\$ 48.3$ million, or $\$ 4.85$ per planted acre was found. Using the reduced annual loss of $\$ 134.3$ million due to hail, or about $\$ 6.85$ per planted acre (Bangsund and Leistritz 2009), with an increase of $5 \%$ in rainfall, the estimated value of NDCMP cloud seeding would be near $\$ 42$ million or $\$ 2.15$ per planted acre over the nine-year period. Within the NDCMP counties, a $5 \%$ increase in rainfall would have an economic benefit of $\$ 8.4$ million 
annually, or $\$ 3.58$ per planted acre. With an increase of $10 \%$, the economic benefit would be $\$ 16$ million annual, or $\$ 6.84$ per planted acre.

Johnson (1985) did an NDCMP precipitation evaluation for 1976 to 1982 by comparing rainfall in the target region, and downwind of target region, with a control region. The $500 \mathrm{hPa}$ winds were used to determine storm motion direction for determining downwind regions. Results were not statistically significant but showed an overall increase in rainfall downwind of the target site relative to the control sites in July and weak evidence of an increase in downwind August rainfall; however, there was no evidence for the rainfall increase in the target area.

In a different approach, Smith et al. (1992) compared wheat yields for seeded and non-seeded counties before 1961 to wheat yields after 1975. A 6\% increase in wheat yields was observed in the target areas over the control areas; however, the results were not statistically significant. Also, it was not clear the NDCMP was the direct cause but more likely the increase was due to improvements in agricultural technology.

By using climatic data from the National Oceanic and Atmospheric Administration (NOAA) Cooperative Observer Program (COOP) rain gauge network, Smith et al. (2004) studied whether a cloud effect was present. A target/control methodology was used that consisted of 12 counties in eastern Montana as the controls. Eastern Montana was selected due to the rain gauges being upwind of the target area and not contaminated by seeding. Due to the small number of gauges in the NOAA COOP network in Montana prior to 1950, only rainfall data after 1950 were used. For the pre-NDCMP years, 1950-1975 were used and 1976-2002 for the NDCMP years. The primary analysis used was multidimensional, least-absolute-deviation, line fit to seasonal gauge rainfall data. A residual Euclidean distance from the multidimensional line were computed for all 53 years to determine if an increase of rainfall was observed. 
Results showed little to no increase in rainfall between the target compared to the control areas and the results were considered to not be statistically significant with a p-value $(0.322)$.

Wise (2005) analyzed the effects of NDCMP using a target, control, and downwind approach with respect to each seeding district and used NDARBCON rain gauge data from 1977 to 2003. Control rain gauges were adjacent to the target region and downwind rain gauges were further away downwind as determined by daily mean storm motion. To determine the control/downwind regions for each month, radarderived storm tracks from 1999 to 2002 were used. Storm motion was broken into Southwest (SW), Northwest (NW), Southeast (SE) and Northeast (NE) mean storm motions. Between 1999 to 2002, District I's storm motion came from the SW at $72 \%, 20 \%$ from the NW, and $8 \%$ from the SE. District II had similar flow regime frequencies with $70 \%$ from the SW, $37 \%$ from the NW, $2 \%$ from the NE, and $1 \%$ from the SE. The downwind regions extended from the target region to $75 \mathrm{~km}$ downwind according to wind direction. Climatological summertime rainfall data from 1931 to 1960 were used to create climate adjustment ratios to normalize the control region rainfall during the NDCMP. Results were broken down into seven classes, for District I, target/control (NW flow), target/control (SW flow), downwind/control (SW flow) and target/control (NW flow), downwind/control (NW flow), target/control (SW flow) and downwind/control (SW flow) for District II. The target/control and downwind/control with southwest flow for District II results were statistically significant $(\mathrm{p}$-values $<0.10)$. Four classes out of seven had at least $5 \%$ more precipitation for seeded areas and the other three cases had $\pm 3 \%$ differences.

Determining the effectiveness of the NDCMP can help future economic cost/benefit ratio studies and are important so sponsors and the public are well informed. This project's objective is to analyze NDARBCON and NWS COOP's 1977 to 2018 mea- 
surements to determine the effectiveness of NDCMP for increasing summertime precipitation. The objective of rainfall enhancement by the NDCMP is not to enhance rainfall down wind of the target area, but within the target itself; therefore, downwind regimes were not investigated. However, it cannot be ignored that downwind effects could contaminate possible control regions. 


\section{CHAPTER II}

\section{DATA}

\section{NORTH DAKOTA ATMOSPHERIC RESOURCE BOARD COOPERATIVE OBSERVER NETWORK}

The NDARBCON network has used volunteer observers since the project start in 1977. Many NDARBCON stations exist only for one year, while a few sites extend from 1977 to 2018. In 1977 there were 505 NDARBCON rain gauges in the NDCMP region and over 900 gauges state wide in the 1980s. Observers are supplied with a "Tru-Chek" wedge-shaped rain gauge (Fig. 3), postage paid reporting cards, and instructions on the network procedures prior to each reporting season. The instructions state location requirements and how to measure the daily rainfall totals. The rain gauge needs to be in an open area that is at least 50 feet from any obstructions. The rain gauges used by NDARBCON observers measure rainfall to the nearest hundredth of an inch up to a rain amount of one inch, and to the nearest five hundredths of an inch up to a rain amount of six inches. The observation period is April 1 through September 30 each year; however, some observers start on June 1 when the cloud seeding operation begins. The observers recorded the rainfall amount once a day at 0800 AM local time. Due to the readings taking place at 0800 AM, the rainfall measured would typically encompass the previous day, since most Central United States summertime convection happens during the afternoon to evening hours (Liu and Li 2016). At the end of each month, the NDARBCON observers mailed their

filled-out forms to the NDARB office. The rain gauge data is manually entered into 
the NDARB computer system, so if any rain gauge data seems unrealistic, the data gets flagged until it can be confirmed. While most observers reported a reading every day, some observers only report when there is rainfall, and some observers go for an entire period with no rainfall regardless of if rain had fallen or not. Observers may make an observation in the afternoon or evening. The NDARB has conducted quality control on the NDARBCON rain gauge data and tried to correct rain gauges where errors were obvious. No additional quality assurance has been conducted on the NDARBCON data set for this study. All NDARBCON rain gauge data used by this project is from the NDCMP's website.

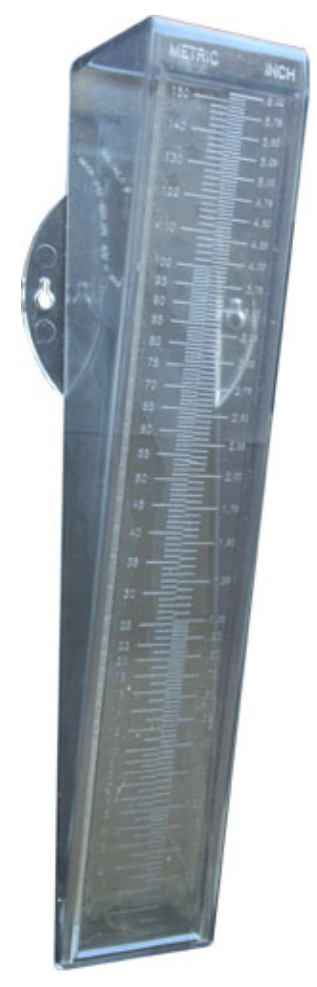

A

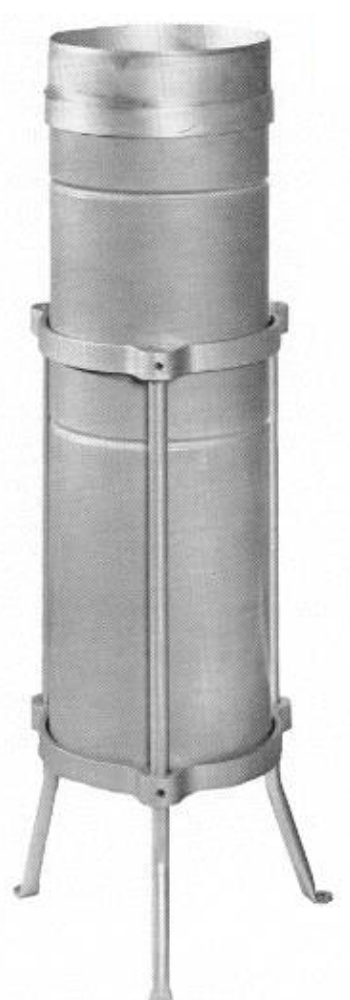

B

Figure 3: The Tru-Chek wedge rain gauge (A) used by the NDARBCON observers and the standard 8-inch rain gauge (B) used by National Weather Service (NWS) Cooperative Observer Network (COOP). Tru-Check rain gauge dimensions are 13" by 2.5 " by 2.5 (Height by Width by Depth). The standard 8-inch rain gauge dimensions are 8 " by $27 "$ (Diameter by Depth). 


\section{NATIONAL WEATHER SERVICE COOPERATIVE OBSERVER PROGRAM}

Through the National Weather Service (NWS) Cooperative Observer Program (COOP), more than 10,000 volunteers take daily weather observations across the United States. COOP data typically consists of daily maximum and minimum temperatures, 24-hour precipitation totals, and snowfall totals. COOP observers are issued an eight-inch non-recording standard rain gauge, which has an open mouth can with straight sides (Fig. 3). Some stations may be supplied with an 11-inch plastic gauge, which is an acceptable substitute. The eight inch standard rain gauge is a simple non recording gauge consisting of four major components: a measuring stick, overflow can, collector funnel, and measuring tube (NWS 1999). Rainfall can be measured within a tenth of an inch and the gauge can hold 20 inches of rainfall. This standard eight-inch gauge meets the World Meteorological Organization standard, and is a design widely used across the world. The data is distributed through the National Centers for Environmental Information's (NCEI) online data base. COOP conducts quality control similar to NDARBCON where any suspicious rainfall total is flagged as inaccurate by NCEI's automated review algorithm. However, sometimes questionable daily rainfall totals are not caught, so additional quality assurance is conducted on the COOP data by the NCEI.

Langerud and Gilstad (2003) compared the NDARBCON and NWS COOP gauges over a 23-year period from 1977 to 1999. NWS COOP and NDARBCON gauges were put into data pairs by identifying NDARBCON gauges close to NWS gauges.NDARBCON gauges within $10 \mathrm{~km}$ of a COOP gauge were compared multiannually and annually, while sites within a five $\mathrm{km}$ radius were compared monthly and daily. The annual and multi-annual comparisons had rainfall totals within approximately half an inch per year and a correlation of 0.998. However, daily comparisons 
had large variation due to network differences. Overall, the conclusion was that the two data sets compare well on a monthly and yearly scale, making it a reliable combined data set to use for this study. 


\section{CHAPTER III}

\section{METHODOLOGY}

\section{TARGET/CONTROL}

The rainfall in this study was evaluated by using a target and control analysis. Target and control methods provide a statistical analysis of the rainfall, not a physical process evaluation. A target is defined as an area where something is being applied

or treated. In this instance, the cloud seeding agent is what is being applied to the seeded counties. The control is defined as an area where conditions are left untreated or untouched. Controls are designed to minimize the effects of variables other than the independent variation (e.g. monthly or seasonal rainfall). This increases the reliability of the results, often through a comparison between the control measurements and the target measurements.

The target regions were determined by the number of years active in the NDCMP. Target counties that have participated for the entire duration were selected from District I and II (see Fig. 2). Of those counties, Bowman, Slope, McKenzie, and Ward Counties were selected. Bowman and Slope Counties were combined to create a larger area of analysis. Controls were designated as counties that have not participated in the NDCMP or participated in a relatively short period compared to the project's lifespan (less than 10 years). Choosing a control area that will not be affected by downwind effects from seeding proved to be difficult. DeFelice et al. (2014) found that extra area effects of cloud seeding, or the downwind effect, can increase precipitation by $5-15 \%$, and Wise (2005) found a noticeable increase in 
downwind rainfall within the NDCMP region. Using Wise (2005) as a basis for areas that could be contaminated by downwind effects, it was determined that having controls upwind from the cloud seeding operation could help mitigate any downwind effects found within the North Dakota counties. Therefore, the control area included counties within North Dakota and the eastern most portion of Montana. This created controls in North Dakota of 'Billings' (which consisted of Billings and Golden Valley County) and 'Mercer' (McLean and Mercer County). The Montana controls were 'Richland' (Richland and part of Dawson County), 'Roosevelt' (Roosevelt and Sheridan County), 'Wibaux' (Golden Valley County, ND, Wibaux and part of Dawson County), 'Fallon' (Fallon and northern Carter County), and Carter.

Combining the NWS COOP and NDARBCON rain gauge network provided dense observations across the study domain from 1950 to 2018 (Fig. 4). Although the density of the NDARBCON network has drastically decreased over the 41-year project, each target and control area had at least six gauges per year for the entire period. NWS COOP data was used as a supplemental resource to provide historical rain gauge amounts as well as consistent rainfall amounts at individual locations over a long period of time. Included NWS COOP rain gauges were available within all target and control locations in both North Dakota and Eastern Montana dating back to the 1900s. This provided enough data to perform similar analyses for 1950-1975 and 1977-2018. The year 1950 was determined by Smith et al. (2004) as an adequate starting point for any pre-NDCMP analysis. It was noted that even going back two years before 1950 would decrease the number of usable rain gauges by half. Limited cloud seeding efforts began in western North Dakota as early as 1951, but it is assumed that the COOP gauges available at that time would not measure a dramatic change in rainfall during those efforts as there was less seeding activity during this period 
than compared to the NDCMP years. Thus, it was assumed the effect on measured rainfall is negligible.

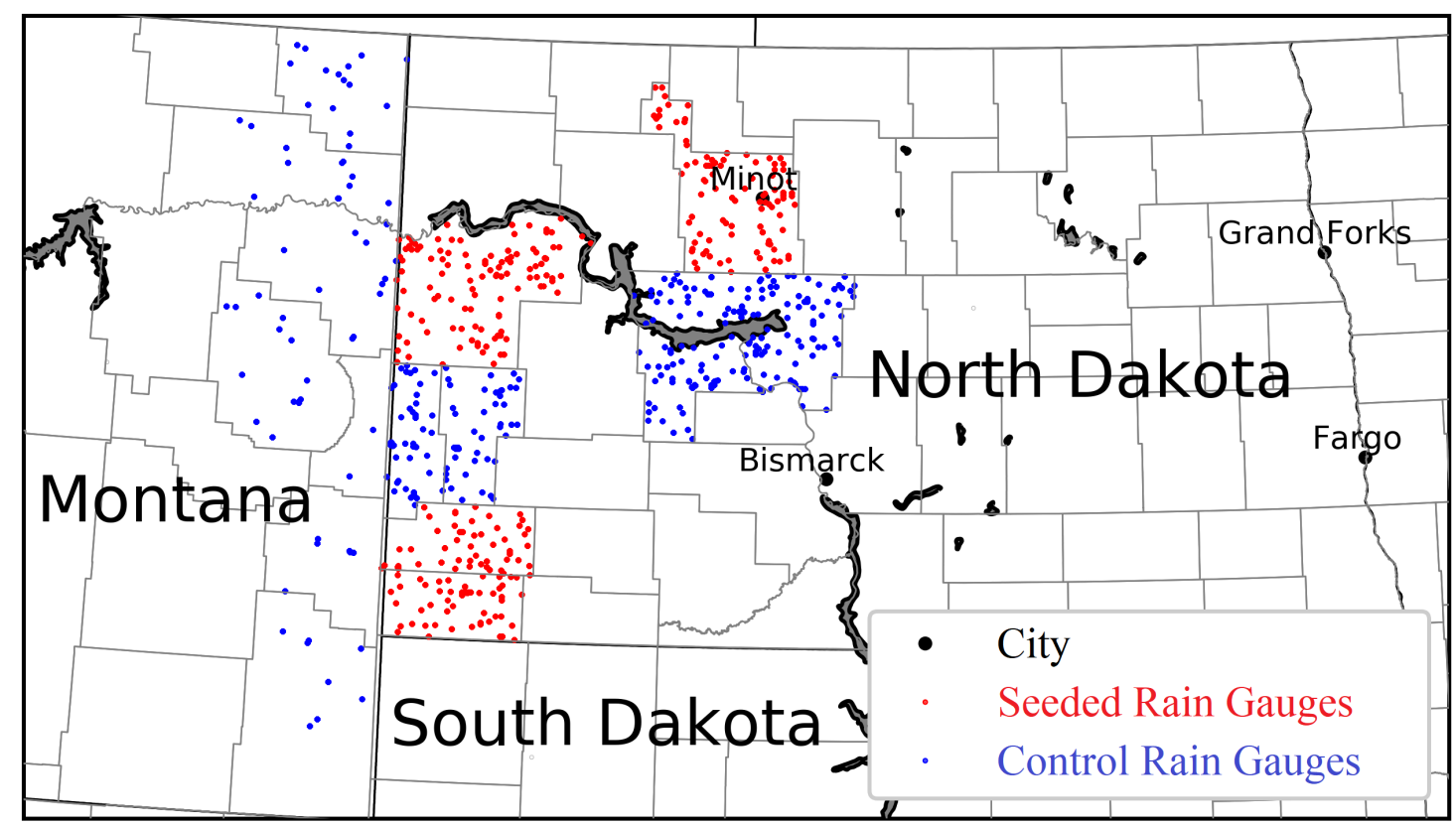

Figure 4: NDARBCON and NWS COOP rain gauge locations within target (red) and control (blue) counties from 1950 to 2018.

The NDARBCON and NWS COOP gauges are used interchangeably in this study to fill in missing data gaps and provide consistent long-term data. It is noted that the rainfall amounts from 1950 to 1975 may not be representative of current climate in western North Dakota. However, the amount received during that period is not essential for this study. What had to remain the same were the climatic single ratios of rainfall between the target and control regions. This time period is used to account for natural variations in rainfall between the different target and control regions. It was assumed that the ratios calculated for this period were representative of the ratios during the study period without the effects of seeding. These assumptions are acknowledged as possible contributions to the uncertainty in the study. 
To examine the effects of cloud seeding on the target region rainfall, three analysis methods were used. The first method was a weighted averaging scheme over the target and control region. The weighted averaging scheme used rain gauges within a circle to determine an estimate of rainfall at a point at the middle of the circle. The second method was a county-based averaging scheme. This scheme treated all rain gauges equally within the given target and control areas. The third method combines all target and all controls into one theoretical target and theoretical control dataset and was then averaged by the number of rain gauges present in each dataset.

\section{MISSING DATA}

Despite having vast amounts of rain gauges available throughout the history of the NDCMP, time consistency (e.g. year-to-year reporting) of rain gauge observations were an issue with observers. Each year from 1977 on fewer NDARBCON rain gauge observers reported rainfall over the season. At times there was even a variation of rain gauges reported for each month. Beside this inconsistency in reporting with NDARBCON rain gauges, the NWS COOP gauges also had a considerable amount of missing data.

To handle missing data for the NDARBCON gauges, gauges were checked to see if a complete record for June, July, or August were available. If the rain gauge had a complete record for at least one of the months, it was used towards the calculation of the monthly total rainfall for that year. Having stations with all three months on record was preferred, but keeping that standard limited the number of gauges that could be used by an average of 4 gauges per year in each target region. Figure 5 shows an example of how rain gauges vary on a monthly and yearly basis in the target county of McKenzie from 1950-2018. Determining stations on a monthly basis incorporated significantly more gauges into the monthly calculations, 


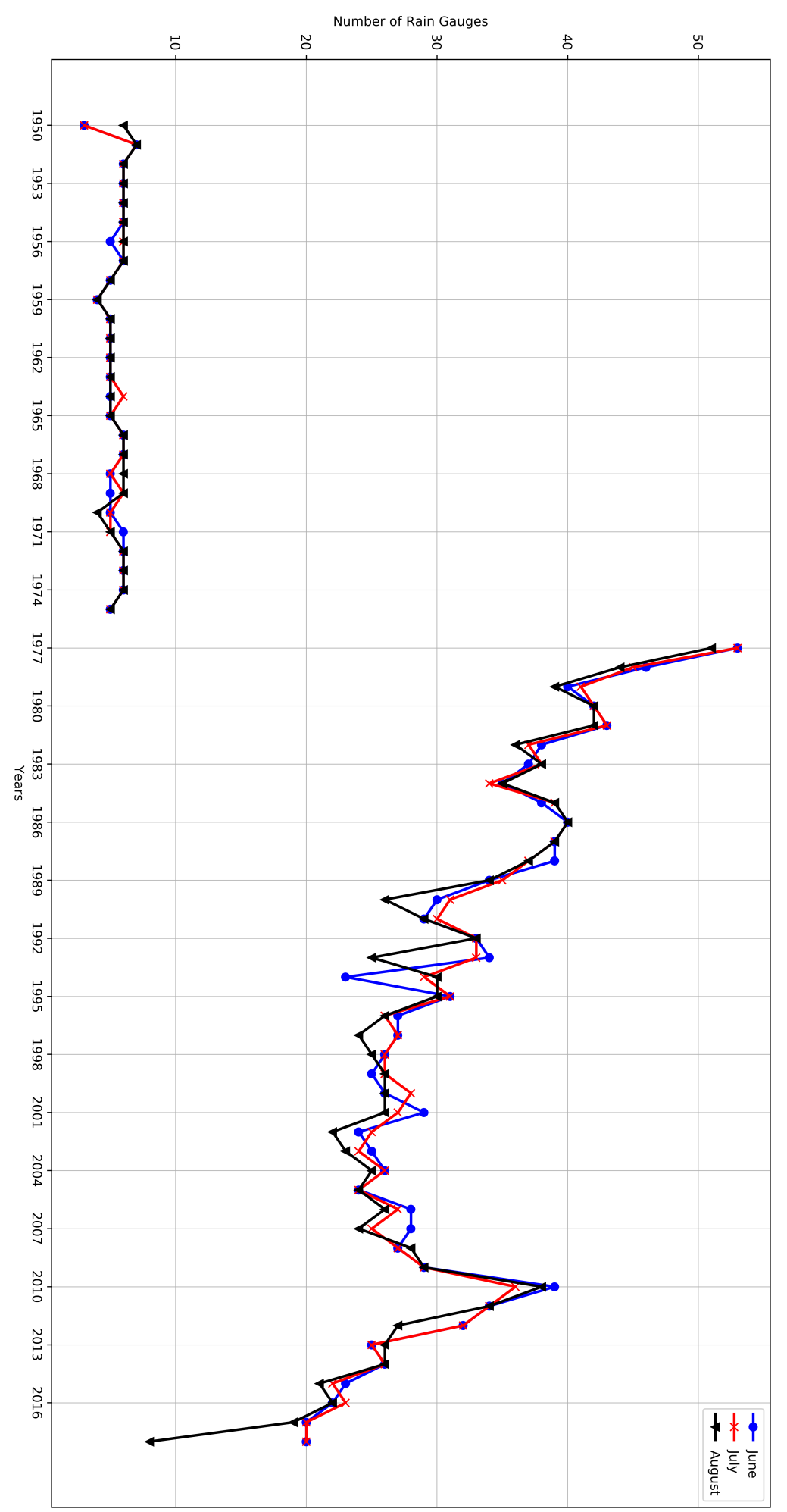

Figure 5: All available National Weather Service (NWS) Cooperative Observer Program (COOP) and North Dakota Atmospheric Resource Board Cooperative Observer Network (NDARBCON) rain gauges for McKenzie County from 1950 to 2018 for June (blue), July (red), and August (black). 
however, knowing the reliability of these measurements was impossible to determine outside of the quality control and quality assurance done by the NDCMP. The same method was applied to the NWS COOP data to remain consistent with NDARBCON data. Since only a few COOP gauges were in operation prior to the start of NDCMP, some months may be based on the rainfall collected in a two or fewer gauges within specific target/control areas.

For months where no rainfall was reported by the station, a "NaN" was placed in the record to signify that there had been no data reports and for it to be removed during later analysis of each station. Most stations had most of the years labeled as "NaN", with less than $40 \%$ of stations reporting the full 41 years of the NDCMP. How the variable number of rain gauge observations affects the calculated rainfall totals is unknown, but it is assumed to not have a significant impact on the overall analysis of this data. It could be stated that having the locations and number of rain gauges varying within the network may eliminate any observer bias but having some stationary gauges are useful to have a climatology of average rainfalls to compare with.

\section{RAINFALL EVALUATION}

Precipitation amounts for each target and control region were calculated for the NDCMP period (1977-2018) and for the pre-NDCMP period (1950-1975). All gauge data within each target and control region were combined to obtain a monthly total rainfall amount for each region. Each station with enough data, as specified in the Data chapter, had its monthly rainfall calculated. Each station's rainfall amounts were calculated by: 


$$
R_{\text {station }}=\sum_{i=1}^{n_{\text {days }}} r_{g}(i)
$$

where $R_{\text {station }}$ is the calculated monthly rainfall amount for the given station, $r_{g}$ is the rainfall amount recorded on the given day by the rain gauge and $n_{\text {days }}$ is the number of days in the month. This calculation was consistent throughout each analysis method.

The monthly rainfall total calculated for each station was then added together to create a monthly rainfall total for the given method of analysis. The monthly rainfall amount was calculated by:

$$
R_{\text {monthly }}=\sum_{i=1}^{n_{\text {stations }}} R_{\text {stations }}(i)
$$

where $R_{\text {station }}$ is the monthly rainfall calculated by each station and $n_{\text {stations }}$ is the number of stations for the given month. This creates a total monthly rainfall based on each station across the specified target and control analysis method. The monthly rainfall total calculated is not averaged and is not intended to be used until an average scheme is applied.

A season rainfall total was calculated by adding June, July, and August average monthly rainfall totals together based on each averaging scheme. This was done by:

$$
R_{\text {seasonal }}=\sum_{i=1}^{n_{\text {months }}} \bar{R}_{\text {monthly }}(i)
$$

where $R_{\text {seasonal }}$ is the calculated seasonal rainfall from each region's average monthly rainfall and $n_{\text {months }}$ is the number of months in the season. A comparison between the target and control was conducted using the monthly means and seasonal total rainfall. 


\section{COUNTY CIRCLES}

This was done to create specific areas to analyze and a way to weight the rain gauge data to a specific point within that circle. Circles with radii of $40 \mathrm{~km}$, centered on a given point for a given county as shown in Table 2, are overlaid on the target and control regions. Figure 6 shows the circles applied over the selected areas within the target and control regions. The radius of $40 \mathrm{~km}$ was chosen to avoid overlap between target and control areas and to keep rain gauge observations to a centralized location within the county, but also to encompass as many rain gauges as possible. The most notable area with cross over is between Billings and Wibaux Circles. These two circles shared a common county of Golden Valley County in North Dakota, since these are control areas, this was considered acceptable. The second area of overlap is Fallon and Carter Circles; unlike Billing and Wibaux, no rain gauges were present in this area of overlap.

Table 2: The latitude and longitude of county center point circles shown in Figure 6.

\begin{tabular}{|c|c|c|}
\hline Counties & Latitude & Longitude \\
\hline McKenzie & 47.753 & -103.509 \\
\hline Bowman & 46.280 & -103.509 \\
\hline Ward & 48.203 & -101.532 \\
\hline Billings & 46.992 & -103.443 \\
\hline Mercer & 47.499 & -101.672 \\
\hline Wibaux & 46.985 & -104.152 \\
\hline Richland & 47.687 & -104.566 \\
\hline Roosevelt & 48.427 & -104.475 \\
\hline Carter & 45.735 & -104.566 \\
\hline Fallon & 46.343 & -104.521 \\
\hline
\end{tabular}




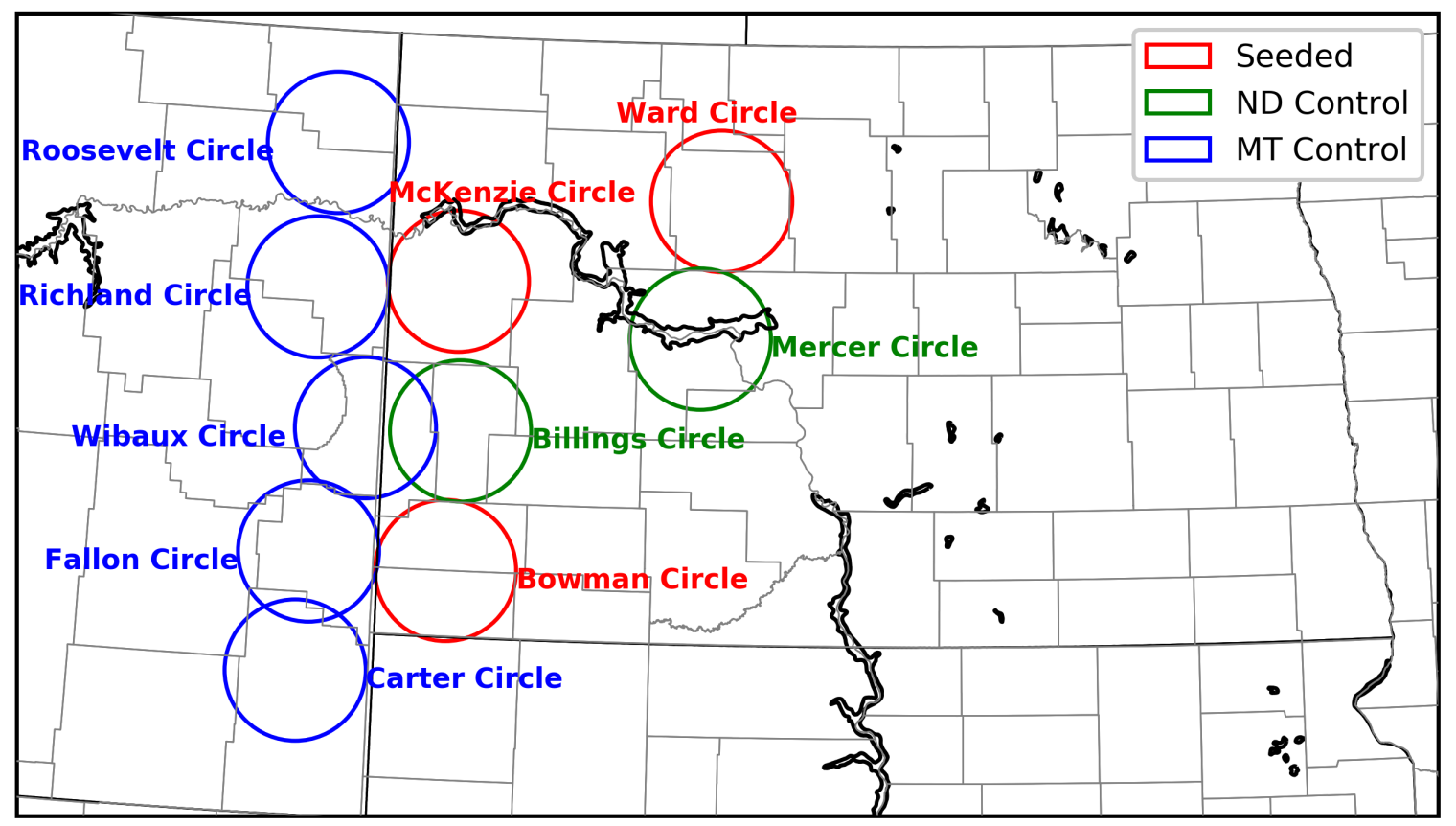

Figure 6: $40 \mathrm{~km}$ circular areas selected as target (red), ND control (green), and MT control (blue) for rainfall analysis.

Each rain gauge that fell within the $40 \mathrm{~km}$ circles were weighted to the center point given in Table 2 by using a Cressman distance weighting scheme given by:

$$
w=\frac{R^{2}-d^{2}}{R^{2}+d^{2}}
$$

where $w$ is the weight function in a percentage, $R$ is the radius of influence, and $d$ is the distance of the gauge from the central grid point. Using this scheme gives rain gauges closer to the central point more weight than gauges near the edges of the circle in estimating rainfall at the center. The distance, $d$, was determined using the Python GeoPy package for calculating distances based on the latitude and longitude from comma-separated values (CSV) data. If a rain gauge fell outside of the $40 \mathrm{~km}$ threshold of the circle, Eq. (3.4) would return a negative number. This resulted in a negative rainfall, indicating that a gauge was out of bounds. This technique was used 
as a consistency test to ensure all rain gauges were within the $40 \mathrm{~km}$ circle. After the weight was calculated, the rainfall amount at the central point was calculated by:

$$
f_{d}=\sum_{i=1}^{n} w(i) * f_{o}(i)
$$

where $f_{d}$ is the calculated rainfall at the central point, $f_{o}$ is the monthly rainfall from a given station from Eq. (3.2), $w$ is the weight calculation from Eq. (3.4), and $n$ is the number of rain gauges within the radius of influence. To account for a difference in the number of rain gauges between the target and control regions, a normalization function was used on Eq. 3.5):

$$
f_{\text {dnormalized }}=\frac{f_{d}}{\sum_{i=1}^{n} w(i)_{\text {month }}}
$$

where $f_{\text {dnormalized }}$ is the calculated rainfall at a central point after being normalized, $f_{d}$ is the rainfall calculated at a point from Eq. (3.5) and $w(i)_{m o n t h}$ is the sum of the weights for the given number of rain gauges, $i$. The higher sum of weights acted in a similar fashion to a general averaging function, but instead of dividing by the number of stations, it depends on how much influence a single station has overall. Therefore, a county with less rain gauges would be weighted less but would still have a rainfall close to an observed average. These calculations were applied to both the NDCMP and pre-NDCMP periods.

\section{COUNTY BASED EVALUATION}

To account for all possible rain gauges within a county, a county-based evaluation of rain gauges also was done. Like the circular approach, some counties were combined to create a larger county area than were within the political county borders (Fig. 7). This was primarily done for control regions to create a larger usable 
network of rain gauges. Bowman and Slope Counties were combined to create one larger target county to account for more variation in the observed rainfall within that area. Rain gauges within eastern Montana were treated differently in the sense that entire counties were not used. Further, some of the rain gauges in Montana were rejected due to the distance from the target region. Each created control area had a threshold of no more than $100 \mathrm{~km}$ across, except for Mercer due to its proximity to a target area. The inclusion of more rain gauges could provide a better insight into the observed average rainfall over the entire county. With a better representation of the county average rainfall, the effects of cloud seeding may be more obvious. Using the circle-based method may remove any visible effects seen on the outer edges of the circle. Therefore, it is important to explore use of all available rain gauges within the entire county without any weighting effect.

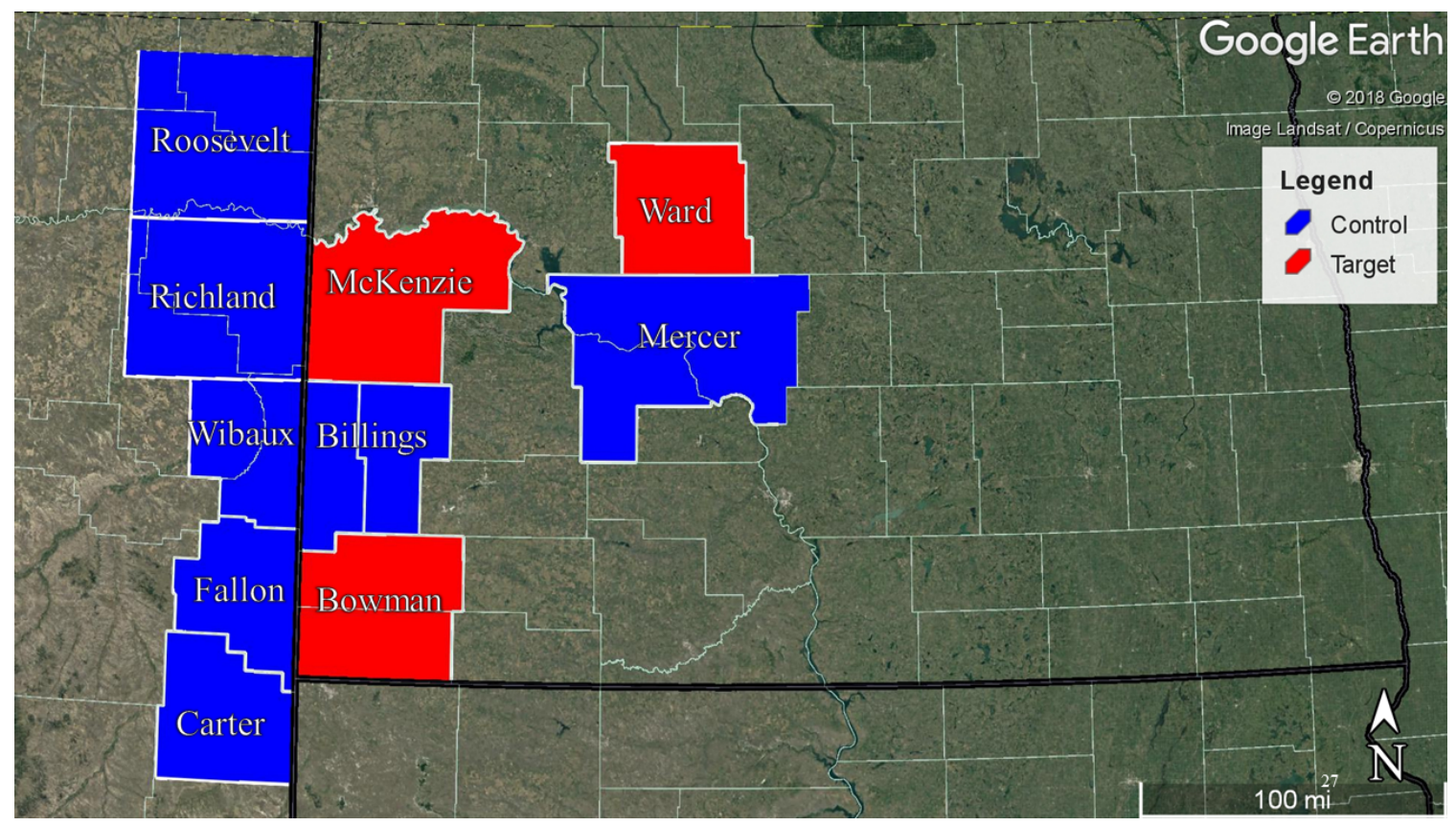

Figure 7: County-based areas for Target (red) and Control (blue). Image created using Google Earth Pro. 
Monthly rainfall and seasonal rainfall for the county-based evaluation were calculated similarly to the circular method. To obtain monthly rainfall, Eq. (3.2) was used to calculate the monthly rainfall within a single rain gauge, then it was summed and divided by the number of stations for each month. This was calculated by:

$$
\bar{R}_{\text {monthly }}=\frac{\sum_{i=1}^{n_{\text {stations }}} R_{\text {station }}(i)}{n_{\text {station }}}
$$

where $\bar{R}_{\text {monthly }}$ is the average monthly rainfall for the entire county, $R_{\text {station }}$ is the monthly rainfall for each station calculated in Eq. (3.1), and $n_{\text {stations }}$ is the number of rain gauges within the county for the given month. A seasonal rainfall total was calculated from this value for the given county by using Eq. (3.3).

\section{ONE TARGET, ONE CONTROL}

For the one target, one control method, all target and all control rain gauges were condensed into a singular area of their own type. In other words, all target gauges were in one pool and all the controls in another. This was done to account for any variation in rainfall due to non-uniformity of rainfall across North Dakota. Each rain gauge in their respective areas would be treated the same regardless of location. By doing this, the number of rain gauges in each area will be similar and possibly eliminate any bias due to number of samples. Monthly rainfall was calculated using Eq. 3.7 for each area of rain gauges and then single and double ratios were calculated for the created pair. 


\section{SINGLE AND DOUBLE RATIOS}

Once the rainfall for a given evaluation was completed, a single ratio between target and control were calculated for the 41-year period of the project. Each target area was assigned to different control areas based on the proximity of their location. The only target area that did not have multiple control areas to compare from was Ward. This was due to the location of Ward relative to acceptable control areas. Most areas that could be considered useful for a control for Ward County were either downwind of seeding or were in the seeding project. Mercer was determined to be the best possible control for Ward, although it may be contaminated due to downwind effects from other target areas. McKenzie was paired with Richland, Roosevelt, Wibaux and Billings, while Bowman was paired with Carter, Fallon, Wibaux and Billings.

The single ratios for the pre-NDCMP and NDCMP target and control were calculated for a given area by:

$$
\begin{gathered}
\left.T=\sum_{n=1}^{\text {years }} f_{d}^{\text {June, July,August,All }} \text { (target area rainfall }\right) \\
C=\sum_{n=1}^{\text {years }} f_{d}^{\text {June, July,August }, \text { All }}(\text { control area rainfall }) \\
S R=\frac{T}{C}
\end{gathered}
$$

where $S R$ is given as a single ratio from the sum of the $\mathrm{T} / \mathrm{C}$ ratios, $T$ is the sum of the target rainfall for either monthly or seasonal over the project lifespan, and $C$ is the control rainfall for the same period. Single ratio values are given in a decimal range where a 1:1 ratio is given as 1.0. Values such as 1.04 would suggest a positive $4 \%$ difference in target vs control rainfall while 0.96 would be associated with a $4 \%$ 
reduction in target rainfall relative to control. Single ratio values greater than 1.0 do not necessarily prove an increase or decrease in rainfall due to cloud seeding. Instead, these differences may also be attributed to natural variation in rainfall between the two regions.

To isolate natural variations from variations due to cloud seeding, a double ratio can be calculated by dividing the single ratios from the NDCMP and preNDCMP time periods:

$$
D R=\frac{S R_{1977-2018}}{S R_{1950-1975}}
$$

where $D R$ is the single value from the double ratio, $S R_{1977-2018}$ is the single ratio from the NDCMP project years, and $S R_{1950-1975}$ is the single ratio from the pre-NDCMP years. The double ratio was calculated for June, July, August, and for seasonal ratios. By using the double ratio to normalize the single ratio, any effect from cloud seeding should be more obvious. If there is a large ratio difference between the 1950 to 1975 and 1977 to 2018 single ratios, it can be suggested that cloud seeding may have contributed to a modification of target rainfall. However, any seasonal rainfall extremes in a target or control area for a given year can skew the data in a way that can suggest an increase or decrease in rainfall that may not be due to seeding.

\section{SINGLE AND MULTIPLE LINEAR REGRESSION}

Single linear regression uses a linear relationship to predict the average numerical value of predictand $(y)$ for a given predictor $(x)$ using a straight line, also known as a regression line. If the slope and the y-intercept of the regression line is known, then any $x$ can be used to predict a $y$. The single linear regression equation is given by: 


$$
y_{i}=\alpha+\beta x_{i}+\epsilon
$$

where $y_{i}$ is the dependent variable, $x_{i}$ is the explanatory variable, $\beta$ is the slope coefficient, $\alpha$ is the y-intercept and $\epsilon$ is the model's error term. In order to generate a useful linear regression that predicts rainfall that would have occurred naturally in the absence of seeding for the target area during the NDCMP years, an equation is developed from the target and control rainfall occurring before the program began. For example, to predict rainfall for the target area of McKenzie for 1977 to 2018 and using the control area of Richland, a linear relationship between rainfall in the target and control areas from 1950-1975 is used. In this example, $y_{i}$ would be a value of seasonal rainfall for McKenzie and $x_{i}$ would be the seasonal rainfall value of the same year from Richland. This would solve for the slope to be used in predicting the rainfall for 1977 to 2018. In this analysis the y-intercept is always set to zero. Once the equation is created, control rainfall values for 1977 to 2018 are plugged into $x_{i}$ to generate the predicted rainfall. This method is used as an estimate of what the rainfall of the target county would be without any possible effect of cloud seeding. Using this methodology, it can be suggested that any significant difference in rainfall would be the result of cloud seeding since it would be expected that the regression equation otherwise would be similar in the two periods.

A multiple linear regression is a statistical technique that uses several explanatory variables to predict the outcome of a response variable. Multiple linear regression can be used to estimate the rainfall in a target area if cloud seeding did not happen by using several control areas' rainfall as predictors. Multiple linear regression could detect slight variations in rainfall by using the control areas to predict the target 
rainfall and comparing the predicted to the observed target rainfall similarly to the single linear regression. The formula for multiple linear regression is:

$$
y_{i}=\beta_{0}+\beta_{1} x_{i 1}+\beta_{2} x_{i 2}+\ldots+\beta_{p} x_{i p}+\epsilon
$$

where $y_{i}$ is the dependent variable, $x_{i}$ is the explanatory variable, $\beta_{o}$ is the $y$ - intercept (constant term), $\beta_{p}$ is the slope coefficients for each explanatory variable, and $\epsilon$ is the model's residual error (Wilks 2011). Multiple linear regression is applied similarly to single linear regression, but two or more control area predictors are used to try to predict what the target rainfall would have been for a specific area.

For determining which control areas would make the best predictors for the target county, the seasonal rainfall totals were correlated over the NDCMP project period and pre-NDCMP period. Higher correlated areas indicate that the two areas experienced similar covariation of rainfall over the 41-year period. The fact that the correlation almost never is perfect can be attributed to geographical differences in location between the two areas (Huff 1979; Habib et al. 2001). For single linear regression, the control county with the highest correlation was used as a predictor for the seeded county and rainfall estimates were calculated to analyze any significant differences. In the multiple linear regression, one predictor with a high correlation to the target area was used, and one with a lower correlation to the first predictor was selected. This was done to account for any additional precipitation covariation that the highest correlated predictor may not have. It was noted that not all predictor pairings produced adequate estimations of rainfall, as some strongly over predicted. An adequate prediction is determined as a prediction within a reasonable margin of the observed precipitation. Strongly over predicted rainfall was determined as 
predicted rainfall that was unrealistic for the area. For example, if a predicted rainfall was 100 inches over the observed rainfall, this is considered unrealistic.

Single linear regression and multiple linear regression statistics were calculated using Microsoft Excel's regression statistical package. In addition to calculating slope coefficients, multiple R, R squared, adjusted R square, and standard error were all calculated for the given predictor(s).

- Multiple $\mathrm{R}$ is the correlation coefficient of how strong the linear relationship is, and this is the square root of $\mathrm{R}$ squared.

- $\mathrm{R}$ squared is the coefficient of determination. This metric examines how well the regression line fits the data. For example, a value of 0.90 means that $90 \%$ of the variation of $\mathrm{y}$-values around the mean are explained by the $\mathrm{x}$-values. In other words, $90 \%$ of the data points fit the model.

- Adjusted R squared adjusts for the number of terms in a model. If more than one predictor is used, this should be used instead of $\mathrm{R}$ squared.

- Adjusted R squared adjusts for the number of terms in a model. If more than one predictor is used, this should be used instead of $\mathrm{R}$ squared.

- Standard error of the regression is an estimate of the standard deviation of the error. This is a different standard error than the one used in the descriptive statistics.

Selected results based on regression analysis are presented in Appendix A

The t-statistic or t-stat is the ratio of the departure of the estimate value of a parameter from its hypothesized value to its standard error (Lane et al. 2003). It can also be used as a measure for testing the significance of the difference between 
the sample mean and a hypothesized value of the mean. In other words, the greater the magnitude of $t$, either negative or positive, the greater the evidence against the null hypothesis that target and control values are drawn from the same statistical population. This means there is greater evidence that there is a significant difference between the data sets. The t-stat is given by:

$$
t=\frac{\bar{x}-\mu}{s / \sqrt{n}}
$$

where $\bar{x}$ is the population mean, $\mu$ is the sample mean, $s$ is the sample standard deviation, and $n$ is the number of samples (Snedecor and Cochran 1989).

To determine the number of years needed to detect a specific percent change in rainfall, Eq. 3.14 can be modified in such a manner that an increase of rainfall of 5 or $10 \%$ can be resolved with $95 \%$ confidence. Modifying Eq. (3.14) to detect a 5 or $10 \%$ change in rainfall relative to the predicted rainfall gives:

$$
t=\frac{(\bar{x}-P)-\mu}{s / \sqrt{n}}
$$

where $\bar{x}$ is the observed mean rainfall, $P$ is the decimal change, $\mu$ is the predicted mean rainfall, $s$ is the observed standard deviation, and $n$ is the number of years. Assuming a constant difference between the observed and the predicted rainfall, and constant standard deviation, the number of years, $n$, can be changed to determine what the estimated number of years would need to be to see a seeding effect of 5 or $10 \%$ due to cloud seeding. The limitations of this method are tied to how well the predictors estimate the rainfall compared to the observed values. County pairs with a large difference in predicted rainfall compared to observed rainfall require more years to detect a statistically significant change in rainfall. The number of years needed to distinguish a certain change in rainfall at a certain confidence level 
is based on Gaussian statistics. Therefore, these are purely an estimate based off the precipitation data, assuming it is normally distributed. Analyses of the number of years needed to see a change in precipitation of a specified percentage are presented in Appendix C.

\section{BOOTSTRAPPING STATISTICAL TEST}

Bootstrapping is a resampling method related to any test or metric that uses random sampling with replacement. Resampling methods quantify uncertainty by calculating standard error, confidence intervals, and performing significance tests on data sets with the same distributions as the observed data set (Hesterberg et al. 2005). Fewer assumptions are required compared to traditional methods based on Gaussian statistics and results are generally more accurate. General bootstrapping assumptions include: each observation is randomly selected from its population, it does not assume a distribution shape, and the sample represents the population it was drawn from. The natural variation of rainfall during the pre-NDCMP and NDCMP years is examined using bootstrapping.

By sampling with replacement, a data point is randomly drawn from the original sample and placed into a new statistical sample. Since each sample is randomly drawn, any data point may be drawn multiple times. In theory, one data point could make up an entire set, but this is extremely unlikely. Sampling with replacement is used instead of sample without replacement method (subsampling) due to the varying number of rain gauges over the project's period.

Since the distributions of rainfall totals (Fig. 8) and calculated single ratios

from the target/control analysis (Fig. 9) are non-Gaussian, using a bootstrapping technique makes it possible to produce a test statistic, the sample mean, that is normally distributed. The bootstrap distribution of sample means is centered close 
to the mean of the original sample, therefore there is little bias as an estimate of the mean of the original sample. This also allows for confidence intervals to be calculated for the mean.

Bootstrapping is used in two different ways in this study. The first way is to examine the natural variation of the single (Eq. (3.10) ) and double (Eq. 3.11) ratios and the second is to determine how the number of rain gauges impacts the analysis. In setting up the first bootstrapping technique, the seasonal rainfall totals for each target and control method is used over the two time periods. Distributions of single ratios are created by bootstrapping the seasonal rainfall over the two time periods to determine the natural variation by calculating the $95 \%$ confidence interval. The double ratios are calculated from the bootstrapped single ratios for the time periods and determining the $95 \%$ confidence intervals. If the lower bounds of the 95\% confidence interval are greater than 1 for the double ratio, it can be stated that there is a positive change in rainfall in the target that is statistically significant.

The second bootstrapping method determines how the number of rain gauges affect the mean rainfall within each county. Since the number of rain gauges greatly varies over the NDCMP lifespan, some years have significantly less rain gauges than other years, which may affect average rainfall within the target and control areas. To set up this bootstrapping test, June 1977 in McKenzie County was used as it contained the greatest number of rain gauges of any area throughout the project period. From there, groups of 1 to 33 rain gauges were randomly sampled 100,000 times to create the bootstrap test statistic for rainfall. Choosing an adequate number of rain gauges was 


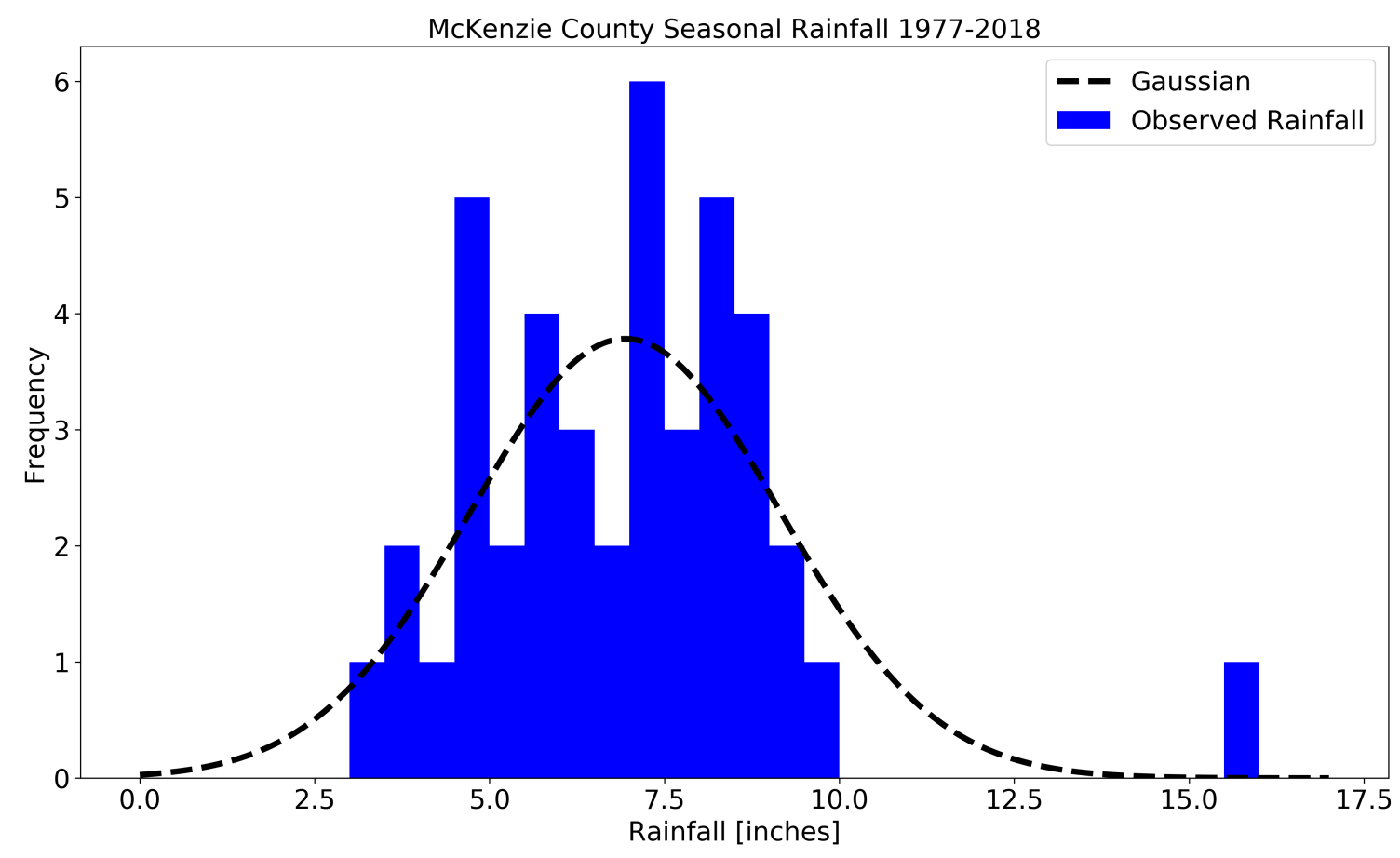

Figure 8: Probability distribution function for McKenzie County seasonal rainfall for 1977-2018.

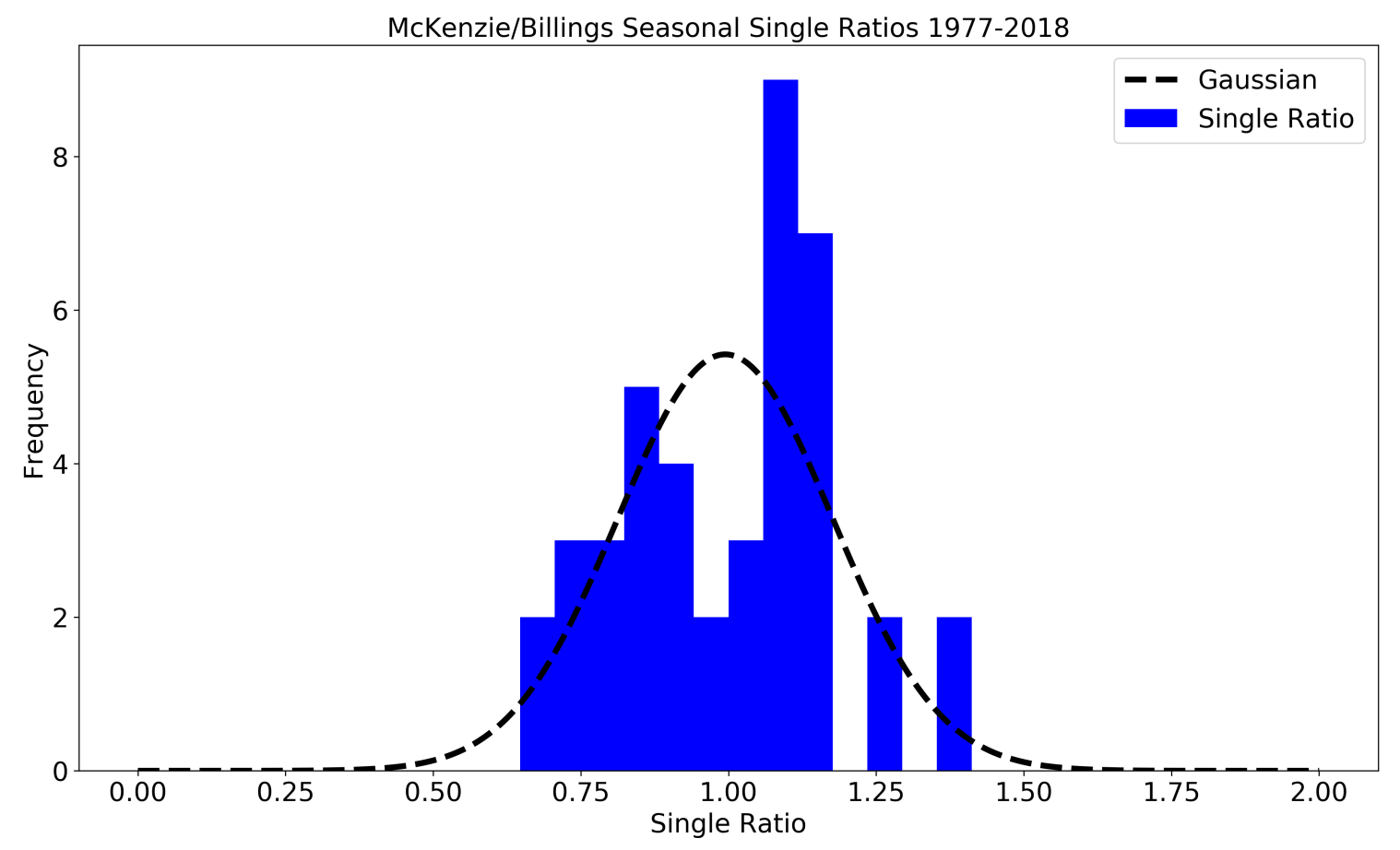

Figure 9: Probability distribution function for the calculated single ratios for countybased seasonal rainfall from the target county McKenzie and control county Billings for 1977-2018. 
done by selecting the number of rain gauges that first has the smallest confidence interval around the actual measured mean for that month. After some initial amount of rain gauges, the confidence interval will only vary by a small margin of a hundredth of an inch or less. Upon determining the necessary number of rain gauges, the single and double ratios were calculated using similar methods to the first bootstrapping test. While this second test cannot determine an actual seeding effect, it is helpful for future studies. Results for the second bootstrapping analysis can be found in Appendix B.

The standard error was calculated during each bootstrapping method. Standard error is a measure of the statistical accuracy of an estimate, equal to the standard deviation of the theoretical distribution of a large population of such estimate. Sample error for the bootstrapping is calculated by:

$$
S E=\frac{s}{\sqrt{n}}
$$

where $S E$ is the standard error, $s$ is the standard deviation of the individual observations in the population, and $n$ is the number of observations within the sample. A secondary way to calculate the standard error using the confidence intervals determined by the bootstrapping method is:

$$
S E=\frac{u-l}{2 * 1.96}
$$

where $S E$ is the standard error, $u$ is the natural log of the upper limit of the $95 \%$ confidence interval, $l$ is the natural log of the lower limit of the $95 \%$ confidence interval, and 1.96 is a constant number used for a 95\% confidence interval (Altman and Bland 2011). 
To determine whether an increase in rainfall determined by the double ratio is statistically significant, the percentage above a ratio of 1.0 is determined. A one-tailed test is a statistical test in which the critical area of a distribution is one sided, such that, it is either greater than or less than a certain value (Lane et al. 2003). A onetailed significance test was used on the bootstrapped double ratios to determine the percentile over 1.0. The percentage above 1.0 indicates the likelihood of an increase in precipitation due to cloud seeding. For example, if the percentage above 1.0 is $90 \%$, this would indicate a $90 \%$ likelihood of an increase in precipitation. However, this does not determine how much of an increase it will be, just that the increase is statistically significant. Any percentage over $90 \%$ was determined to be statistically significant in this analysis.

A Mann-Whitney non-parametric rank test is applied to target/control single ratios involving McKenzie County. Results are presented in Appendix D. Single ratios for the NDCMP period are shown to likely be from a different population than single ratios from the pre-NDCMP period for the McKenzie/Billings, McKenzie/Wibaux, and McKenzie/Richland target/control pairs, but not for the McKenzie/Roosevelt pair. 


\section{CHAPTER IV}

\section{RESULTS}

\section{COUNTY CIRCLES: RAINFALL EVALUATION}

Weighted pre-NDCMP rainfall amounts for target areas versus controls for June, July, August, and seasonal total showed a natural variation in rainfall prior to the NDCMP. While there were cloud seeding experiments ongoing prior to the start of the NDCMP, it is not believed that those efforts had a significant effect on area rainfall during that time. Monthly total rainfall for 1950 to 1975 is listed in Table 3. June experienced the greatest amount of rainfall over the period, as precipitation transitioned from stratiform to convective in nature with the transition to summer (Wang et al. 2019). Stratiform (convective) rainfall is typically associated with larger (smaller) areal coverage. From the perspective of rainfall measurements, observations are typically more representative for stratiform events (Silverman et al. 1981). July and August received less rainfall than June from 1950 to 2018. Differences in seasonal rainfall also are caused by geographic location. For example, Ward and Mercer Counties' received more rainfall than counties further west, consistent with the west to east gradient of precipitation in North Dakota.

Weighted rainfall amounts for the NDCMP years were calculated for June, July, August, and Seasonal. Table 4 shows the monthly and seasonal rainfall in inches calculated using the NOAA COOP and NDARBCON rain gauges for the target/control circle analysis for 1977 to 2018. As previously mentioned, there is a natural variation due to geographic location and distance apart between the target 
and control area. June routinely was the wettest month in western North Dakota amongst all target and control areas. Rainfall totals in July had three areas (McKenzie, Ward, and Mercer) with a higher rainfall than surrounding areas. This large variation could be due to an unusually wet year in 1993, which was observed in the data. In Figure 10, the counties that measured the highest precipitation in 1993 were the target areas of McKenzie (blue) and Ward (black), and the control area of Mercer (pink). For McKenzie County specifically, the measured rainfall in 1993 was more than twice the average seasonal rainfall of 6.92 inches.

Table 3: 25-year monthly and seasonal total observed weighted rainfall in inches calculated using NWS COOP rain gauges for 1950-1975.

\begin{tabular}{|c|c|c|c|c|}
\hline County & $\begin{array}{c}\text { June } \\
\text { Rainfall }\end{array}$ & $\begin{array}{c}\text { July } \\
\text { Rainfall }\end{array}$ & $\begin{array}{c}\text { August } \\
\text { Rainfall }\end{array}$ & $\begin{array}{c}\text { Seasonal } \\
\text { Rainfall }\end{array}$ \\
\hline McKenzie & 88.65 & 52.98 & 41.69 & 183.33 \\
\hline Bowman & 96.05 & 55.55 & 40.88 & 192.49 \\
\hline Ward & 90.79 & 60.05 & 53.03 & 203.87 \\
\hline Billings & 96.73 & 51.02 & 40.53 & 185.28 \\
\hline Mercer & 89.49 & 58.37 & 50.62 & 198.50 \\
\hline Wibaux & 85.13 & 47.48 & 39.89 & 172.51 \\
\hline Richland & 78.47 & 52.46 & 40.30 & 171.24 \\
\hline Roosevelt & 80.61 & 52.15 & 44.72 & 177.49 \\
\hline Carter & 86.82 & 46.63 & 34.72 & 168.18 \\
\hline Fallon & 77.47 & 45.40 & 31.53 & 154.42 \\
\hline
\end{tabular}

Table 4: 41-year monthly and seasonal total rainfall in inches for target/control circle analysis over 1977-2018.

\begin{tabular}{|c|c|c|c|c|}
\hline Counties & $\begin{array}{c}\text { June } \\
\text { Rainfall }\end{array}$ & $\begin{array}{c}\text { July } \\
\text { Rainfall }\end{array}$ & $\begin{array}{c}\text { August } \\
\text { Rainfall }\end{array}$ & $\begin{array}{c}\text { Seasonal } \\
\text { Rainfall }\end{array}$ \\
\hline McKenzie & 124.34 & 101.31 & 65.05 & 290.71 \\
\hline Bowman & 126.44 & 87.78 & 66.46 & 280.69 \\
\hline Ward & 144.41 & 104.74 & 79.29 & 328.44 \\
\hline Billings & 119.99 & 95.50 & 71.69 & 287.19 \\
\hline Mercer & 144.79 & 115.65 & 80.98 & 341.43 \\
\hline Wibaux & 110.33 & 86.32 & 68.46 & 265.12 \\
\hline Richland & 107.28 & 90.37 & 57.72 & 255.38 \\
\hline Roosevelt & 109.28 & 95.05 & 56.89 & 261.23 \\
\hline Carter & 116.11 & 78.95 & 61.00 & 254.07 \\
\hline Fallon & 104.85 & 67.84 & 54.95 & 227.65 \\
\hline
\end{tabular}




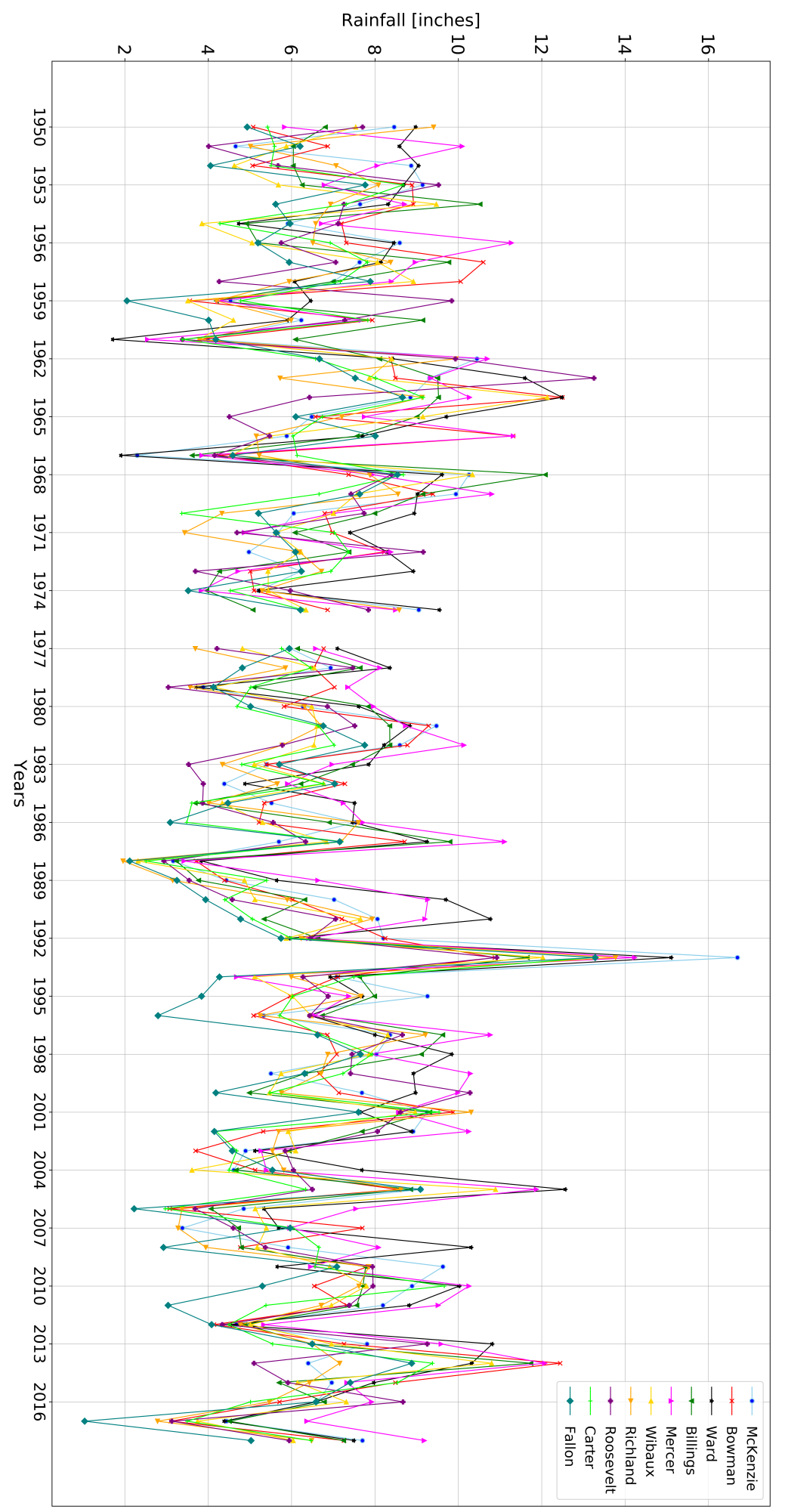

Figure 10: Seasonal rainfall in inches for circular method target and control regions using NWS COOP and NDARBCON rain gauges for 1950-1975 and 1977-2018. 


\section{COUNTY CIRCLES: SINGLE AND DOUBLE RATIOS}

Direct comparisons between the rainfall seen in Table 3 and Table 4 cannot be done by analyzing the total rainfall amounts due to the differences in length of the time periods. The comparisons between the two of these can only be made by analyzing the differences in their single ratios. Monthly single ratios computed between the target and control regions showed the best example of varying rainfall amounts for each area, as seen in Table 5. There are higher natural variations for the target areas and eastern Montana controls (Richland, Roosevelt, Wibaux, Carter, and Fallon) versus those in North Dakota (Billings and Mercer). June and August had the greatest variation between all target and controls, with July having more uniform rainfall between the areas. The target area of Bowman received $24 \%$ more rainfall seasonally than Fallon during 1950 to 1975. In the McKenzie/Billings pair single ratios, the value of 0.94 in June suggests that Billings experienced more rainfall between the years of 1950 to 1975 than McKenzie. The same situation can be said for McKenzie/Roosevelt in August, otherwise the seasonal total single ratios were greater than or equal to 1.0. The calculated single ratios are then used to correct for any natural variation seen during the NDCMP

Monthly single ratios between the target and control regions were also computed for the NDCMP time period. Table 6 shows the calculated single ratios for the NDCMP. The lower ratio amounts seen in August matched the results found by Wise (2005) when analyzing target and control regions. Although the single ratio for August overall shows that the control region receives more rainfall, the overall seasonal single ratios shows most target regions received more rainfall than their controls. The

exception to this is in Ward/Mercer, which could be affected by multiple impacts of their location relative to the rest of the NDCMP, and Bowman/Billings. 
Table 5: Pre-NDCMP Single ratios calculated for target/control observed weighted rainfall over 1950-1975.

\begin{tabular}{|c|c|c|c|c|}
\hline Target/Control Pair & June & July & August & Seasonal \\
\hline McKenzie/Billings & 0.94 & 1.03 & 1.02 & 0.99 \\
\hline McKenzie/Richland & 1.13 & 1.01 & 1.03 & 1.07 \\
\hline McKenzie/Wibaux & 1.04 & 1.11 & 1.04 & 1.06 \\
\hline McKenzie/Roosevelt & 1.10 & 1.01 & 0.93 & 1.03 \\
\hline Bowman/Billings & 1.02 & 1.08 & 1.00 & 1.03 \\
\hline Bowman/Wibaux & 1.12 & 1.16 & 1.02 & 1.11 \\
\hline Bowman/Carter & 1.10 & 1.19 & 1.17 & 1.14 \\
\hline Bowman/Fallon & 1.23 & 1.22 & 1.29 & 1.24 \\
\hline Ward/Mercer & 1.01 & 1.02 & 1.04 & 1.02 \\
\hline
\end{tabular}

Table 6: NDCMP Single ratios calculated for Target/Control observed weighted rainfall over 1977-2018.

\begin{tabular}{|c|c|c|c|c|}
\hline Target/Control Pair & June & July & August & Seasonal \\
\hline McKenzie/Billings & 1.03 & 1.06 & 0.90 & 1.01 \\
\hline McKenzie/Richland & 1.15 & 1.12 & 1.12 & 1.13 \\
\hline McKenzie/Wibaux & 1.12 & 1.17 & 0.95 & 1.09 \\
\hline McKenzie/Roosevelt & 1.13 & 1.06 & 1.14 & 1.11 \\
\hline Bowman/Billings & 1.05 & 0.91 & 0.92 & 0.97 \\
\hline Bowman/Wibaux & 1.14 & 1.01 & 0.97 & 1.05 \\
\hline Bowman/Carter & 1.08 & 1.14 & 1.08 & 1.10 \\
\hline Bowman/Fallon & 1.20 & 1.29 & 1.20 & 1.23 \\
\hline Ward/Mercer & 0.99 & 0.90 & 0.97 & 0.96 \\
\hline
\end{tabular}

Double ratios were calculated to normalize the observed single ratios for the NDCMP years using the single ratios for the pre-NDCMP years. By normalizing the single ratios, any natural variation between the target and control regions can be eliminated, to isolate the potential impacts due to cloud seeding. Table 7 shows the double ratios calculated from the target/control single ratios for 1977 to 2018 and 1950 to 1975. All four McKenzie/control double ratio comparisons show more seasonal rainfall in the target than the control. Three of the four seasonal double ratios show values less than 1.0 in the Bowman/control comparisons. While these indicate the potential of an increase in rainfall in McKenzie County due to seeding, 
and a decrease in rainfall in Bowman County, the natural variation in the double ratios must be examined before any conclusions can be drawn.

Table 7: Double ratios for June, July, August, and Seasonal computed from target/control observed single ratios from weighted rainfall by dividing 1977-2018 by 1950-1975 single ratios.

\begin{tabular}{|c|c|c|c|c|}
\hline Target/Control Pair & June & July & August & Seasonal \\
\hline McKenzie/Billings & 1.10 & 1.03 & 0.88 & 1.02 \\
\hline McKenzie/Richland & 1.02 & 1.11 & 1.09 & 1.06 \\
\hline McKenzie/Wibaux & 1.08 & 1.05 & 0.91 & 1.03 \\
\hline McKenzie/Roosevelt & 1.03 & 1.05 & 1.23 & 1.08 \\
\hline Bowman/Billings & 1.03 & 0.84 & 0.92 & 0.94 \\
\hline Bowman/Wibaux & 1.02 & 0.87 & 0.95 & 0.95 \\
\hline Bowman/Carter & 0.98 & 0.96 & 0.92 & 0.96 \\
\hline Bowman/Fallon & 0.98 & 1.06 & 0.93 & 1.00 \\
\hline Ward/Mercer & 0.98 & 0.88 & 0.93 & 0.94 \\
\hline
\end{tabular}

\section{COUNTY CIRCLES: BOOTSTRAPPING RATIOS}

Due to the large variance in monthly ratios, only the seasonal ratios were bootstrapped, as these will be an adequate indicator of whether a seeding effect is seen. By using the bootstrapping statistical test, an estimate of the $95 \%$ confidence interval is made. The $95 \%$ confidence interval can infer what the natural variation between the target/control regions can be. Table 8 shows the bootstrap statistical test results for the natural variation calculated by the $95 \%$ confidence interval of the target/control single ratios over the pre-NDCMP period. The observed single ratios for the pre-NDCMP has a natural variation of \pm 10 to $15 \%$. In some situations, the lower bound of the confidence interval was near or above 1.0, and at the high end, well above 1.0. These can suggest that in bootstrapped dataset, the target area receives more rainfall than the control.

Table 9 shows the bootstrapping results for the NDCMP years calculated from the single ratios in the weighted circle target/control analysis. These results showed 
a similar outcome to the pre-NDCMP bootstrapping results. The natural variation in single ratios for the NDCMP years falls within the \pm 5 to $10 \%$ range. From these results, it can be concluded that the observed single ratios have less variation during the NDCMP than in the pre-NDCMP.

Table 8: Natural variation in single ratios between target/control weighted circles determined using bootstrap statistics for the pre-NDCMP years. The bootstrapped data were sampled 10,000 times.

\begin{tabular}{|c|c|c|c|c|}
\hline Target/Control Pairs & Years & $\mathbf{n}$ & $\begin{array}{l}\text { Observed } \\
\text { Single } \\
\text { Ratio }\end{array}$ & $\begin{array}{c}95 \% \\
\text { Confidence } \\
\text { Interval }\end{array}$ \\
\hline McKenzie/Billings & $1950-1975$ & 26 & 0.99 & $0.88-1.10$ \\
\hline McKenzie/Wibaux & $1950-1975$ & 26 & 1.06 & $0.95-1.18$ \\
\hline McKenzie/Richland & $1950-1975$ & 26 & 1.07 & $0.99-1.15$ \\
\hline McKenzie/Roosevelt & $1950-1975$ & 26 & 1.03 & $0.90-1.16$ \\
\hline Bowman/Billings & $1950-1975$ & 26 & 1.03 & $0.93-1.15$ \\
\hline Bowman/Wibaux & $1950-1975$ & 26 & 1.11 & $1.00-1.24$ \\
\hline Bowman/Fallon & $1950-1975$ & 26 & 1.24 & $1.15-1.34$ \\
\hline Bowman/Carter & $1950-1975$ & 26 & 1.14 & $1.04-1.24$ \\
\hline Ward/Mercer & $1950-1975$ & 26 & 1.02 & $0.92-1.14$ \\
\hline
\end{tabular}

Table 9: The natural variation in single ratios between target/control using weighted circles calculated using the bootstrap statistics over the NDCMP years. The bootstrapped data were sampled 10,000 times.

\begin{tabular}{|c|c|c|c|c|}
\hline Target/Control Pairs & Years & $\mathbf{n}$ & $\begin{array}{c}\text { Observed } \\
\text { Single } \\
\text { Ratio }\end{array}$ & $\begin{array}{c}\mathbf{9 5 \%} \\
\text { Confidence } \\
\text { Interval }\end{array}$ \\
\hline McKenzie/Billings & $1977-2018$ & 42 & 1.01 & $0.93-1.09$ \\
\hline McKenzie/Wibaux & $1977-2018$ & 42 & 1.09 & $1.01-1.17$ \\
\hline McKenzie/Richland & $1977-2018$ & 42 & 1.13 & $1.07-1.20$ \\
\hline McKenzie/Roosevelt & $1977-2018$ & 42 & 1.11 & $1.03-1.19$ \\
\hline Bowman/Billings & $1977-2018$ & 42 & 0.97 & $0.91-1.04$ \\
\hline Bowman/Wibaux & $1977-2018$ & 42 & 1.05 & $0.99-1.13$ \\
\hline Bowman/Fallon & $1977-2018$ & 42 & 1.23 & $1.14-1.33$ \\
\hline Bowman/Carter & $1977-2018$ & 42 & 1.10 & $1.03-1.17$ \\
\hline Ward/Mercer & $1977-2018$ & 42 & 0.96 & $0.91-1.01$ \\
\hline
\end{tabular}

Double ratios were bootstrapped to determine the $95 \%$ confidence interval. To determine if cloud seeding causes a statistically significant increase in rainfall 
the observed double ratio $95 \%$ confidence interval needs to reside completely above a value of one. This demonstrates that target rainfall has increased, on average, over the observed 41 years following the pre-NDCMP years. Table 10 shows the variation in the double ratios between each target and control circle from a bootstrap statistical test with 10,000 samples. The natural variation in double ratios range from \pm 10 to $15 \%$ with McKenzie showing a slight increase in rainfall for the NDCMP period over its respective controls. Of the four McKenzie/control pairs, McKenzie/Richland showed a $90 \%$ likelihood of an increase in precipitation due to cloud seeding based on the one-tailed significance test. For the target/control pair of McKenzie/Wibaux, the distribution of double ratios shows more cases where the target had more rainfall than the control, however, there is a large number of cases with the control having more than the target (Fig. 11). For Bowman and its control pairs, the low end of the 95\% confidence interval also was below 1.0, therefore it can be stated that the change in rainfall can also be negative, which is supported by the one-tailed significance test above 1.0 .

Table 10: Bootstrapped double ratio statistic between target/control weighted circles using 10,000 samples. The double ratios were calculated from the single ratios for 1977 to 2018 and 1950-1975.

\begin{tabular}{|c|c|c|c|}
\hline Target/Control Pairs & $\begin{array}{c}\text { Observed } \\
\text { Double } \\
\text { Ratio }\end{array}$ & $\begin{array}{c}\mathbf{9 5 \%} \\
\text { Confidence } \\
\text { Interval }\end{array}$ & $\begin{array}{c}\text { One-Tailed } \\
\text { Significance } \\
\text { Test } \\
\text { Above } \\
\mathbf{1 . 0}\end{array}$ \\
\hline McKenzie/Billings & 1.02 & $0.88-1.16$ & $62.5 \%$ \\
\hline McKenzie/Wibaux & 1.03 & $0.90-1.17$ & $68.0 \%$ \\
\hline McKenzie/Richland & 1.06 & $0.96-1.16$ & $90.0 \%$ \\
\hline McKenzie/Roosevelt & 1.08 & $0.94-1.24$ & $85.0 \%$ \\
\hline Bowman/Billings & 0.94 & $0.83-1.06$ & $16.0 \%$ \\
\hline Bowman/Wibaux & 0.94 & $0.83-1.07$ & $21.0 \%$ \\
\hline Bowman/Fallon & 0.98 & $0.89-1.10$ & $43.0 \%$ \\
\hline Bowman/Carter & 0.96 & $0.86-1.07$ & $27.0 \%$ \\
\hline Ward/Mercer & 0.93 & $0.83-1.05$ & $14.0 \%$ \\
\hline
\end{tabular}




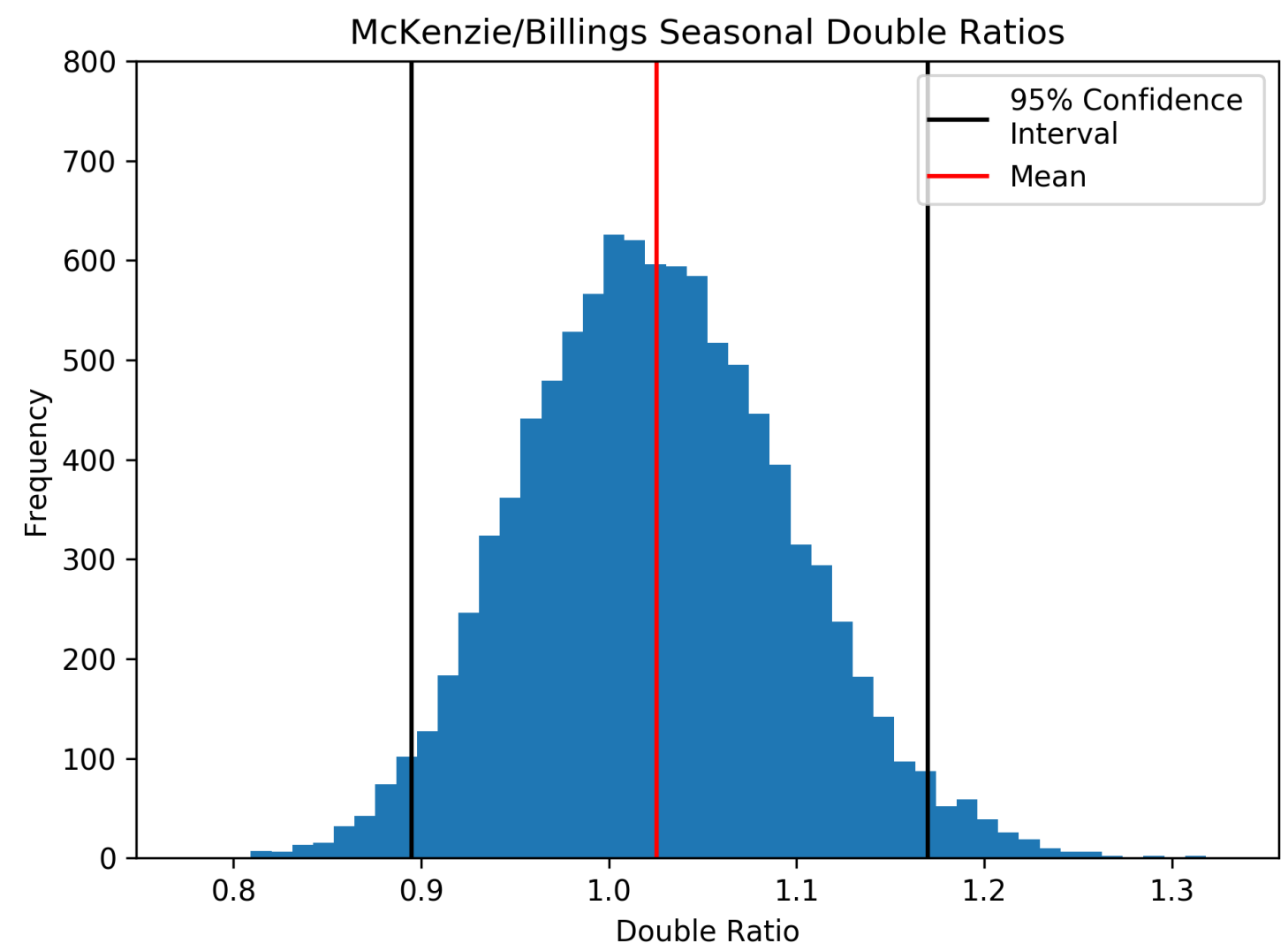

Figure 11: Distribution of mean double ratios for seasonal rainfall calculated from the circular method bootstrapped 10,000 for McKenzie/Wibaux. The mean (red) observed double ratio and 95\% confidence interval (black) are shown.

\section{COUNTY BASED: RAINFALL EVALUATION}

To account equally for all operational rain gauges, the county-based approach was also used. This approach introduced more data in both the pre-NDCMP and NDCMP years. Between the two methods, the county seasonal rainfall total was higher in most counties compared to the weighted rainfall totals. This variation in rainfall can be explained by a few different factors, such as, larger sampling area, more rain gauges, rainfall is normalized by number of stations rather than distance from a center point or more counties measuring higher rainfall amounts in the wet 
year of 1993 (Fig. 12). Previously, McKenzie, Ward, and Mercer measured the highest rainfall in 1993, whereas in the county-based method, McKenzie, Carter, Ward, Mercer and Roosevelt all measured higher rainfall amounts. Therefore, the rain calculated in this method represents the county average, rather than creating an artificial rainfall amount at a center point. The differences in rainfall calculated over the county influenced the single ratios seen in the pre-NDCMP period. Table 11 shows the monthly and seasonal total county-based rainfall calculated from NOAA COOP rain gauge data for 1950 to 1975. June accounts for approximately half of the seasonal rainfall totals in all counties, followed by July then August with the gradient in rainfall increasing from west to east across the state.

Table 12 shows the total rainfall for June, July, August, and Seasonal as calculated for the NDCMP years' county-based approach. The calculated total rainfall generally was higher after adding the additional rain gauges in portions of the target and control areas, while some counties saw minor decreases. Monthly rainfall can be skewed by multiple stations being relatively close in location and sampling one storm, while gauges on the other side of the county may not be experiencing precipitation on the same days. While this is noted as a potential source of contamination, it was assumed to not have a substantial effect on the total monthly or seasonal rainfall. 


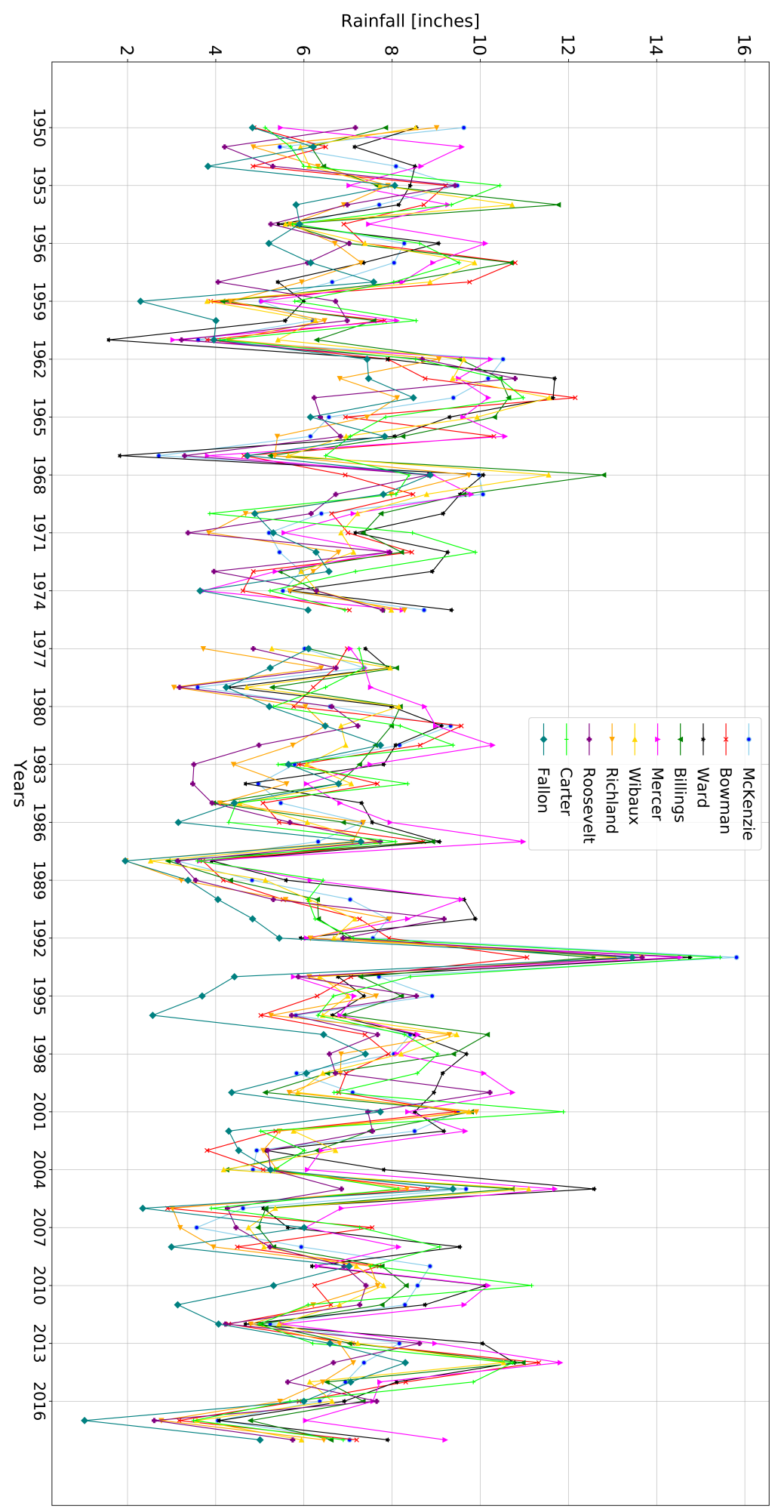

Figure 12: Seasonal rainfall in inches for county-based method target and control regions using NWS COOP and NDARBCON rain gauges for 1950-1975 and 19772018. 
Table 11: 25-year monthly and seasonal total county-based rainfall, in inches, calculated from NWS COOP rain gauge network for 1950-1975.

\begin{tabular}{|c|c|c|c|c|}
\hline Counties & $\begin{array}{c}\text { June } \\
\text { Rainfall }\end{array}$ & $\begin{array}{c}\text { July } \\
\text { Rainfall }\end{array}$ & $\begin{array}{c}\text { August } \\
\text { Rainfall }\end{array}$ & $\begin{array}{c}\text { Seasonal } \\
\text { Rainfall }\end{array}$ \\
\hline McKenzie & 89.15 & 53.46 & 44.16 & 186.78 \\
\hline Bowman & 94.82 & 54.05 & 40.29 & 189.17 \\
\hline Ward & 90.24 & 58.39 & 52.12 & 200.76 \\
\hline Billings & 105.39 & 55.98 & 47.69 & 209.07 \\
\hline Mercer & 90.82 & 60.88 & 49.76 & 201.46 \\
\hline Wibaux & 101.06 & 54.20 & 45.78 & 201.05 \\
\hline Richland & 78.79 & 50.18 & 42.14 & 171.11 \\
\hline Roosevelt & 73.38 & 49.04 & 43.26 & 165.69 \\
\hline Carter & 100.15 & 56.48 & 39.71 & 196.35 \\
\hline Fallon & 78.48 & 44.77 & 32.14 & 155.39 \\
\hline
\end{tabular}

Table 12: 41-year monthly and seasonal total county-based rainfall in inches calculated from the NWS COOP and NDARBCON rain gauge network over 1977-2018.

\begin{tabular}{|c|c|c|c|c|}
\hline Counties & $\begin{array}{c}\text { June } \\
\text { Rainfall }\end{array}$ & $\begin{array}{c}\text { July } \\
\text { Rainfall }\end{array}$ & $\begin{array}{c}\text { August } \\
\text { Rainfall }\end{array}$ & $\begin{array}{c}\text { Seasonal } \\
\text { Rainfall }\end{array}$ \\
\hline McKenzie & 124.3 & 100.39 & 66.83 & 291.53 \\
\hline Bowman & 125.73 & 87.13 & 66.18 & 279.06 \\
\hline Ward & 143.25 & 107.56 & 78.26 & 329.07 \\
\hline Billings & 124.29 & 97.55 & 74.41 & 296.26 \\
\hline Mercer & 141.77 & 115.15 & 84.03 & 340.96 \\
\hline Wibaux & 118.49 & 92.16 & 70.99 & 281.65 \\
\hline Richland & 105.56 & 89.36 & 56.78 & 251.72 \\
\hline Roosevelt & 110.2 & 94.09 & 55.67 & 259.96 \\
\hline Carter & 137.61 & 90.11 & 75.03 & 302.76 \\
\hline Fallon & 104.89 & 67.76 & 53.78 & 226.43 \\
\hline
\end{tabular}

\section{COUNTY BASED: SINGLE AND DOUBLE RATIOS}

Table 13 shows the single ratios calculated from the target/control observed county averaged rainfall for 1950 to 1975. Single ratios for pre-NDCMP period were calculated using the same method as the weighted circle analysis. The single ratios show the control counties receiving more seasonal rainfall than the target in seven out of the nine cases. Comparing these results to the circular method single ratios, 
almost all control region rainfall was higher in the county-based method than the circular method. This is evident by the number of single ratios less than 1 in the county-based method versus the circular method.

Table 13: Single ratios calculated from target/control observed county average rainfall over 1950-1975.

\begin{tabular}{|c|c|c|c|c|}
\hline Target/Control Pair & June & July & August & Seasonal \\
\hline McKenzie/Billings & 0.84 & 0.95 & 0.92 & 0.89 \\
\hline McKenzie/Richland & 1.13 & 1.06 & 1.04 & 1.09 \\
\hline McKenzie/Wibaux & 0.88 & 0.98 & 0.96 & 0.92 \\
\hline McKenzie/Roosevelt & 1.21 & 1.09 & 1.02 & 1.12 \\
\hline Bowman/Billings & 0.89 & 0.96 & 0.84 & 0.90 \\
\hline Bowman/Wibaux & 0.93 & 0.99 & 0.88 & 0.94 \\
\hline Bowman/Carter & 0.94 & 0.95 & 1.01 & 0.96 \\
\hline Bowman/Fallon & 1.20 & 1.20 & 1.25 & 1.21 \\
\hline Ward/Mercer & 0.99 & 0.96 & 1.04 & 0.99 \\
\hline
\end{tabular}

Single ratios were calculated for the NDCMP years' rainfall for June, July, August, and Seasonal in Table 14. The single ratios for the NDCMP period show an increase in the number of target areas receiving more rainfall than the control. Out of the nine possible combinations, four target regions received more rainfall than the control. While this can be attributed to the natural variation due to geographical differences, and more rain gauges sampling rainfall, there is a notable difference in the NDCMP years compared to pre-NDCMP years for McKenzie/Billings and McKenzie/Wibaux. Although some target/control single ratios are less than or equal to 1.0, this does not indicate a decrease in rainfall in the target compared to the control.

The observed double ratios for the county based NDCMP and pre-NDCMP period rainfall showed most of the target areas receiving more rainfall than the control area as seen in Table 15. Results showed an increase in rainfall in seven out of the nine target/control comparisons based on the double ratio calculation. The target/control pair of McKenzie/Billings and McKenzie/Wibaux showed the largest increases of rainfall of 10 and $12 \%$ in target counties during the NDCMP years compared to the 
prior period. Other target/control pairs for McKenzie also displayed an increase over their control pairings. Bowman showed an increase in rainfall in all target/control pairs besides for the Bowman/Carter pairing. Ward/Mercer showed a small decrease in rainfall.

Table 14: NDCMP Single ratios calculated for target/control observed county averaged rainfall over 1977-2018.

\begin{tabular}{|c|c|c|c|c|}
\hline Target/Control Pair & June & July & August & Seasonal \\
\hline McKenzie/Billings & 1.00 & 1.03 & 0.89 & 0.98 \\
\hline McKenzie/Richland & 1.17 & 1.12 & 1.17 & 1.15 \\
\hline McKenzie/Wibaux & 1.05 & 1.09 & 0.94 & 1.03 \\
\hline McKenzie/Roosevelt & 1.12 & 1.06 & 1.20 & 1.12 \\
\hline Bowman/Billings & 1.01 & 0.89 & 0.88 & 0.94 \\
\hline Bowman/Wibaux & 1.06 & 0.94 & 0.93 & 0.99 \\
\hline Bowman/Carter & 0.91 & 0.96 & 0.88 & 0.92 \\
\hline Bowman/Fallon & 1.19 & 1.28 & 1.23 & 1.23 \\
\hline Ward/Mercer & 1.01 & 0.93 & 0.93 & 0.96 \\
\hline
\end{tabular}

Table 15: Double ratios computed from target/control observed single ratios from county-based rainfall for 1977-2018 and 1950-1975.

\begin{tabular}{|c|c|c|c|c|}
\hline Target/Control Pair & June & July & August & Seasonal \\
\hline McKenzie/Billings & 1.19 & 1.08 & 0.97 & 1.10 \\
\hline McKenzie/Richland & 1.04 & 1.06 & 1.13 & 1.06 \\
\hline McKenzie/Wibaux & 1.19 & 1.24 & 0.96 & 1.12 \\
\hline McKenzie/Roosevelt & 0.93 & 0.97 & 1.18 & 1.00 \\
\hline Bowman/Billings & 1.13 & 0.93 & 1.05 & 1.04 \\
\hline Bowman/Wibaux & 1.14 & 0.95 & 1.06 & 1.05 \\
\hline Bowman/Carter & 0.97 & 1.01 & 0.87 & 0.95 \\
\hline Bowman/Fallon & 0.99 & 1.07 & 0.98 & 1.01 \\
\hline Ward/Mercer & 1.02 & 0.97 & 0.89 & 0.97 \\
\hline
\end{tabular}

COUNTY BASED: BOOTSTRAPPING RATIOS

The natural variation of the single and double ratios is determined for the seasonal rainfall totals using bootstrapping. The 95\% confidence intervals range 
\pm 6 to $10 \%$ for the pre-NDCMP period single ratios shown in Table 16. McKenzie/Billings target/control showed that in all randomly drawn single ratio samples, there was more mean rainfall observed in Billings than in McKenzie. This was also seen in the McKenzie/Wibaux and Bowman/Billings target/control pairing. McKenzie/Richland, McKenzie/Roosevelt and Bowman/Fallon always had more rainfall in the target than the control.

Table 16: Natural variation in county based single ratios between target/control determined using 10,000 samples for the bootstrap statistics for the pre-NDCMP years.

\begin{tabular}{|c|c|c|c|c|}
\hline Target/Control Pairs & Years & $\mathbf{n}$ & $\begin{array}{c}\text { Observed } \\
\text { Single } \\
\text { Ratio }\end{array}$ & $\begin{array}{c}\mathbf{9 5 \%} \\
\text { Confidence } \\
\text { Interval }\end{array}$ \\
\hline McKenzie/Billings & $1950-1975$ & 26 & 0.89 & $0.81-0.97$ \\
\hline McKenzie/Wibaux & $1950-1975$ & 26 & 0.92 & $0.85-1.00$ \\
\hline McKenzie/Richland & $1950-1975$ & 26 & 1.09 & $1.02-1.16$ \\
\hline McKenzie/Roosevelt & $1950-1975$ & 26 & 1.12 & $1.03-1.22$ \\
\hline Bowman/Billings & $1950-1975$ & 26 & 0.90 & $0.82-0.98$ \\
\hline Bowman/Wibaux & $1950-1975$ & 26 & 0.94 & $0.85-1.02$ \\
\hline Bowman/Fallon & $1950-1975$ & 26 & 1.21 & $1.12-1.32$ \\
\hline Bowman/Carter & $1950-1975$ & 26 & 0.96 & $0.89-1.04$ \\
\hline Ward/Mercer & $1950-1975$ & 26 & 0.99 & $0.90-1.09$ \\
\hline
\end{tabular}

Natural variation in the single ratio confidence intervals were narrower during the NDCMP period. The tighter confidence intervals indicate less variation in the single ratios over the project time period. Table 17 shows the natural variation in each target/control pair from 1977 to 2018. Notable differences between the NDCMP and the pre-NDCMP years can be seen in the 95\% confidence intervals for McKenzie/Billings and McKenzie/Wibaux with both regions having upper bounds above 1.0. The $95 \%$ confidence intervals range $\pm 4-8 \%$ between the target/control pairs. The single ratios and the $95 \%$ confidence intervals determined by the pre-NDCMP and NDCMP periods are used to construct the bootstrapped double ratios. 
The double ratio bootstrapping results shown in Table 18 provided insight into the natural variation in the ratios. The $95 \%$ confidence intervals showed a larger variation in the double ratios ranging \pm 8 to $12 \%$. Most target/control paired regions indicate an increase in mean target rainfall during the NDCMP over the pre-NDCMP period. In some case the double ratio $95 \%$ confidence interval lies completely above one. For example, the distribution of double ratios for McKenzie/Wibaux shows an increase in rainfall for more than half of the bootstrapped double ratios in the target versus the control (Fig. 13). Based on the one-tailed significance test above 1.0, McKenzie/Billings, McKenzie/Wibaux, and McKenzie/Richland had a $90 \%$ or greater likelihood of an increase in precipitation during the NDCMP period that may be due to cloud seeding. McKenzie/Roosevelt, Bowman/Carter and Ward/Mercer observed double ratios showed either no increase or slight decrease, but the $95 \%$ confidence intervals showed the mean increase in rainfall may, in fact, be positive. The one-tailed significance test shows low confidence in the likelihood of an increase in rainfall due to cloud seeding for those areas. These results were similar to that of Wise (2005) for an increase in rainfall in some target regions versus control regions, but as this study was done with stationary targets, results seen in this paper cannot be directly compared to the previous study. 
Table 18: The bootstrapped double ratio statistic between target/control countybased precipitation using the single ratios for 1950-1975 and 1977-2018. Each bootstrapping test was sampled 10,000 times.

\begin{tabular}{|c|c|c|c|}
\hline Target/Control Pairs & $\begin{array}{c}\text { Observed } \\
\text { Double } \\
\text { Ratio }\end{array}$ & $\begin{array}{c}\mathbf{9 5 \%} \\
\text { Confidence } \\
\text { Interval }\end{array}$ & $\begin{array}{c}\text { One-Tailed } \\
\text { Significance } \\
\text { Test } \\
\text { Above } \\
\mathbf{1 . 0}\end{array}$ \\
\hline McKenzie/Billings & 1.10 & $0.99-1.22$ & $96.5 \%$ \\
\hline McKenzie/Wibaux & 1.12 & $1.00-1.23$ & $98.5 \%$ \\
\hline McKenzie/Richland & 1.06 & $0.98-1.15$ & $94.0 \%$ \\
\hline McKenzie/Roosevelt & 1.00 & $0.90-1.10$ & $46.5 \%$ \\
\hline Bowman/Billings & 1.04 & $0.93-1.16$ & $75.0 \%$ \\
\hline Bowman/Wibaux & 1.05 & $0.94-1.17$ & $85.0 \%$ \\
\hline Bowman/Fallon & 1.01 & $0.91-1.12$ & $60.0 \%$ \\
\hline Bowman/Carter & 0.95 & $0.86-1.05$ & $19.0 \%$ \\
\hline Ward/Mercer & 0.96 & $0.87-1.07$ & $27.5 \%$ \\
\hline
\end{tabular}

Table 17: Natural variation in county based single ratios between target/control determined using bootstrap statistics for the NDCMP years.

\begin{tabular}{|c|c|c|c|c|}
\hline Target/Control Pairs & Years & $\mathbf{n}$ & $\begin{array}{l}\text { Observed } \\
\text { Single } \\
\text { Ratio }\end{array}$ & $\begin{array}{c}95 \% \\
\text { Confidence } \\
\text { Interval }\end{array}$ \\
\hline McKenzie/Billings & $1977-2018$ & 42 & 0.98 & $0.93-1.04$ \\
\hline McKenzie/Wibaux & $1977-2018$ & 42 & 1.03 & $0.97-1.09$ \\
\hline McKenzie/Richland & $1977-2018$ & 42 & 1.15 & $1.10-1.21$ \\
\hline McKenzie/Roosevelt & $1977-2018$ & 42 & 1.12 & $1.05-1.18$ \\
\hline Bowman/Billings & $1977-2018$ & 42 & 0.94 & $0.88-1.00$ \\
\hline Bowman/Wibaux & $1977-2018$ & 42 & 0.99 & $0.93-1.05$ \\
\hline Bowman/Fallon & $1977-2018$ & 42 & 1.23 & $1.15-1.31$ \\
\hline Bowman/Carter & $1977-2018$ & 42 & 0.92 & $0.86-0.98$ \\
\hline Ward/Mercer & $1977-2018$ & 42 & 0.96 & $0.92-1.00$ \\
\hline
\end{tabular}




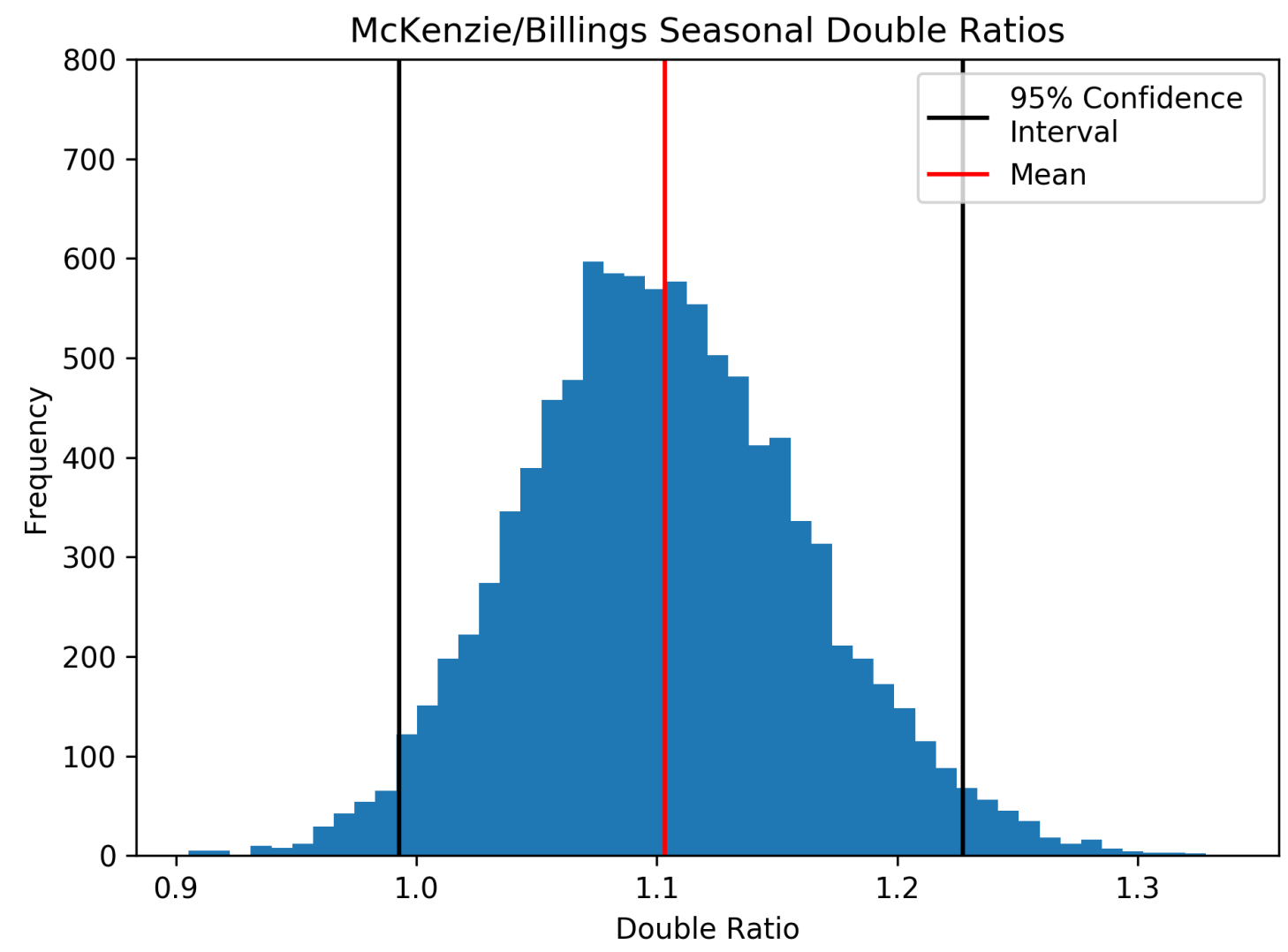

Figure 13: Distribution of mean double ratios for seasonal rainfall calculated from the county-based method bootstrapped 10,000 for McKenzie/Wibaux. The mean (red) observed double ratio and $95 \%$ confidence interval (black) are shown.

\section{ONE TARGET, ONE CONTROL}

The one target one control method combines all target and all control rain gauges except for Ward in the target and Mercer in the control. This target/control pair was removed due to the likelihood of contamination of Mercer as a control, as well as the increase in rainfall from west to east across North Dakota. An average monthly and seasonal rainfall was calculated for both areas. Then were compared in a single and double ratio test. The method used to calculate the single and double ratios were identical to the previous two analysis styles. By pooling together all target 
and control rain gauges, it was intended to have a similar number of rain gauges in each region per year.

Table 19 shows the total rainfall for the target and control region measured by the NWS COOP rain gauge data before the start of the NDCMP. The average number of rain gauges are shown over the 25-year period. Prior to the start of NDCMP, the control regions had more active rain gauges throughout all the pooled control counties, with an average number of 32 compared to 11 in the target region. The difference in observed rainfall between the target and control regions are similar, with only a five-inch difference in the seasonal totals. With the addition of the NDARBCON rain gauge network at the start of the NDCMP, the target region consistently had more rain gauges from 1977 to 2018 with a seasonal average of 60 rain gauges over the 41 years, and only 46 per season for the control.

Table 20 shows the total rainfall in inches for 1977 to 2018 for June, July, August, and Seasonal, along with the average number of rain gauges for each month over the 41 years. The addition of 16 more years worth of rain gauge data had the same result of more rainfall being measured in June and July in the target than the control, and more rainfall in the control for August. These results are not conclusive of a seeding effect, as the trend is matching the previous year period.

The natural variation for the seasonal rainfall for the NDCMP years was similar to the results found in Smith et al. (2004), where they could not conclude with statistical certainty that an increase in rainfall was caused by cloud seeding. Table 21 shows the natural variation of single ratios (Eq. (3.10) for 1950 to 1975 and 1977 to 2018, as well as the double ratio (Eq. (3.11)). The natural variation for during the NDCMP was smaller than the observed $\pm 10 \%$ in Smith et al. (2004), rather it was \pm $3 \%$ for the single ratio and $\pm 6 \%$ for the double ratio. The double ratio being equal to 
1.0 indicated no difference in target/control rainfall ratio between pre-NDCMP and NDCMP target and control datasets.

Table 19: 25-year total average rainfall in inches for June, July, August, and Seasonal for 1950-1975 in the target and control region using NWS COOP rain gauge data. The average number of rain gauges over the 25-year period are shown.

\begin{tabular}{|c|c|c|c|c|c|c|c|c|}
\hline County & $\begin{array}{c}\text { June } \\
\text { Rainfall }\end{array}$ & $\begin{array}{c}\text { June } \\
\text { Gauges }\end{array}$ & $\begin{array}{c}\text { July } \\
\text { Rainfall }\end{array}$ & $\begin{array}{c}\text { July } \\
\text { Gauges }\end{array}$ & $\begin{array}{c}\text { August } \\
\text { Rainfall }\end{array}$ & $\begin{array}{c}\text { August } \\
\text { Gauges }\end{array}$ & $\begin{array}{c}\text { Seasonal } \\
\text { Rainfall }\end{array}$ & $\begin{array}{c}\text { Seasonal } \\
\text { Gauges }\end{array}$ \\
\hline Seeded & 91.45 & 11 & 53.49 & 11 & 42.63 & 11 & 187.57 & 11 \\
\hline Control & 88.13 & 32 & 51.62 & 32 & 42.64 & 32 & 182.39 & 32 \\
\hline
\end{tabular}

Table 20: 41-year total average rainfall in inches for June, July, August, and Seasonal for 1977-2018 in the target and control region using NDARBCON and NWS COOP rain gauge data. The average number of rain gauges over the 41 years are shown for each month and seasonal average.

\begin{tabular}{|c|c|c|c|c|c|c|c|c|}
\hline County & $\begin{array}{c}\text { June } \\
\text { Rainfall }\end{array}$ & $\begin{array}{c}\text { June } \\
\text { Gauges }\end{array}$ & $\begin{array}{c}\text { July } \\
\text { Rainfall }\end{array}$ & $\begin{array}{c}\text { July } \\
\text { Gauges }\end{array}$ & $\begin{array}{c}\text { August } \\
\text { Rainfall }\end{array}$ & $\begin{array}{c}\text { August } \\
\text { Gauges }\end{array}$ & $\begin{array}{c}\text { Seasonal } \\
\text { Rainfall }\end{array}$ & $\begin{array}{c}\text { Seasonal } \\
\text { Gauges }\end{array}$ \\
\hline Seeded & 125.06 & 61 & 93.72 & 61 & 65.94 & 59 & 284.73 & 60 \\
\hline Control & 118.90 & 47 & 92.61 & 46 & 66.25 & 45 & 277.76 & 46 \\
\hline
\end{tabular}

Table 21: Natural variation in rainfall calculated for 1950 to 1975, 1977 to 2018 and the double ratio. The bootstrap statistic sampled seasonal observed rainfall by year 10,000 times.

\begin{tabular}{|c|c|c|c|}
\hline Target/Control Pair & Years & $\begin{array}{c}\text { Observed } \\
\text { Ratio }\end{array}$ & $\begin{array}{c}\mathbf{9 5 \%} \\
\text { Confidence } \\
\text { Interval }\end{array}$ \\
\hline Seeded/Control & $1950-1975$ & 1.02 & $0.97-1.08$ \\
\hline Seeded/Control & $1977-2018$ & 1.02 & $0.99-1.06$ \\
\hline Seeded/Control & Double Ratio & 1.00 & $0.94-1.06$ \\
\hline
\end{tabular}




\section{CHAPTER V}

\section{DISCUSSION}

Being able to quantify area-wide precipitation amounts is difficult using rain gauge observations due to the high spatial variability of convective rain (Silverman et al. 1981). The NDCMP operational campaign takes place during the summer months, where convective rain is more likely than stratiform. The higher the density of rain gauges, the better the precipitation amount measurement for a summertime convective storm; however, if only one gauge samples rainfall, the uncertainty is large (Silverman et al. 1981). The sample variance becomes substantial in networks with only one rain gauge per convective storm.

Using radar observations as a method to quantify the effectiveness of cloud seeding within a storm has been available in North Dakota for several decades. Previous studies on weather modification used radar observations to analyze area average

rainfall as a method for comparing effects of cloud seeding (Smith et al. 1985) and by using polarimetric radar observations to analyze liquid water content, rainfall rates and hydrometeor type (Kucera et al. 2008; Delene et al. 2011). Dennis et al. (1975a) used observations of radar echo area and radar-estimated rainfall amounts to determine a cloud seeding effect in a randomized seeding experiment. In seeded cases, both the radar echo and radar-estimated rainfall was larger than in cases that were not seeded.

In experiments where the rain gauge network is not dense, radar derived rainfall should be used as a supplemental component to the study (Woodley et al. 2001) for 
years with available radar data. Using radar data to supplement the current rain gauge network does have limitations due to beam height of the radar in target and control areas. There are two NWS Weather Surveillance Radar 1988 Doppler (WSR88D) radars in western North Dakota; one in Minot within Ward County and one in Bismarck within Burleigh County. While the Minot WSR-88D can be useful in Ward County for radar derived precipitation totals, it would not be useful in McKenzie County. The average radar beam height for the lowest degree scan in McKenzie County is $4.1 \mathrm{~km}$ above ground level (AGL) from the Minot WSR-88D and 5.02 km (AGL) from the Bismarck WSR-88D. Zhang et al. (2012) developed a national Radar QPE Quality Index (RQI) that found that with an increasing beam height, the RQI decreases. In other words, the radar is unable to accurately calculate radar derived surface precipitation totals with an increasing beam height. Increasing beam height above ground leads to a higher probability that the precipitation observed aloft is different from that reaching the ground (Wilson et al. 1979). Radar derived rainfall estimate errors can be minimized with dual-polarization capabilities (Zhang et al. 2014). Along with the WSR-88D radar network, the NDCMP operates two C-band radars located in Stanley, ND and Bowman, ND. Although these are located closer to the target and control regions, C-band radars become attenuated easier than the S-band WSR-88D (Delrieu et al. 1999) leading to a higher probability of underestimating precipitation. Currently the two C-band radars operated by the NDCMP are not dual-polarized while the WSR-88D operated by the NWS are.

As the NDCMP continues, using pre-NDCMP data will become less useful in studies like the one presented in this paper. One limitation in using 1950-1975 as a preNDCMP normalization factor is that the cloud seeding that was done during that time was assumed to have little to no influence on the monthly and seasonal rainfall. Hence, it could be used as a normalization factor for double ratios or used for a predictor for 
the single linear regression or multiple linear regression. Other limitations recognized in this study were that the NDCMP is a non-randomized seeding operation. Such that, every possible storm can be seeded and will be if the appropriate criterion is met and aircraft are available. Therefore, there is not an established control region built into the project's operational program. Without a designated control in the operational area, it can be difficult to determine the effectiveness of the program. It is believed that the two North Dakota control regions were contaminated by downwind effects. Using the Montana rain gauges as an upwind control was useful to avoid any downwind contamination from the NDCMP. Adding additional rain gauges upstream can be useful for obtaining a better estimate of what rainfall may have been in the target area if cloud seeding was not ongoing.

Using pre-NDCMP rainfall data as a normalization factor has limitations in verifying a result of a significant change in rainfall between the two time periods. More rain gauges can be added to the project target and control areas, and additional years of data can be obtained, but the pre-NDCMP data remains the same. Acknowledging this limitation is very important in understanding how it can affect future studies that try to use a similar approach. Adding additional rain gauges to both target and control areas will be beneficial for future studies, as more stations will reduce the standard error and provide a better estimate for the county rainfall. However, it is not possible to add additional rain gauges to the pre-NDCMP years in the methods presented in this study, as all available rain gauges were used. Adding more years by going further back in time provides less rain gauge coverage over western North Dakota, thus no improvements would be made as sample variation would increase with less gauges.

Results found in the circle method showed less of an increase in rainfall in the target over the control than the county-based method when comparing the calculated 
double ratios. The county-based method has McKenzie having an increase in rainfall that is statistically significant by the one-tailed test over the control. The difference in the ratios are due to how each method calculates the rainfall for the given area. Estimating rainfall for a central point within the circle has more variability than taking an average over the whole county. Rain gauges closer to the central point account for most of the rainfall seen within the circle, while gauges on the outer edge provide less information. For example, if a single rain gauge at the center of the circle was the only rain gauge to measure rainfall within the circle for a given day, it would be treated as being seen in the entire county. It is also assumed that any seeding effect would be seen within the circle and the near outer edge gauges would not display a strong seeding effect. This assumption does not account for rain gauges on the downwind outer edge of the circle. The circle method used in this study could be improved on by reducing the size of the circle and using more circles within a given area. Circles could be divided into an east and west component, as it is assumed the cloud seeding effect would be more prominent in the downwind portion of the county rather than upwind. One case where the county-based method may have limitations is that Bowman rainfall could be affected by using Slope rain gauges that are not currently participating in the NDCMP. At the time of this study, only a portion of Slope County participates in the NDCMP, although all rain gauges throughout the county are being used. This was assumed to not influence the results, but caution should be taken when using the entire county in future studies.

The single and double ratios computed in this study could be influenced by rainfall events that were extremes, such as the measured rainfall in 1993 (Fig. 10, Fig. 12). If one county experienced an unusually wet season but the control pair did not, the difference in rainfall would appear to be due to seeding, however that may not be the case. Providing more years of data can mitigate the effects of me- 
teorological extremes by averaging over more years of data. To test whether years with meteorological extremes have a large effect on the overall analysis, future studies could remove years that were unusually wet (dry) to try and detect a seeding effect without large variations year to year.

Differences in the increased rainfall seen in the county-based method between McKenzie and Bowman could be caused by a lack of a southern buffer zone in District I. Until 2018, District I had a 10-statue mile buffer zone to the north and east but has since discontinued this buffer zone (NDARB 2018). District II has a buffer zone on all sides except for into Montana (Fig. 14). The additional southern buffer zone allows pilots to seed storms as they approach the target areas, thereby allowing more time for the seeding agents to be ingested into the storm before entering the target areas. Without this southern buffer zone on District II, Bowman and Slope Counties may not be large enough to see the full effect of the rainfall enhancement, where McKenzie County can. As stated by Wise (2005), $72 \%$ of mean storm motion in District I comes from the southwest and $70 \%$ for District II. When comparing the size of the two counties by square miles, McKenzie is $2861 \mathrm{mi}^{2}$ and Bowman is 1167 $\mathrm{mi}^{2}$, this allows for storms to remain within McKenzie County for longer depending on where storms enter the county and mean storm flow.

The orientation of the control counties compared to the target region could influence the results of this study. This was evident in the double ratios in the countybased method with McKenzie seeing an increase in rainfall compared to the counties to its South and Southwest. As previously mentioned, most of the mean storm motion in North Dakota comes from the southwest during the summer months, therefore storms were likely to produce rainfall in both target and control regions. McKenzie compared to Roosevelt saw a low correlation and a double ratio indicating no increase in rainfall in McKenzie relative to Roosevelt in the county-based analysis. 


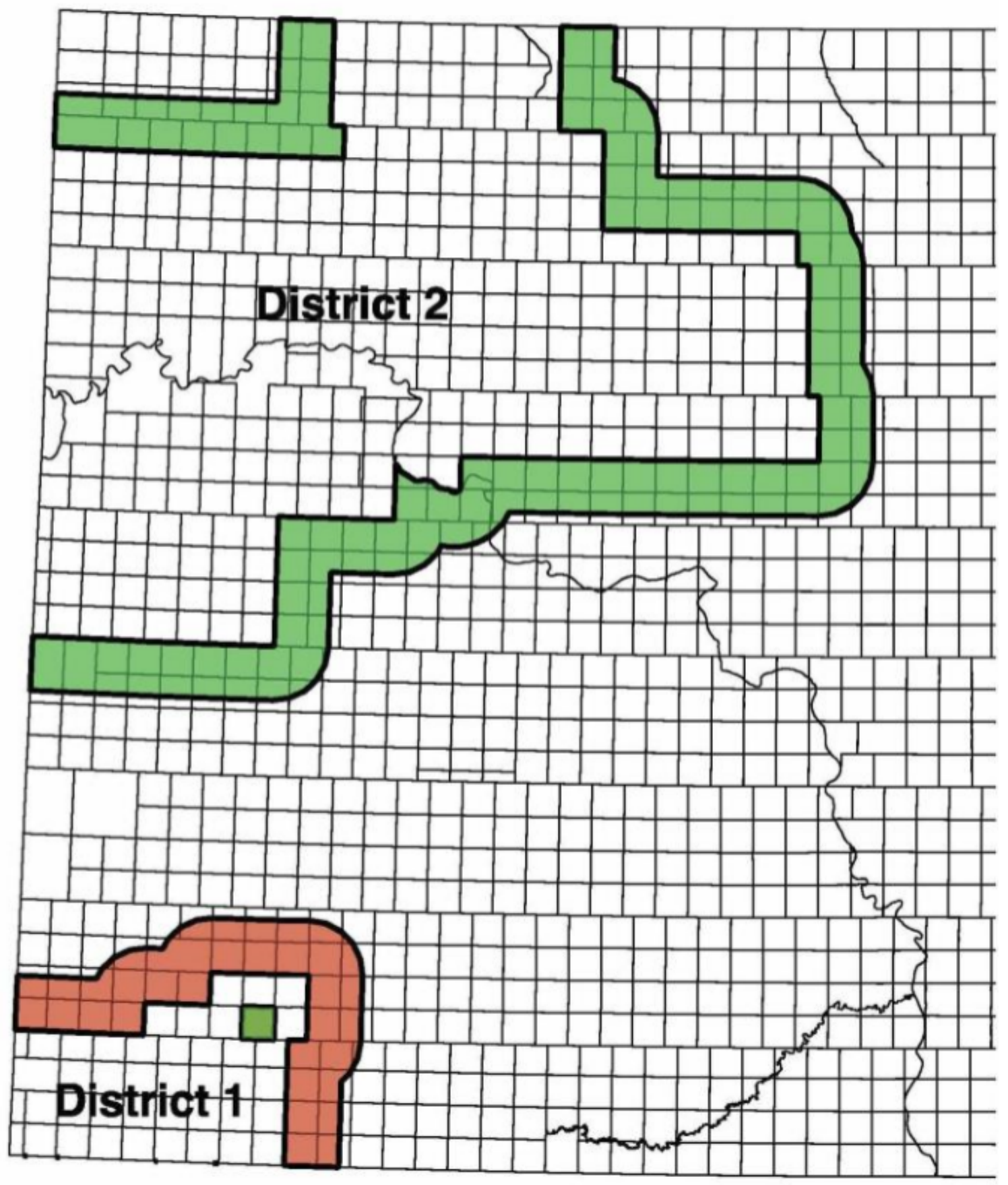

Figure 14: Image recreated from the NDCMP 2018 final report showing the 10-statue mile buffer zone for Districts I and II. The area shaded in red is the buffer zone that is no longer active as of 2018. 
Roosevelt is oriented to the northwest of McKenzie, where only $37 \%$ of summertime storms originate. Thereby it is likely that both counties would not measure rainfall from the same storm or on the same day when southwest flow is present. Bowman saw a decrease in rainfall compared to its southwest control. This could be due to the limited number of rain gauges available in Carter County. The county average rainfall may not be accurately measured due to a limited number of usable gauges. A similar sampling issue could influence the results for Bowman compared to Fallon County. Fallon County had an average of 4 rain gauges between 1977 to 2018. It is estimated that the county average rainfall could only be measured within a half an inch per year with fewer than 5 rain gauges (See Appendix B).

Analyzing single and double ratios will become difficult if the trend of fewer NDARBCON observers and less rain gauges available throughout the NDCMP continues. Results for either single or double ratio are dependent on having an accurate average rainfall for each month over the project lifespan. With more uncertainty, the $95 \%$ confidence intervals would be wider for the observed double and single ratios. Bootstrapping on a decreasing number of rain gauges becomes less effective for trying to determine the $95 \%$ confidence interval around an average rainfall and determining the natural variation of single and double ratios. If the county average rainfall can only be measured within a half an inch per month, any differences in rainfall between target and control could be due to uncertainties in the measurements, rather than cloud seeding itself.

Additional analysis needs to be conducted on District I and II on the differences in meteorology and project operations. While conducting the present study, McKenzie's rainfall appeared to have a larger increase over the NDCMP period than that of Bowman when paired with Billings using the county-based method. This can be directly related to the increase in the single ratio from 1950 to $1975(0.89)$ and 
1977 to 2018 (0.98) and a 95\% confidence interval with a lower bound greater than 1.0 for McKenzie in the county-based method. Whereas, Bowman when paired with Billings double ratio shows a $4 \%$ increase in rainfall, but the $95 \%$ confidence interval lower bounds were less than 1.0 in the county-based method.

Other analyses for the impact of the NDCMP on precipitation enhancement that can be explored includes using high resolution convective allowing models to compare observed monthly and seasonal rainfall to model forecasted rainfall. Models would be used as a case study style analysis to try to predict the rainfall totals without the effects of cloud seeding, then would be compared to observed precipitation. To ensure the model is forecasting rainfall totals accurately, the model would need to be run for control area precipitation and compared before being applied to target area rainfall. Previous studies used a simple 1-dimensional cloud model to determine the seedability of clouds in seeding operations to the NDCMP in North Dakota (Dennis et al. 1975b; Smith et al. 1985) but at the time it was not possible to model storms with the capabilities of modern computing techniques. However, these studies were able to model an effect on rainfall due to cloud seeding along with predicting the seedability of storms.

The North Dakota Agricultural Weather Network (NDAWN) stations provide measurements of rainfall with over 120 stations in North Dakota, Minnesota and Montana. The NDAWN station data sets varied in number from starting in 1992 to as recent as 2018. While NDARBCON and NOOA COOP have stations with different varying duration in data like NDAWN, the NDAWN rainfall has not been systematically compared to other rainfall measurements. In future studies, this network of rain gauges can provide additional rain gauge data if the two networks are determined to be correlated. The NDAWN rain gauge 24-hour rainfall is measured at 0600 UTC to 0600 UTC. These gauges are sampled at a different time than the NDARBCON and 
NWS COOP gauges, therefore daily rainfall totals must be calculated from hourly data to match the sampling period over the NDARBCON. When averaged or totaled over a monthly and seasonal time scale, the differences may not be as noticeable and could have a higher correlation.

As the NDCMP continues, more rain gauges will be necessary for further analysis of the project effectiveness. The decline in reporting rain gauges will lead to larger standard error in any further studies, and therefore reduce the quality of the results. The addition of automated rain gauges throughout the western portion of North Dakota and eastern Montana could provide valuable insight into the natural variation of rainfall seen in each county. Overall, a denser rain gauge network and the addition of more years with quality measurements will be needed to draw a definitive conclusion on the success of the NDCMP. 


\section{CHAPTER VI}

\section{CONCLUSIONS}

The NDARBCON and NWS COOP rain gauge data was used to explore the results of numerous statistical analysis methods. For each analysis method, target and control regions were defined by certain specifications. A normalizing factor based on the single ratio for the 1950 to 1975 time period for June, July, August and Seasonal precipitation was calculated for each target and control region. The normalizing factor was applied to the single ratios calculated for 1977 to 2018. A bootstrapping statistical analysis was conducted on the data to determine the natural variation of single and double ratios from $95 \%$ confidence intervals. Each bootstrapping resampling ranged from 10,000 to 100,000 samples.

Of the circle results, there were four out of the nine double ratio results where the target received at least $2 \%$ more precipitation than the control determined by the double ratio ( Table 10). Of those nine cases, one result (McKenzie/Richland) shows an increase that was considered statistically significant based on the one-tailed significance test. The county-based results provided a better analysis of rainfall over the target and control regions. Six out of the nine target regions received at least $2 \%$ or more rainfall than the control in the double ratio calculation. Of those six, three were determined to be statistically significant based on the one-tailed significance test (Table 18). Of the cases with increases in rainfall, McKenzie was the target county in the comparisons. Results for the single and multiple linear regressions supported the increases in rainfall found in the county-based double ratio analysis. 
While the results of this study seem promising in demonstrating an increase in rainfall as a result of cloud seeding in McKenzie County, additional analysis needs to be performed to ensure that these results are not a byproduct of unusually wet (dry) seasons in the target or control regions. Further statistical analysis on District I and II rainfall should be done to determine the effects of these events. One method would be to remove the year 1993 from the analysis, as it was an unusually wet year, and follow the methods used within this study. A physical study using radar observations available from the NDCMP two C-band radars and the NWS WSR-88D S-band radars to analyze where the precipitation from a seeded storm is precipitating. For regions such as District I, these results would be particularly useful in determining if the seeded storms are producing additional rainfall in the target area, or if the effects are seen outside the target area.

Future studies will benefit from having additional years of data only if more rain gauges are added within each county. It is suggested to continue the use of upstream controls over potential controls in North Dakota due to downwind seeding effects. Analyzing the effects of cloud seeding in respect to wind direction may provide a better target/control comparison than stationary targets. While the results of this study suggest minor increases in target rainfall, in many cases the apparent increases could be a result of natural variation or an effect of poor sampling over time. If fewer rain gauges are available for future studies, the addition of radar derived 24-hour rainfall will prove to be a beneficial supplement to the current rain gauge network. 


\section{REFERENCES}

Altman, D. G., and J. M. Bland, 2011: How to obtain the confidence interval from a P value. BMJ, 343, d2090-d2090, https://doi.org/10.1136/bmj.d2090.

Bangsund, D. A., and F. L. Leistritz, 2009: Economic Impacts of Cloud Seeding on Agricultural Crops in North Dakota. North Dakota State University, Department of Agribusiness and Applied Economics, http://www.swc.nd.gov/arb/pdfs/SeedingEconImpact.pdf (Accessed January 28, 2016).

Boe, B., and North Dakota Atmospheric Research Board, 1997: Analysis of data collected during the North Dakota Tracer Experiment: studies of precipitation and hail development in Northern Great Plains convective storms: final report. Bismarck, ND: North Dakota Atmospheric Resource Board,

— , and Coauthors, 1992: The North Dakota Thunderstorm Project: A Cooperative Study of High Plains Thunderstorms. Bull. Amer. Meteor. Soc., 73, 145.

Bruintjes, R. T., 1999: A Review of Cloud Seeding Experiments to Enhance Precipitation and Some New Prospects. Bulletin of the American Meteorological Society, 80, 805-820, https://doi.org/10.1175/1520-0477(1999)080;0805:AROCSE;2.0.CO;2.

DeFelice, T. P., J. Golden, D. Griffith, W. Woodley, D. Rosenfeld, D. Breed, M. Solak, and B. Boe, 2014: Extra area effects of cloud seeding - An updated assessment. Atmospheric Research, 135-136, 193-203,

https://doi.org/10.1016/j.atmosres.2013.08.014.

Delene, D. J., 2016: Suitability of North Dakota For Conducting Effective Hygroscopic Seeding. J. Wea. Modification, 48, 43-67.

— C. Grainger, P. Kucera, D. Langerud, M. Ham, R. Mitchell, and C. Kruse, 2011: The Second Polarimetric Cloud Analysis and Seeding Test. J. Wea. Modification, 43, 14-28. 
Delrieu, G., L. Hucke, and J. D. Creutin, 1999: Attenuation in Rain for Xand C-Band Weather Radar Systems: Sensitivity with respect to the Drop Size Distribution. Journal of Applied Meteorology, 38, 57-68, https://doi.org/10.1175/15200450(1999)038;0057:AIRFXA;2.0.CO;2.

Dennis, A. S., A. Koscielski, D. E. Cain, J. H. Hirsch, and P. L. Smith, 1975a: Analysis of Radar Observations of a Randomized Cloud Seeding Experiment. J. Appl. Meteor. Climatol., 14, 897-908.

—, J. R. Miller Jr., E. I. Boyd, and D. E. Cain, 1975b: Effects of Cloud Seeding on Summertime Precipitation in North Dakota. South Dakota School of Mines and Technology,.

Gabriel, K. R., 1999: Ratio Statistics for Randomized Experiments in Precipitation Stimulation. J. Appl. Meteor., 38, 290-301.

Garstang, M., R. Bruintjes, R. Serafin, H. Orville, B. Boe, W. Cotton, and J. Warburton, 2005: Weather Modification: Finding Common Ground. Bulletin of the American Meteorological Society, 86, 647-656, https://doi.org/10.1175/BAMS-86-5647.

Habib, E., W. F. Krajewski, and G. J. Ciach, 2001: Estimation of Rainfall Interstation Correlation. Journal of Hydrometeorology, 2, 621-629, https://doi.org/10.1175/1525-7541(2001)002¡0621:EORIC ¿2.0.CO;2.

He, X., H. Guan, X. Zhang, and C. T. Simmons, 2014: A wavelet-based multiple linear regression model for forecasting monthly rainfall. International Journal of Climatology, 34, 1898-1912, https://doi.org/10.1002/joc.3809.

Hesterberg, T., S. Monaghan, D. S. Moore, A. Clipson, and R. Epstein, 2005: BOOTSTRAP METHODS AND PERMUTATION TESTS. W. H. Freeman and Company, 85 pp.

Huff, F. A., 1979: Spatial and temporal correlation of precipitation in Illinois. 17.

Johnson, H. L., 1985: An Evaluation of the North Dakota Cloud Modification Project: 1976-1982.

Kucera, P., A. Theisen, and D. Langerud, 2008: Polarimetric Cloud Analysis and Seeding Test (POLCAST). J. Wea. Modification, 40, 64-76. 
Lane, D. M., D. Scott, M. Hebl, R. Guerra, D. Osheron, and H. Zimmer, 2003: Online Statistics Eduation: A Multimedia Course of Study. 692 pp.

Langerud, D., and A. Gilstad, 2003: Comparative Analysis of the Atmospheric Resource Board Cooperative Observer Network with the National Weather Service Rain Gauge Network. North Dakota Atmospheric Resource Board,.

List, R., K. R. Gabriel, B. A. Silverman, Z. Levin, and T. Karacostas, 1999: The Rain Enhancement Experiment in Puglia, Italy: Statistical Evaluation. Journal of Applied Meteorology, 38, 281-289, https://doi.org/10.1175/1520-0450(1999)038;0281:TREEIP¿2.0.CO;2.

Liu, W., and X. Li, 2016: Life Cycle Characteristics of Warm-Season Severe Thunderstorms in Central United States from 2010 to 2014.

Mann, H. B., and D. R. Whitney, 1947: On a Test of Whether one of Two Random Variables is Stochastically Larger than the Other.

Muralikrishna, I. V., V. Manickam, S. S. Bhardwaj, H. Peddj, and A. P. Rao, 2009: Design And Evaluation Of Hygroscopic Seeding Operations In Andhra Pradesh, India. The Journal of Weather Modification, 41, 135-143.

National Research Council, 2003: Critical Issues in Weather Modification Research. The national Academics of Sciences, Engineering, and Medicine, 144 pp.

National Weather Service, 1999: Standard 8 Inch Rain Gage. https://training.weather.gov/nwstc/METEOR/srg/rain8in.html (Accessed April 3, 2019).

NDARB, 2010: North Dakota Cloud Modification Project Operations Manual: A Program Designed for the Seeding of Convective CLouds with Glaciogenic Nuclei to Increase Rainfall and Diminish Hail Damage on the Northern Great Plains.

—_, 2014: North Dakota Cloud Seeding Questions and Answers. North Dakota Water Commission and State Engineer,.

__ 2018: 2018 Final Operations Report North Dakota Cloud Modification Project. North Dakota Atmospheric Resource Board, http://www.swc.nd.gov/arb/ndcmp/pdfs/finalreport.pdf (Accessed January 15, 2019).

Schaefer, V. J., 1968: The Early History of Weather Modification. Bulletin of the American Meteorological Society, 49, 337-342, https://doi.org/10.1175/1520- 
0477-49.4.337.

Schaffner, L. W., J. E. Johnson, H. Vruegdenhill, and J. Enz, 1983: Economic Effects of Added Growing Season Rainfall on North Dakota Agriculture. Department of Agricultural Econmics,

Schneider, M. D., and D. Langerud, 2011: Operational Improvements on the North Dakota Cloud Modification Project. Journal of Weather Modification, 43, $84-88$.

Shier, R., 2004: Statistics: 2.3 The Mann-Whitney U Test.

Silverman, B. A., 2003: A Critical Assessment of Hygroscopic Seeding of Convective Clouds for Rainfall Enhancement. Bulletin of the American Meteorological Society, 84, 1219-1230, https://doi.org/10.1175/BAMS-84-9-1219.

—, L. Koshio Rogers, and D. Dahl, 1981: On the Sampling Variance of Raingage Networks. J. Appl. Meteor., 20, 1468-1478, https://doi.org/10.1175/15200450(1981)020;1468:OTSVOR ¿2.0.CO;2.

Smith, P. L., A. A. Doneaud, J. H. Hirsch, J. R. Miller Jr., and P. E. Price, 1985: Development of Evaluation Techniques for Operational Convective Cloud Modification Projects: 1984-85 Studies. South Dakota School of Mines and Technology,.

—, L. R. Johnson, D. L. Priegnitz, and J. Paul W Mielke, 1992: A TargetControl Analysis of Wheat Yield Data for the North Dakota Cloud Modification Project Region. The Journal of Weather Modification, 24, 98-105.

—, P. W. Mielke, Jr, and F. J. Kopp, 2004: Exploratory Analysis of Climatic Raingage Data For Evidence of Effects of the North Dakota Cloud Modification Project on Rainfall in the Target Area. North Dakota Atmospheric Resource Board,

Snedecor, G. W., and W. G. Cochran, 1989: Statistical Methods. Eight Edition. Iowa State University Press,.

Wang, J., X. Dong, A. Kennedy, B. Hagenhoff, and B. Xi, 2019: A Regime Based Evaluation of Southern and Northern Great Plains Warm-Season Precipitation Events in WRF. Wea. Forecasting,.

Wilks, D. S., 2011: Statistical Methods in the Atmospheric Sciences. Third. Academic Press, 676 pp. 
Wilson, J., E. Brandes, and ERL/NOAA, 1979: Radar Measurement of RainfallA Summary. Bull. Amer. Meteor. Soc., 60, 1048-1060.

Wise, E., 2005: Precipitation evaluation of the North Dakota Cloud Modification Project (NDCMP). University of North Dakota, 63 pp.

Woodley, W. L., R. Drori, D. Rosenfeld, S. Orr, and G. Bomar, 2001: Results of Monthly and Seasonal Gauge vs. Radar Rainfall Comparisons in the Texas Panhandle. Journal of Weather Modification, Volume 33, 46-60.

Zhang, A., H. Shi, T. Li, and X. Fu, 2017: A bootstrap method to estimate the influence of rainfall spatial uncertainty in hydrological simulations. Hydrology and Earth System Sciences Discussions, 1-31, https://doi.org/10.5194/hess-2017-273.

Zhang, J., Y. Qi, C. Langston, and B. Kaney, 2012: Radar Quality Index (RQI) - a combined measure for beam blockage and VPR effects in a national network. IAHS Publ, 6.

$-,-\longrightarrow,-$, - and K. Howard, 2014: A Real-Time Algorithm for Merging Radar QPEs with Rain Gauge Observations and Orographic Precipitation Climatology. Journal of Hydrometeorology, 15, 1794-1809, 


\section{APPENDICES}




\section{APPENDIX A: SINGLE AND MULTIPLE LINEAR REGRESSION}

Single linear regression and multiple linear regression showed similar results to the single and double ratio. This method was computed for several combinations of predictors for a single predictand. McKenzie and Bowman had the most possible combinations for predictors, as each of their controls were paired with every other control used in this study. Ward has only one usable control, therefore combinations were limited. Correlation coefficients were calculated between every target and control area within the study for 1950 to 1975 and 1977 to 2018 using rainfall from the countybased method. Table A1 shows the calculated correlation coefficient between each target and control area for 1950 to 1975 . The correlation coefficients were determined from the seasonal rainfall from the county-based analysis method. When constructing the single linear regression, the controls with the highest correlation to the target area were used in predicting the rainfall for 1977-2018. Although the predictions over the 41-year period tend to predict the rainfall well, the single linear regression method had limitations in predicting unusually wet years such as 1993 (Fig. A1).

Table A1: Correlation Coefficients for 1950 to 1975 between target and control counties based off seasonal rainfall calculated from the county-based method.

\begin{tabular}{|c|c|c|c|c|c|c|c|c|c|c|}
\hline County & McKenzie & Bowman & Ward & Billings & Mercer & Wibaux & Richland & Roosevelt & Fallon & Carter \\
\hline McKenzie & 1.00 & 0.46 & 0.67 & 0.59 & 0.63 & 0.73 & 0.81 & 0.68 & 0.55 & 0.49 \\
\hline Bowman & 0.46 & 1.00 & 0.47 & 0.58 & 0.75 & 0.65 & 0.35 & 0.33 & 0.71 & 0.76 \\
\hline Ward & 0.67 & 0.47 & 1.00 & 0.52 & 0.64 & 0.61 & 0.53 & 0.55 & 0.52 & 0.49 \\
\hline Billings & 0.59 & 0.58 & 0.52 & 1.00 & 0.54 & 0.85 & 0.55 & 0.48 & 0.56 & 0.49 \\
\hline Mercer & 0.63 & 0.75 & 0.64 & 0.54 & 1.00 & 0.56 & 0.47 & 0.46 & 0.64 & 0.54 \\
\hline Wibaux & 0.73 & 0.65 & 0.61 & 0.85 & 0.56 & 1.00 & 0.74 & 0.47 & 0.70 & 0.61 \\
\hline Richland & 0.81 & 0.35 & 0.53 & 0.55 & 0.47 & 0.74 & 1.00 & 0.65 & 0.57 & 0.47 \\
\hline Roosevelt & 0.68 & 0.33 & 0.55 & 0.48 & 0.46 & 0.47 & 0.65 & 1.00 & 0.38 & 0.50 \\
\hline Fallon & 0.55 & 0.71 & 0.52 & 0.56 & 0.64 & 0.70 & 0.57 & 0.38 & 1.00 & 0.62 \\
\hline Carter & 0.49 & 0.76 & 0.49 & 0.49 & 0.54 & 0.61 & 0.47 & 0.50 & 0.62 & 1.00 \\
\hline
\end{tabular}




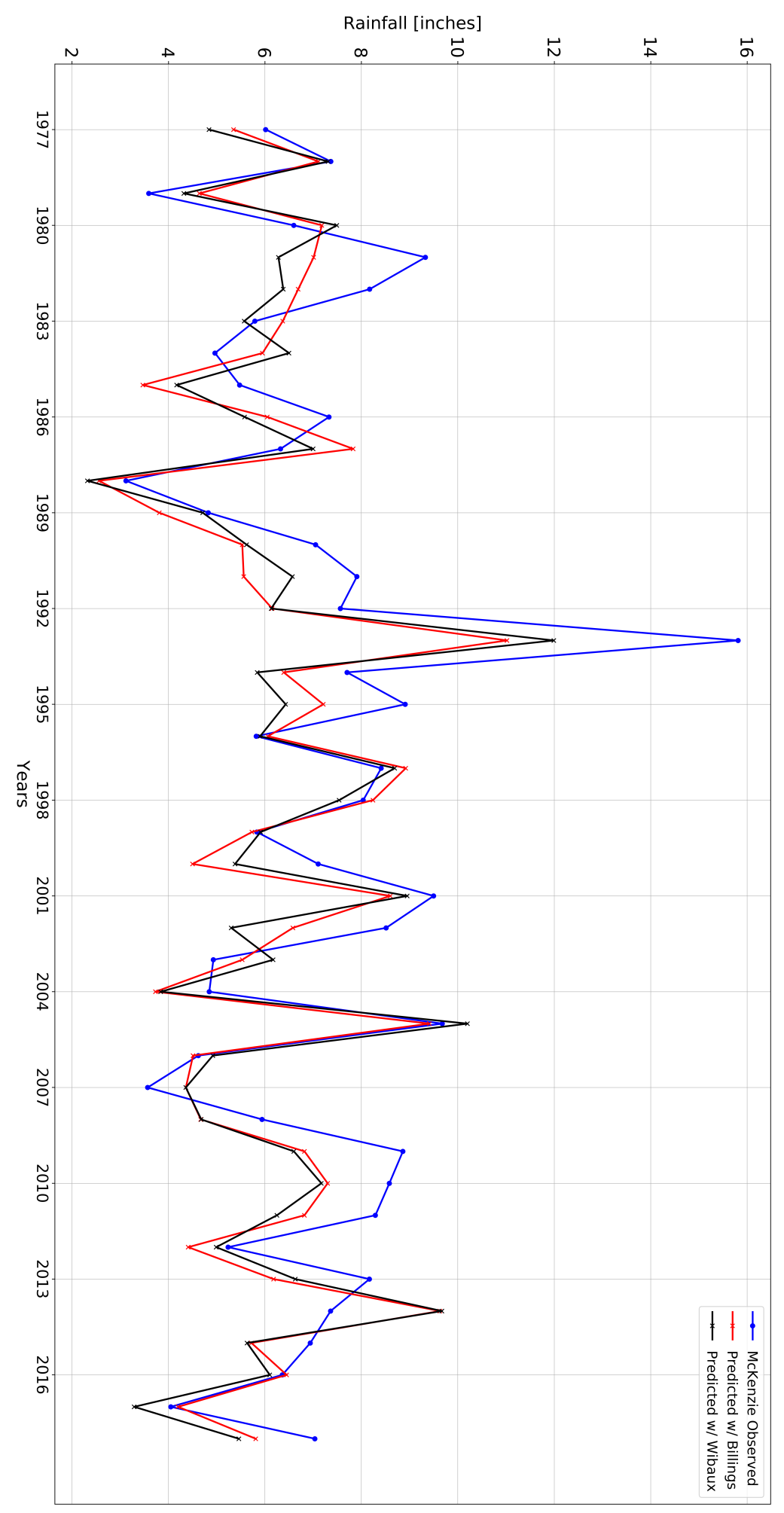

Figure A1: McKenzie county-based seasonal rainfall (blue) in inches compared to the single linear regression predicted seasonal rainfall for McKenzie using Billings (red) and Wibaux (black) as predictors. 
Results from the single linear regression for McKenzie had more rainfall in the observed than the predicted seasonal total rainfall. Table A2 shows the results of using the single linear regression generated from the 1950 to 1975 rainfall to predict 1977-2018 rainfall by using the control counties as a predictor for the target county. The total and average rainfall in inches were calculated over 1977 to 2018 for the seasonal rainfall. The single ratio for McKenzie County based on its controls showed an increase in observed rainfall over predicted rainfall from 2 to $12 \%$. In this method, the results of the regression approach can be interpreted similarly to that of the double ratio used in the previous methods. However, the standard error of the estimate for these measurements typically ranged \pm 2 to $3 \%$ in total rainfall each year.

Bowman and its predictors had a larger standard error of the estimate $( \pm 2.5$ to $3.5 \%$ ) than McKenzie, as well as lower correlated controls. This result is evident in an over or underestimation in the rainfall for 1977 to 2018. The single ratios for Bowman and its predictors ranged from a decrease of $4 \%$ to an increase of $7 \%$ based on the predictor used. Predicting Ward's rainfall using Mercer saw a similar result as Bowman/Carter, with a decrease of $4 \%$.

Table A2: Single Linear Regression results generated from the 1950 to 1975 rainfall regression equation. The total rainfall and average rainfall in inches were calculated over the period of 1977 to 2018.

\begin{tabular}{|c|c|c|c|c|c|c|c|}
\hline Predictand & Predictor & $\begin{array}{c}\text { Standard } \\
\text { Error } \\
\mathbf{\%}\end{array}$ & $\begin{array}{c}\text { Predicted } \\
\text { Total }\end{array}$ & $\begin{array}{c}\text { Predicted } \\
\text { Average }\end{array}$ & $\begin{array}{c}\text { Observed } \\
\text { Total }\end{array}$ & $\begin{array}{c}\text { Observed } \\
\text { Average }\end{array}$ & $\begin{array}{c}\text { Single } \\
\text { Ratio }\end{array}$ \\
\hline McKenzie & Billings & 0.065 & 260.04 & 6.19 & 291.54 & 6.94 & 1.12 \\
\hline McKenzie & Wibaux & 0.059 & 258.69 & 6.15 & 291.54 & 6.94 & 1.13 \\
\hline McKenzie & Richland & 0.046 & 275.23 & 6.55 & 291.54 & 6.94 & 1.06 \\
\hline McKenzie & Roosevelt & 0.061 & 286.24 & 6.82 & 291.54 & 6.94 & 1.02 \\
\hline Bowman & Billings & 0.067 & 263.32 & 6.27 & 279.06 & 6.64 & 1.06 \\
\hline Bowman & Wibaux & 0.066 & 260.91 & 6.21 & 279.06 & 6.64 & 1.07 \\
\hline Bowman & Fallon & 0.060 & 271.30 & 6.45 & 279.06 & 6.64 & 1.03 \\
\hline Bowman & Carter & 0.055 & 289.45 & 6.89 & 279.06 & 6.64 & 0.96 \\
\hline Ward & Mercer & 0.074 & 333.01 & 7.93 & 321.17 & 7.84 & 0.96 \\
\hline
\end{tabular}


The multiple linear regression had two predictor counties used to predict rainfall in a target county. Table A3 shows the multiple linear regression results with a standard error of the estimate less than 1.50 inches $( \pm 6 \%)$ per year, except for Ward, which had high standard errors of the estimate in all situations. McKenzie seasonal rainfall predicted by the Richland/Roosevelt multiple linear regression equation had the lowest standard error of the estimate $( \pm 4 \%)$ each year. The observed rainfall was $3 \%$ more rainfall than the predicted (Fig. A2). Some predictors, such as Billing/Mercer for Ward had a high standard error of the estimate, $\pm 7 \%$ each year, and showed the predicted rainfall had $30 \%$ more rain than the observed. It is believed that this would not be an accurate representation of what would have been possible without cloud seeding, but rather a poor estimate from that specific pairing. When Billings and Mercer were paired for other target regions, there was also a large standard error of the estimate and a 10\% decrease for McKenzie and $6 \%$ for Bowman (not shown).

Table A3: Multiple Linear Regression results using two predictors for the seasonal rainfall total in inches for a selected target region. Pairings with a standard error of the estimate less than 1.50 are shown, except for Ward. The single ratio is determined from the total observed and total predicted rainfall.

\begin{tabular}{|c|c|c|c|c|c|c|c|}
\hline Predictand & Predictor(s) x1/x2 & $\begin{array}{c}\text { Standard } \\
\text { Error } \\
\mathbf{9}\end{array}$ & $\begin{array}{c}\text { Predicted } \\
\text { Total }\end{array}$ & $\begin{array}{c}\text { Predicted } \\
\text { Average }\end{array}$ & $\begin{array}{c}\text { Observed } \\
\text { Total }\end{array}$ & $\begin{array}{c}\text { Observed } \\
\text { Average }\end{array}$ & $\begin{array}{c}\text { Single } \\
\text { Ratio }\end{array}$ \\
\hline McKenzie & Billings/Roosevelt & 0.051 & 331.20 & 7.88 & 291.54 & 6.94 & 0.88 \\
\hline McKenzie & Wibaux/Richland & 0.045 & 272.83 & 6.49 & 291.54 & 6.94 & 1.07 \\
\hline McKenzie & Wibaux/Roosevelt & 0.045 & 279.79 & 6.66 & 291.54 & 6.94 & 1.04 \\
\hline McKenzie & Wibaux/Mercer & 0.055 & 278.71 & 6.63 & 291.54 & 6.94 & 1.05 \\
\hline McKenzie & Richland/Billings & 0.045 & 284.05 & 6.52 & 291.54 & 6.94 & 1.03 \\
\hline McKenzie & Richland/Roosevelt & 0.042 & 281.69 & 6.71 & 291.54 & 6.94 & 1.03 \\
\hline McKenzie & Roosevelt/Fallon & 0.050 & 284.14 & 6.76 & 291.54 & 6.94 & 1.03 \\
\hline Bowman & Billings/Mercer & 0.056 & 296.89 & 7.06 & 279.06 & 6.64 & 0.94 \\
\hline Bowman & Billings/Fallon & 0.056 & 271.17 & 6.45 & 279.06 & 6.64 & 1.03 \\
\hline Bowman & Billings/Carter & 0.052 & 283.88 & 6.75 & 279.06 & 6.64 & 0.98 \\
\hline Bowman & Carter/Fallon & 0.048 & 285.17 & 6.79 & 279.06 & 6.64 & 0.98 \\
\hline Ward & Billings/Mercer & 0.070 & 457.80 & 10.90 & 321.17 & 7.84 & 0.70 \\
\hline
\end{tabular}




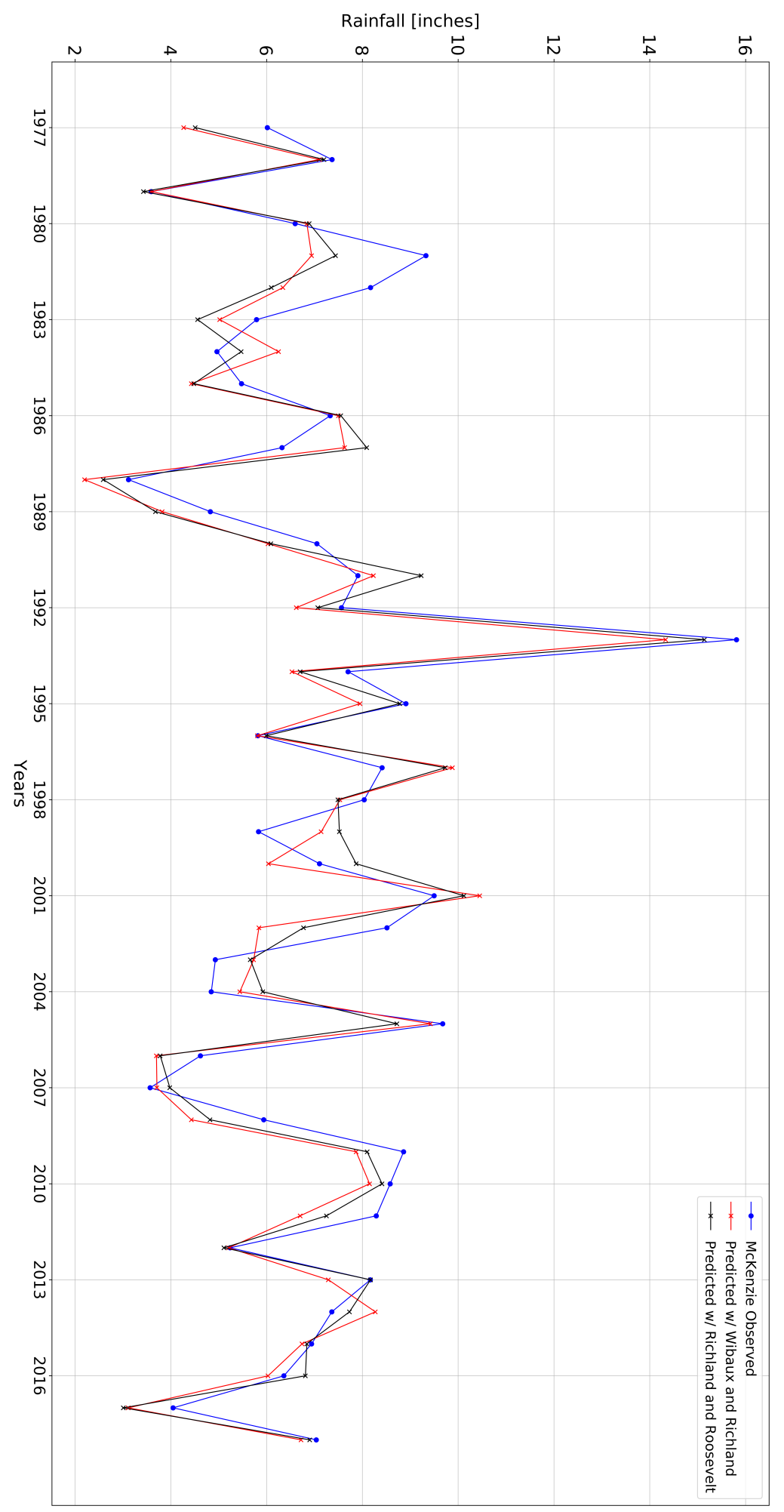

Figure A2: McKenzie county-based seasonal rainfall (blue) in inches compared to the multiple linear regression predicted seasonal rainfall for McKenzie using Wibaux and Richland (red) and Richland and Roosevelt (black) as predictors. 


\section{APPENDIX B: RAIN GAUGES NECESSARY FOR ADEQUATE COUNTY-BASED MEASUREMENTS}

Other techniques were explored to find an adequate method for analyzing the NDCMP. Bootstrapping was applied to one target (McKenzie) to determine the number of rain gauges necessary to adequately sample a county based off the month and year. June and July 1977 in McKenzie County had the most rain gauges at any point in the NDCMP. The number of rain gauges that were sampled ranged from 1 to 33 for June 1977. The rain gauge data was sampled 100,000 times to create a bootstrap mean rainfall. Since the data was sampled with replacement, single rain gauges could be selected multiple times per sample but using 100,000 samples should mitigate any bias from selecting outliers or the same gauge repeatedly. The bootstrapping results for June 1977 for McKenzie County showed that after 15 rain gauges, the county average rainfall could be measured within a tenth of an inch and with 30 rain gauges the county average rainfall can be measured within one hundredth of an inch (Fig. B1). The addition of more rain gauges will help decrease the standard error of the observed rainfall, which contributes to a better measurement of the average monthly rainfall or county seasonal rainfall.

Of the counties examined in this study, McKenzie and Mercer have an average of 30 rain gauges during the NDCMP (Fig. B2). Bowman and Ward average 26-29 rain gauges during the project. The remaining counties average between 4-16 rain gauges with the Montana controls averaging the least number of gauges. It should be noted that the number of rain gauges to adequately sample rainfall in a county can vary based on the size of the county. 


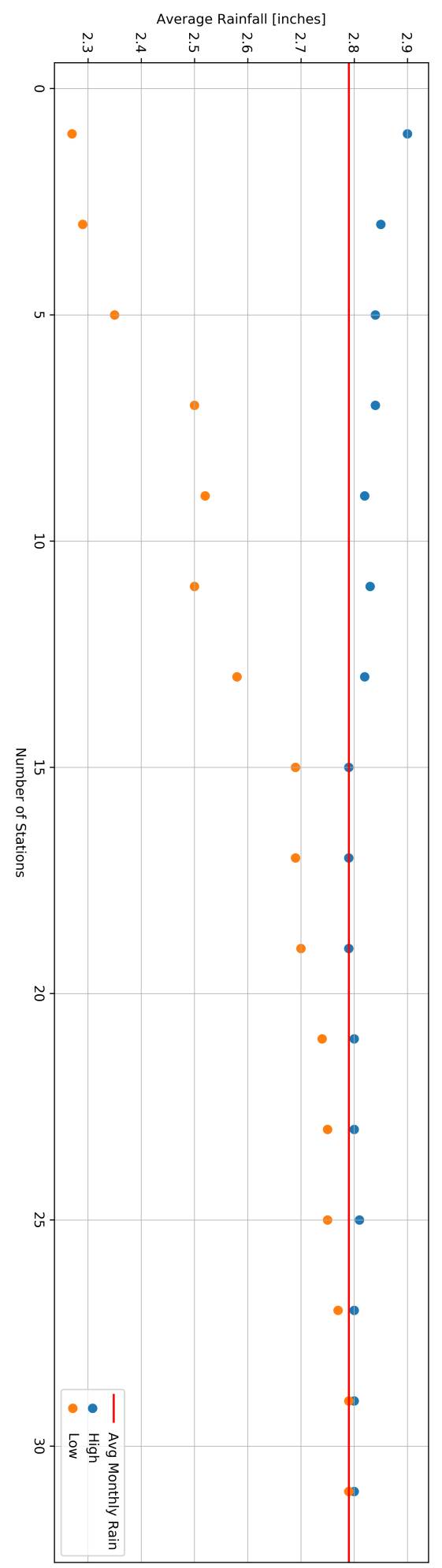

Figure B1: Necessary number of rain gauges to adequately measure the average rainfall for McKenzie County in June 1977. The blue dots show the high end of the $95 \%$ confidence interval and the orange shows the low end. The average county-based rainfall is shown in red. 


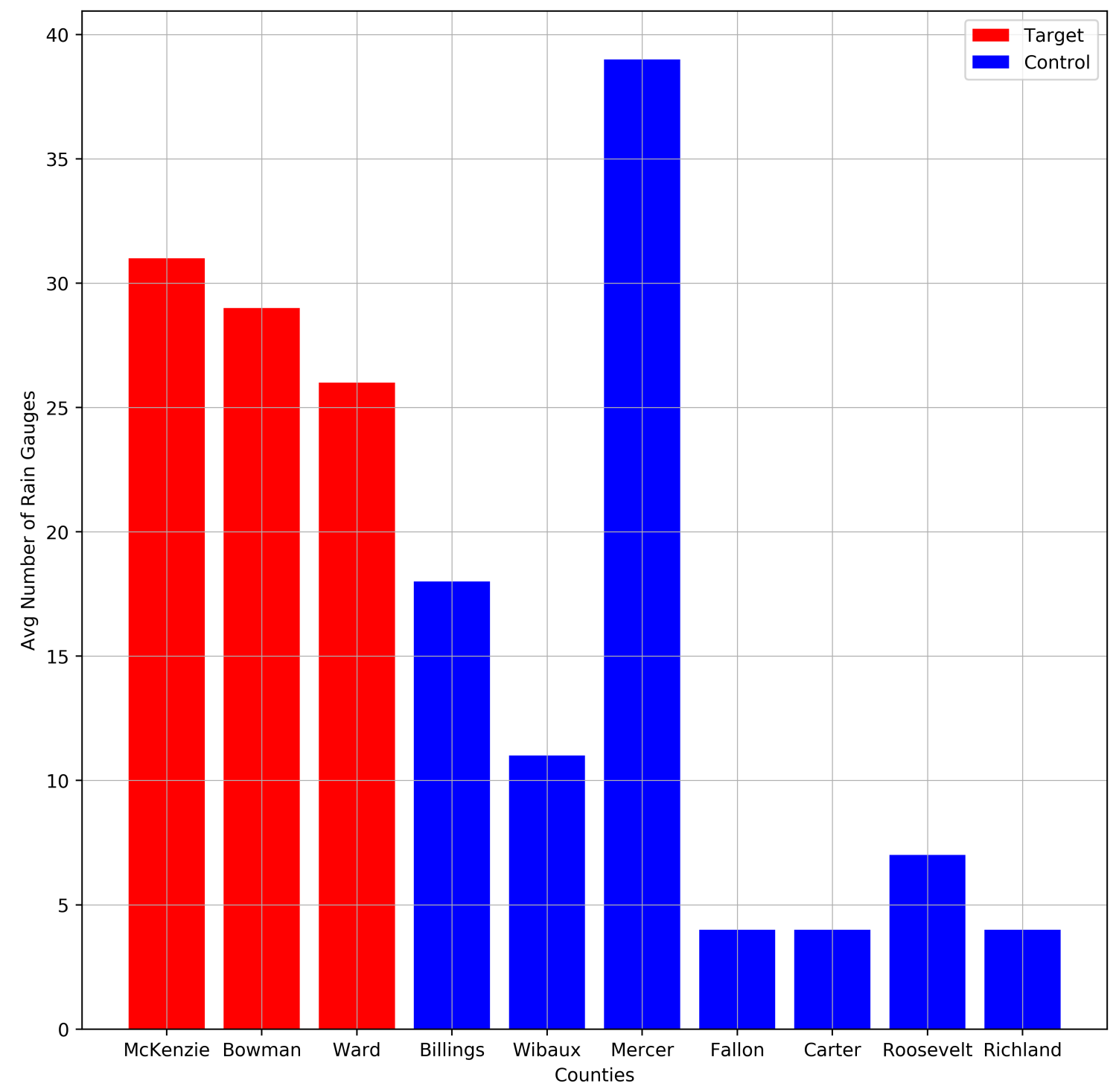

Figure B2: Average number of rain gauges within each Target (red) and Control (blue) area for the county-based method.

\section{CONSTANT NUMBER OF RAIN GAUGES}

Using the results determined by the number of rain gauges needed to measure county-based rainfall within a tenth and a hundredth of an inch, an exploratory analysis was conducted using a bootstrap sample containing a constant number of rain gauges. The analysis used a constant number of 30 rain gauges each year over 
the 41-year project to explore if there would be a shift in the total measured rainfall in both the target and control counties. McKenzie and Billings were used to compare the monthly and seasonal rainfall using 30 rain gauges each month. Creating a data set of 30 rain gauges for both Billing and McKenzie shows an increase in seasonal rainfall using the county-based method in both areas between 0.67 (Billings) and 0.70 (McKenzie) inches over the 41-year period. Due to both areas experiencing nearly the same increase in rainfall from the additional stations, the single ratios remained the same. As there was no significant difference between the single ratios and the computational resources needed to do this method, no other cases were analyzed. The addition of more true observations would improve this analysis. However, with the limitation of using a single rain gauge multiple times, the total and average rainfall may not be improved. More work could be beneficial in this analysis style, but it would not improve the results of the study as it currently stands. 


\section{APPENDIX C: YEARS NEEDED TO DETECT SEEDING EFFECTS}

An estimate for the number of years needed to detect a 5 and $10 \%$ increase in rainfall when comparing observed to single and multiple linear regression predicted rainfall was computed. This was done by using a t statistic test by adjusting the sample number (years) of data. A $10 \%$ increase took less years to detect than a $5 \%$ increase while being $95 \%$ confident it was not due to random chance. The number of years needed to detect this effect was done for single linear regression and multiple linear regression. It was noted that controls that had lower standard error of the estimate required less years to detect an increase due to seeding. Table $\mathrm{C} 1$ shows the standard error needed to detect a 5 and $10 \%$ effect on rainfall, the number of years needed to detect the change, and the $t$ statistic calculated to determine these values are $95 \%$ confident. To detect a $10 \%$ change at least 26 to 40 years of data is needed when using the observed and predicted rainfall values from the single linear regression. For detecting a 5\% effect, 66 to 150 years of data is needed depending on the target/control pair used in the single linear regression. McKenzie/Richland required the most data to detect a $5 \%$ and $10 \%$ and change.

The same process was done for the multiple linear regression pairs used in Table A3. Table C2 shows the needed standard error, number of years needed to detect a 5 and $10 \%$ change in rainfall, and the t statistic for being $95 \%$ confident the values are not due to random chance. Having the two predictors did not improve the number of years needed to detect a $10 \%$ change, however the years needed to detect the $5 \%$ change increased in most cases. To detect a $10 \%$ change, the number of years needed ranged from 30 to 42 years. To detect a 5\% change, 86 to 167 years of data is needed for the multiple linear regression method. One notable difference can be seen in the estimated standard error to detect these increases in the single linear regression and multiple linear regression methods. Single linear regression can detect 
Table C1: Standard Error, number of years, and t statistic calculated from observed and single linear regression predicted rainfall. These estimates the number of years of data needed to predict a 5 and $10 \%$ effect within a $95 \%$ confidence interval.

\begin{tabular}{|c|c|c|c|c|c|c|c|}
\hline Predictand & Predictor & $\begin{array}{c}\text { Standard } \\
\text { Error } \\
\text { to } \\
\text { Detect } \\
\mathbf{1 0 \%}\end{array}$ & $\begin{array}{c}\text { Years } \\
\text { to } \\
\text { Detect } \\
\mathbf{1 0 \%}\end{array}$ & t-stat & $\begin{array}{c}\text { Standard } \\
\text { Error } \\
\text { to } \\
\text { Detect } \\
\mathbf{5 \%}\end{array}$ & $\begin{array}{c}\text { Years } \\
\text { to } \\
\text { Detect } \\
\mathbf{5 \%}\end{array}$ & t-stat \\
\hline McKenzie & Billings & 0.404 & 28 & 2.089 & 0.243 & 77 & 1.990 \\
\hline McKenzie & Wibaux & 0.390 & 30 & 2.048 & 0.221 & 93 & 1.986 \\
\hline McKenzie & Richland & 0.345 & 40 & 2.041 & 0.174 & 150 & 1.985 \\
\hline McKenzie & Roosevelt & 0.429 & 26 & 2.063 & 0.263 & 66 & 1.997 \\
\hline Bowman & Billings & 0.413 & 28 & 2.071 & 0.246 & 79 & 2.001 \\
\hline Bowman & Wibaux & 0.406 & 29 & 2.067 & 0.238 & 84 & 1.995 \\
\hline Bowman & Fallon & 0.406 & 29 & 2.072 & 0.24 & 83 & 1.991 \\
\hline Bowman & Carter & 0.380 & 33 & 2.057 & 0.211 & 107 & 1.984 \\
\hline Ward & Mercer & 0.447 & 30 & 2.060 & 0.270 & 82 & 1.991 \\
\hline
\end{tabular}

Table C2: Standard Error, number of years, and t statistic calculated from observed and multiple linear regression predicted rainfall. These estimates the number of years of data needed to predict a 5 and $10 \%$ effect within a $95 \%$ confidence interval.

\begin{tabular}{|c|c|c|c|c|c|c|c|}
\hline Predictand & Predictor(s) x1/x2 & $\begin{array}{c}\text { Standard } \\
\text { Error } \\
\text { to } \\
\text { Detect } \\
\mathbf{1 0 \%}\end{array}$ & $\begin{array}{c}\text { Years } \\
\text { to } \\
\text { Detect } \\
\mathbf{1 0 \%}\end{array}$ & t-stat & $\begin{array}{c}\text { Standard } \\
\text { Error } \\
\text { to } \\
\text { Detect } \\
\mathbf{5 \%}\end{array}$ & $\begin{array}{c}\text { Years } \\
\text { to } \\
\text { Detect } \\
\mathbf{5 \%}\end{array}$ & t-stat \\
\hline McKenzie & Billings/Wibaux & 0.387 & 31 & 2.069 & 0.221 & 93 & 1.999 \\
\hline McKenzie & Billings/Roosevelt & 0.365 & 35 & 2.032 & 0.192 & 123 & 1.985 \\
\hline McKenzie & Wibaux/Richland & 0.337 & 41 & 2.044 & 0.166 & 165 & 1.983 \\
\hline McKenzie & Wibaux/Roosevelt & 0.337 & 41 & 2.044 & 0.166 & 165 & 1.983 \\
\hline McKenzie & Wibaux/Mercer & 0.356 & 35 & 2.053 & 0.196 & 118 & 1.983 \\
\hline McKenzie & Richland/Billings & 0.337 & 42 & 2.036 & 0.165 & 167 & 1.984 \\
\hline McKenzie & Richland/Roosevelt & 0.376 & 33 & 2.048 & 0.205 & 108 & 1.995 \\
\hline McKenzie & Roosevelt/Fallon & 0.356 & 36 & 2.035 & 0.187 & 130 & 1.990 \\
\hline Bowman & Billings/Wibaux & 0.407 & 30 & 2.050 & 0.235 & 86 & 1.999 \\
\hline Bowman & Billings/Mercer & 0.377 & 35 & 2.032 & 0.203 & 116 & 1.985 \\
\hline Bowman & Billings/Fallon & 0.377 & 35 & 2.031 & 0.202 & 117 & 1.991 \\
\hline Bowman & Billings/Carter & 0.357 & 39 & 2.037 & 0.183 & 142 & 1.986 \\
\hline Bowman & Carter/Fallon & 0.353 & 40 & 2.034 & 0.178 & 150 & 1.983 \\
\hline Bowman & Roosevelt/Fallon & 0.388 & 33 & 2.037 & 0.215 & 103 & 1.985 \\
\hline Ward & Billings/Mercer & 0.407 & 37 & 2.035 & 0.223 & 120 & 1.984 \\
\hline
\end{tabular}


a 5 and $10 \%$ change with a larger standard error than multiple linear regression. The standard error ranges from 0.345 to 0.447 for the single linear regression and 0.337 to 0.407 for the multiple linear regression. 


\section{APPENDIX D: MANN-WHITNEY U TEST}

The Mann-Whitney U test is a non-parametric test that can be used on nonnormally distributed data in place of an unpaired t-test (Shier 2004). Mann-Whitney $\mathrm{U}$ tests are commonly referred to as Mann-Whitney-Wilcoxon, Wilcoxon rank-sum test, or Wilcoxon-Mann-Whitney tests, but are all the same test of the null hypothesis. The Mann-Whitney U test can determine whether two independent samples were selected from populations having the same distributions. The U statistic is calculated by:

$$
U=n_{1} n_{2}+\frac{n_{2}\left(n_{2}+1\right)}{2}-\sum_{n_{1}=1}^{n_{2}} R_{i}
$$

where $\mathrm{U}$ is the Mann-Whitney $\mathrm{U}$ test, $\mathrm{n}_{1}$ is the first sample size, $\mathrm{n}_{2}$ is the second sample size, and $\mathrm{R}_{i}$ is the rank of the sample size (Mann and Whitney 1947). This calculation was done using the SciPy Statistical package Mann-Whitney U stat in python. From the U statistic, p-values can be calculated. This was done by the SciPy package for a one tailed test. For a two-tail p-value, the p-value was multiplied by two.

The data entered was from the single ratios calculated for 1950 to 1975 and 1977 to 2018 for McKenzie $\left(\mathrm{n}_{1}\right)$ paired individually with Billings, Wibaux, Richland and Roosevelt $\left(\mathrm{n}_{2}\right)$ and Bowman with Billings to determine if these ratios were from the same population. In this test, a small p-value states that the data is from a different population or is significantly different from each other. A large p-value suggests the data comes from the same population, or the ratios are relatively the same. Table D1 shows the results from the Mann-Whitney U statistical test calculated for the single ratios for 1950-1975 and 1977-2018 and observed double ratios. The p-values calculated for McKenzie/Wibaux and McKenzie/Richland are statistically significant 
for a p-value $<0.10$. This meant that the data is not from the same population, and there is a significant difference between the two data sets. McKenzie/Billings was over the p-value criteria calculated for the two-tailed test, but still showed some statistical significance.

More in-depth analysis using the Mann-Whitney U statistical method may provide more detailed insight on the statistical significance of the data. This method was purely experimental to examine the target/control pairs where there was an increase in rainfall and one where no change was seen. These results may provide a better p-value than that calculated from the bootstrapping confidence intervals.

Table D1: Mann-Whitney U statistic test on the 1950-1975 and 1977-2018 single ratios. The $\mathrm{U}$ statistic and p-value are calculated for the target/control pairs.

\begin{tabular}{|c|c|c|}
\hline Target/Control Pair & U Statistic & p-value \\
\hline McKenzie/Billings & 450.0 & 0.128 \\
\hline McKenzie/Wibaux & 372.0 & 0.029 \\
\hline McKenzie/Richland & 405.0 & 0.076 \\
\hline McKenzie/Roosevelt & 540.0 & 0.945 \\
\hline Bowman/Wibaux & 472.0 & 0.354 \\
\hline
\end{tabular}


